Aus dem Institut für Tierphysiologie und Tierernährung der Georg-August-Universität Göttingen

Untersuchungen zum Threoninstoffwechsel bei Laborratten und Küken in Abhängigkeit von der Protein- und Threoninversorgung

\author{
Dissertation \\ zur Erlangung des Doktorgrades \\ der Fakultät für Agrarwissenschaften \\ der Georg-August-Universität Göttingen
}

vorgelegt von

Chul-Won Lee

geboren in Jeju/ Korea

Göttingen, Juli 2001 
D7

Referent:

Prof. Dr. habil. F. Liebert

Korreferent:

Prof. Dr. rer. nat. U. Eberhardt

Tag der mündlichen Prüfung:

12. Juli. 2001 
INHALTSVERZEICHNIS

Seite

1. EINLEITUNG und PROBLEMSTELLUNG

2. LITERATURÜBERSICHT

2.1 Besonderheiten des Protein- und Aminosäuren-Stoffwechsels bei Laborratten und Küken

2.2 Die Rolle der Leber im Aminosäuren-Stoffwechsel

2.3 Stoffwechsel des Threonins bei Laborratten und Küken

2.3.1 Enzyme für den Threoninabbau

2.3.2 Die besondere Bedeutung der Threonindehydrogenase 8

2.3.3 Die Lokalisation der Threoninoxidation in verschiedenen Geweben

2.4 Der Threoninstoffwechsel in Beziehung zum Threonin-Versorgungsgrad

2.4.3 Schwein

2.4.4 Mensch

3.2.1.1 Bilanzversuche 19

$\begin{array}{lll}3.2 .1 .2 & \text { Wachstumsversuche } & 20\end{array}$ 
3.2.2 Laborrattenversuche 20

$\begin{array}{lll}\text { 3.2.2.1 Bilanzversuche } & 21\end{array}$

3.3 Futterkomponenten und Futterherstellung 21

3.3.1 Futterkomponenten 21

$\begin{array}{lll}\text { 3.3.2 Futterherstellung } & 23\end{array}$

3.4 Versuchsmischungen und Durchführung der Versuche 23

3.4.1 Versuch 1 (Bilanzversuch Küken, N-Steigerungsversuch mit HPSojaextraktionsschrot) 23

3.4.2 Versuch 2 (Wachstumsversuch Küken, 2 Protein- und 2 Threoninstufen mit Weizen/Weizenkleber) 25

3.4.3 Versuch 3 (Bilanzversuch Küken, 2 Protein- und 2 Threoninstufen $\begin{array}{ll}\text { mit HP-Sojaextraktionsschrot) } & 26\end{array}$

3.4.4 Versuch 4 (Wachstumsversuch Küken, praxisübliche Futtermischungen) 28

3.4.5 Versuch 5 (Bilanzversuch Küken, 2 Glycin- und

2 Threoninstufen mit Weizen/Weizenkleber) 29

3.4.6 Versuch 6 (Bilanzversuch Laborratte, N-Steigerungsversuch mit Kasein) 30

3.4.7 Versuch 7 (Bilanzversuch Laborratte, 2 Protein- und 3 Threoninstufen mit Weizenkleber) 32

3.5 Durchführung der Analysen 33

3.5.1 Bestimmung der Threonindehydrogenase-Aktivität 33

3.5.2 Berechnung der Threonindehydrogenase-Aktivität 36

3.5.3 N-Bestimmung 36

3.5.4 Aminosäure-Bestimmung 36

3.6 N-Verwertungsmodell und AS-Wirksamkeitsberechnung 37

$\begin{array}{lll}3.7 & \text { Statistische Auswertung } & 38\end{array}$ 
4.1 Versuch 1 (Bilanzversuch Küken, N-Steigerungsversuch mit HPSojaextraktionsschrot)

4.2 Versuch 2 (Wachstumsversuch Küken, 2 Protein- und 2 Threoninstufen mit Weizen/Weizenkleber)

4.3 Versuch 3 (Bilanzversuch Küken, 2 Protein- und 2 Threoninstufen mit HP-Sojaextraktionsschrot)

4.4 Versuch 4 (Wachstumsversuch Küken, praxisübliche Futtermischungen)

4.5 Versuch 5 (Bilanzversuch Küken, 2 Glycin- und 2 Threoninstufen mit Weizen/Weizenkleber)

4.6 Versuch 6 (Bilanzversuch Laborratte, N-Steigerungsversuch mit Kasein)

4.7 Versuch 7 (Bilanzversuch Laborratte, 2 Protein- und 3 Threoninstufen mit Weizenkleber)

5.1 Zusammenhänge zwischen Proteinniveau und TDG-Aktivität beim Küken

5.2 Zusammenhänge zwischen Protein- und Threoningehalt der Futtermischungen und TDG-Aktivität beim Küken (Wachstumsversuch)

5.3 Zusammenhänge zwischen Protein- und Threoningehalt der Futtermischungen und TDG-Aktivität beim Küken (Bilanzversuch)

5.4 Zusammenhänge zwischen Alter und TDG-Aktivität beim Küken

5.5 Zusammenhänge zwischen Glycin- und Threoningehalt der Futtermischungen und TDG-Aktivität beim Küken

5.6 Zusammenhänge zwischen Proteinniveau und TDG-Aktivität bei der Laborratte

5.7 Zusammenhänge zwischen Protein- und Threoningehalt der Futtermischungen und TDG-Aktivität bei der Laborratte

5.8 Zum Threoninstoffwechsel von Laborratten und Küken in Abhängigkeit von der Protein-, Threonin- und Glycinversorgung 
$\begin{array}{ll}\text { 6. ZUSAMMENFASSUNG } & 68\end{array}$

$\begin{array}{ll}\text { 7. SUMMARY } & 71\end{array}$

8. LITERATURVERZEICHNIS

9. ABKÜRZUNGSVERZEICHNIS 88

10. TABELLENANHANG 90 


\section{EINLEITUNG UND PROBLEMSTELLUNG}

Threonin gehört zu den neutralen Aminosäuren und wurde erst 1938 identifiziert. Threonin ist essentiell für Säugetiere und Vögel. Eine optimale Versorgung mit Threonin ist demnach für Erhaltung und Wachstum notwendig. Eine Threoninkatabolisierung, die einen unwiderruflichen Verlust an dieser Aminosäure darstellt, ist deshalb möglichst zu vermeiden. Threonin kann in pflanzlichen Rationen auf Getreidebasis limitierend sein und liefert über seinen Abbau zugleich Vorstufen für die Synthese von Glycin und Serin. Threonin ist beim Abbau teilweise glukoplastisch und dient einer Energiespeicherung in Form von Glucose in der Leber und im Muskelgewebe. Threonin wirkt lipotroph und wirkt einer starken Fetteinlagerung in die Leber entgegen. Darüber hinaus ist Threonin bedeutsam für das Immunsystem (Synthese von Immunoglobulinen und Antikörpern) und ein wesentlicher Bestandteil von Kollagen und Elastin.

Eine genaue Kenntnis der Faktoren, die den Threoninstoffwechsel kontrollieren, ist notwendig, um eine bessere Basis für die Optimierung der Threoninbedarfsdeckung zu schaffen. Die Mechanismen des Threoninabbaus zu kennen und zu quantifizieren, ist dabei von besonderer Bedeutung. Die Threonindehydrogenase stellt in diesem Zusammenhang offensichtlich ein Schlüsselenzym der Leber dar. Beim Threoninabbau durch die Threonindehydrogenase entsteht Glycin. Die de novo Synthese von Glycin aus Threonin kann den metabolischen Bedarf für Glycin über den Threonindehydrogenase-Weg teilweise decken. Da Glycin eine essentielle Aminosäure beim wachsenden Küken darstellt und für die Synthese von Purinbasen (Harnsäuresynthese) notwendig ist, könnte dieser Threonindehydrogenase-Weg beim Küken von besonderer Bedeutung sein.

Ziel der vorliegenden Untersuchungen ist deshalb, die Threonindehydrogenase-Aktivität als Kriterium für die in der Leber stattfindende Katabolisierung von Threonin unter den Bedingungen Threonin limitierter Diäten bei Küken und Laborratten zu prüfen. 
Dabei sollten folgende Schwerpunkte in den Mittelpunkt gestellt werden:

1. Einfluss unterschiedlicher Proteinniveaus auf die Threonindehydrogenase-Aktivität unter den Bedingungen Threonin limitierter Futtermischungen bei Küken und Laborratte.

2. Einfluss unterschiedlicher Protein- und Threoninniveaus auf die ThreonindehydrogenaseAktivität unter den Bedingungen Threonin limitierter Futtermischungen bei Küken und Laborratte.

3. Einfluss unterschiedlicher Glycin- und Threoninniveaus der Futtermischungen auf die Threonindehydrogenase-Aktivität unter den Bedingungen einer Threoninlimitanz beim Küken.

4. Einfluss des Alters auf die Threonindehydrogenase-Aktivität beim Küken. 


\section{LITERATURÜBERSICHT}

\subsection{Besonderheiten des Protein- und Aminosäuren-Stoffwechsels bei Laborratten und Küken}

Für ausgewachsene Laborratten sind folgende Aminosäuren essentiell: Histidin, Isoleucin, Leucin, Lysin, Methionin, Phenylalanin, Threonin, Tryptophan und Valin. Für wachsende Laborratten ist auch Arginin essentiell. Das wachsende Küken hat die gleichen essentiellen Aminosäuren wie die wachsende Laborratte. Für das Geflügel ist Arginin aufgrund des fehlenden Eigensynthese-Mechanismus im Ornithinzyklus eine essentielle Aminosäure. Zusätzlich ist Glycin eine essentielle Aminosäure beim wachsenden Küken (BAKER et al., 1968; KIRCHGESSNER, 1992). Daher ist Glycin im Aminosäuren- Stoffwechsel bei Küken von großer Bedeutung (COON et al., 1974; SCHUTTE et al., 1997). Serin spielt ebenfalls eine wichtige Rolle beim Küken, weil Glycin aus Serin durch Serin-HydroxymethylTransferase gebildet werden kann. Deshalb wird zur Bewertung des Versorgungsgrades in der Geflügelernährung häufig eine gemeinsame Betrachtung von Glycin und Serin vorgenommen. (NRC, 1994; SCHUTTE et al., 1997).

Bei der Laborratte wird Ammoniak aus dem Aminosäurestoffwechsel in der Leber über den Harnstoffzyklus in Harnstoff überführt. Der Harnstoff wird in die Niere transportiert und mit dem Harn ausgeschieden. Beim Küken fehlt das Enzym zur Bildung des Carbamylphosphats (Carbamylphosphat-Synthetase). Deswegen kann der Harnstoffzyklus nicht ablaufen. Beim Küken erfolgt die Eliminierung des Stickstoffs durch Einbau in Purinbasen über Harnsäure. Zuerst werden die aus dem Glutamin gelieferten zwei Aminogruppen an den Purinring angefügt. Danach wird das Glycin an diesen Purinring gebunden. Aspartat gibt eine Aminogruppe an den Purinring ab. Das erste Zwischenprodukt mit einem vollständigen Purinring ist die Inosinsäure. Die Inosinsäure wird über Adenosin zu Inosin. Das Inosin wird zu einer Purinbase, Hypoxanthin, und D-Ribose hydrolysiert. Diese gebildeten Purine sind nicht nur als Bausteine der Nucleinsäuren, sondern auch als Zwischenprodukte der NAusscheidung bedeutend. Der weitere Stoffwechsel geht von Xanthin über eine Xanthinoxydase zur Harnsäure, die beim Küken über die Nieren ausgeschieden wird. Bei der Laborratte wird die in deutlich geringerem Umfang gebildete Harnsäure durch Uratoxidase weiter in das Ausscheidungsprodukt Allantoin umgewandelt und exkretiert (PÜSCHNER und SIMON, 1988; NELSON und COX, 2000). 


\subsection{Die Rolle der Leber im Aminosäuren-Stoffwechsel}

Die Leber entzieht der Zirkulation (Portalvene) einen erheblichen Teil der aus dem Darmkanal resorbierten Aminosäuren für den Aufbau körpereigener Proteine, für die Energiegewinnung und für zahlreiche andere Biosynthesen. Die Leber erneuert ihren Proteinbestand fortlaufend. Die Leberproteine haben deshalb einen sehr hohen Turnover mit einer mittleren Halbwertszeit von nur wenigen Tagen. In der Leber werden auch die meisten Blutplasmaproteine synthetisiert. Aminosäuren können ins Blut gelangen und in andere Organe gebracht werden, wo sie als Bausteine für die Biosynthese der Gewebeproteine verwendet werden. Die Aminosäuren sind Vorstufen bei der Biosynthese der Purin- und Pyrimidinbasen der Nucleotide und bei der Synthese speziellerVerbindungen, wie Porphyrine, Hormone und andere stickstoffhaltigen Verbindungen. Der Umfang der Proteinsynthese in der Leber ist vom Entwicklungsstadium, der Ernährung und der Leistung abhängig.

Die Bedeutung der Leber im Stoffwechsel der Aminosäuren und der Proteine wurde von SCHENCK und KOLB (1990), DEVLIN (1997) und NELSON und COX (2000) wie folgt zusammengefaßt:

- Abbau der Aminosäuren und Synthese des Harnstoffs

Überschüssige Aminosäuren werden in der Leber abgebaut. Der Abbau der essentiellen Aminosäuren ist im wesentlichen auf die Leber beschränkt. Eine Ausnahme machen die verzweigtkettigen Aminosäuren, die vorwiegend in peripheren Geweben verstoffwechselt werden. Die Aminosäuren, die nicht für die Proteinsynthese in der Leber Verwendung finden, werden desaminiert und $\mathrm{zu}$ Acetyl-CoA und Übergangsverbindungen des Citratcyclus abgebaut. Diese Übergangsverbindungen können durch die Gluconeogenese in Glucose und Glycogen umgewandelt werden. Acetyl-CoA kann für die Bildung von ATP-Energie über den Citratcyclus oxidiert oder zur Neusynthese von Fettsäuren verwendet werden. Die Aminosäuren werden auch durch Transaminierung umgebaut, was eine Übertragung der $\mathrm{NH}_{2}$ Gruppe auf eine 2-Oxosäure bedeutet. Sie werden auch zu primären Aminen decarboxyliert, die zum Teil als Bausteine verschiedener Substanzen wichtig sind.

Der beim Abbau der Aminosäuren frei werdende Ammoniak wird von der Leber über den Harnstoffzyklus zum ungiftigen Harnstoff umgesetzt. Die Purinbasen werden in der Leber 
über Hypoxanthin und Xanthin zu Harnsäure abgebaut. Bei Haustieren wird in der Leber die Harnsäure durch die Uricase in großer Menge in Allantoin überführt. Der Ammoniak wird in der Geflügelleber durch die Harnsäuresynthese entgiftet. Dies findet zum Teil auch in den Nieren statt.

- Die Synthese von nicht essentiellen Aminosäuren

Die nicht essentiellen Aminosäuren können in der Leber gebildet werden, wenn die Resorption von nicht essentiellen Aminosäuren nicht bedarfsdeckend ist.

- Spezielle Biosynthesen

In der Leber findet die Bildung von Kreatin und Cholin statt. Durch Methylierung wird das Kreatin gebildet, das an das Blutplasma abgegeben und von der Muskulatur aufgenommen wird. Cholin wird bei unzureichender Cholin-Resorption aus Serin und Methionin synthetisiert.

- Synthese von Albuminen, Lipoproteinen, Glycoproteinen und Transportproteinen für Vitamine und Spurenelemente.

Eine wichtige Aufgabe der Leber besteht darin, Plasmaeiweiße aufzubauen. Die Leber bildet auch die Albumine und die meisten $\alpha$ - und $\beta$-Globuline einschließlich der Gerinnungsfaktoren und Transportproteine, wie Coeruloplasmin für Kupfer und Transferrin für Eisen. Die Leber synthetisiert verschiedene Glycoproteine und wichtige Transportproteine wie Lipoproteine.

- Die Synthese der Gallensäuren und die Synthese von mehr als 1000 verschiedenen Enzymen, deren Wirkung durch verschiedene Metabolite und Hormone reguliert wird.

- Abbau des Hämoglobins in den Kupfferschen Sternzellen und Abbau der Peptidhormone. 


\subsection{Stoffwechsel des Threonins bei Laborratten und Küken}

Threonin ist essentiell, da es nicht an Transaminierungen teilnimmt und deshalb vom tierischen Organismus nicht synthetisiert werden kann. Es ist beim Abbau gluco- und ketoplastisch. Die potentiellen Wege des Katabolismus von L-Threonin beziehen die Aktivitäten von drei verschiedenen Enzymen ein.

\subsubsection{Enzyme für den Threoninabbau}

- Threoninaldolase (EC 4.1.2.5; TA)

Die Threoninaldolase kommt zytosolisch vor. Der Abbau des Threonins findet durch die pyridoxalphosphathaltige Threoninaldolase statt, wobei Glycin und Acetaldehyd entstehen. Das Acetaldehyd kann durch eine Aldehyd-Dehydrogenase in aktivierte Essigsäure überführt werden. Die Threoninaldolase kann nach Beobachtungen von MELTZER und SPRINSON (1952) bei der Ratte L-Threonin in Glycin überführen. Threoninaldolase ist das gleiche Protein wie Serin-Glycin-Hydroxymethyltransferase (EC 2.1.2.1), die die Interkonversion von Glycin und Serin (SCHIRCH und GROSS, 1968) katalysiert. Einige Untersuchungen (BIRD und NUNN, 1983; YEUNG, 1986; PAGANI et al., 1991) haben gezeigt, dass die Bedeutung der Aktivität der Threoninaldolase in der Rattenleber überschätzt wurde und daß dieses Enzym tatsächlich sehr wenig oder keine Aktivität für die Katabolisierung von L-Threonin bei Ratten besitzt. Der $K_{\mathrm{m}}$-Wert von Threonin-Aldolase für L- Threonin und Pyridoxal 5'phosphat in der Rattenleber beträgt $20 \mathrm{mM}$ (MALKIN und GREENBERG, 1964) und 0,11 mM (KARASEK und GREENBERG, 1957).

- Threonindehydratase (EC 4.2.1.16; TDH)

Threonindehydratase ist ebenfalls zytosolisch. Durch Threonindehydratase kann Threonin unter Abspaltung von $\mathrm{H}_{2} \mathrm{O}$ und $\mathrm{NH}_{3}$ in $\alpha$-Ketobutyrat bei der Ratte (INOUE und PITOT, 1970) und beim Menschen (AKOPOV et al., 1979) überführt (FREEDLAND und AVERY, 1964) und anschließend oxidativ in Propionyl-CoA und $\mathrm{CO}_{2}$ gespalten werden. PropionylCoA kann dann zu Succinyl-CoA weiterreagieren. In der Rattenleber werden Threonin und Serin durch eine allgemeine zytosolische Dehydratase desaminiert (GOLDSTEIN et al., 1962). Dies ist weitgehend abhängig von der Diät und der hormonalen Regulation (INOUE et al., 
1971). Ein Katabolismus von L-Threonin durch Threonindehydratase scheint, außer im Zustand der Gluconeogenese (BIRD und NUNN, 1983; BALLÈVRE et al., 1991), ebenfalls von geringer Bedeutung zu sein. Die $K_{\mathrm{m}}$-Werte der Threonindehydratase für L-Threonin und Pyridoxal 5'-phosphat in der Rattenleber betragen $87 \mathrm{mM}$ und $0,37 \mu \mathrm{M}$ (NAKAGAWA und KIMURA, 1969).

- Threonindehydrogenase (EC 1.1.1.103; TDG)

Die Threonindehydrogenase ist ein mitochondriales Enzym (URATA und GRANICK, 1963; GREEN und ELLIOT, 1964; DALE, 1978). Threonindehydrogenase wird in der Mitochondrien-Matrix gefunden und bildet anscheinend einen löslichen Komplex mit 2Amino-3-Oxobutyrat CoA Ligase (Glycin Acetyltransferase ; EC 2.3.1.29; TRESSEL et al. 1986), der die Umwandlung von 2-Amino-3-Oxobutyrat zu Acetyl-CoA und Glycin katalysiert (MCGLVRAY und MORRIS, 1969; DALE, 1978; BIRD und NUNN, 1979). Aminoaceton, das einzige bekannte Stoffwechselprodukt von 2-Amino-3-Oxobutyrat, wird bei der Ratte (GREEN und ELLIOT, 1964) und beim Menschen (MAUZERALL und GRANICK, 1956) nicht enzymatisch gebildet (LAVER et al., 1959). Die $K_{\mathrm{m}}$-Werte der Threonindehydrogenase für L-Threonin in der Küken-, Ratten- und Schweinleber betragen 8,4 mM (AOYAMA und MOTOKAWA, 1981), 10,6 mM (BIRD und NUNN, 1983) und 5,0 $\mathrm{mM}$ (TRESSEL et al., 1986) und die $K_{\mathrm{m}}$-Werte für $\mathrm{NAD}^{+}$in der Küken-, Ratten- und Schweinleber liegen bei 0,98 mM (AOYAMA und MOTOKAWA, 1981), $80 \mu \mathrm{M}$ (BIRD und NUNN, 1983) und 0,1 mM (TRESSEL et al., 1986).

Threonindehydrogenase aus der Kükenleber ist ein Monomer und hat ein Molekulargewicht (MG) von 88.000. Das pH-Optimum liegt zwischen 8,6 und 8,7 und der isoelektrische Punkt des Enzyms durch Elektrofocusing bei 5,9 (AOYAMA und MOTOKAWA, 1981). Threonindehydrogenase aus der Schweineleber ist ein Tetramer, das aus identischen Untereinheiten von $\mathrm{MG}=25.000$ besteht. Das pH-Optimum liegt zwischen 8,0 und 8,4 und der isoelektrische Punkt des Enzyms durch Elektrofocusing bei 5,5 (TRESSEL et al., 1986).

Weiterhin wurde die TDG bei verschiedenen Organismen und Tierarten untersucht (u.a. Froschleber: HARTSHORNE und GREENBERG, 1964; Arthrobacter: McGILVRAY und MORRIS, 1971; Escherichia coli: BOYLAN und DEKKER, 1981; Ziegenleber: RAY und RAY, 1985). 


\subsubsection{Die besondere Bedeutung der Threonindehydrogenase}

Der Abbau von Threonin über die Threonindehydrogenase ist ein bedeutender Weg der Threoninoxidation, dabei entsteht Glycin (BAKER et al. 1972) aus Threonin. Durch diesen Weg kann der metabolische Bedarf für Glycin gedeckt werden. Für wachsende Küken ist Glycin essentiell und somit für eine optimale Protein-Synthese und den Protein-Ansatz notwendig. Beim Geflügel wird der zu exkretierende Stickstoff durch Einbau in Purinbasen über die Harnsäure ausgeschieden, dabei wird Glycin als Baustein benötigt. Glycin ist zwar eine nicht essentielle Aminosäure für die meisten Säugetiere, dennoch benötigen einige Proteine eine hohe Menge Glycin für ihre Synthese (z.B., Kollagen, eins der reichlich im Körper vorhandenen Strukturproteine). Folglich haben junge Tiere für das Wachstum hohe Anforderungen an die Glycinversorgung. Die Angaben von BALLÈVRE et al. (1991) zeigen, dass Glycin auch für das Wachstum der Ferkel begrenzend werden kann und eine Threoninergänzung die Wachstumsrate der Ferkel, die eine Glycin-limitierte Diät erhielten, verbesserte. Die de novo Synthese von Glycin über den Abbau von Threonin kann demnach den Glycinbedarf über den TDG-Weg teilweise decken (Le FLOC'H et al. 1994).

BIRD et al. (1984) errechneten, aufgrund von in-vitro Studien mit intakten hepatischen Mitochondrien von Ratten, daß bei ausreichender Versorgung mit L-Threonin mindestens 65\% des katabolisierten Threonin in Glycin und Acetyl-CoA umgewandelt werden. Die Threonindehydrogenase ist für $87 \%$ beim Abbau des Threonins in der Leber von normal gefütterten Ratten (BIRD und NUNN, 1983) und für ca. 80\% des abgebauten Threonins in der Schweineleber verantwortlich (BALLÈVRE et al., 1990). Die Aktivität der Threonindehydrogenase wurde in isolierten hepatischen Mitochondrien von Küken bei Threonin-Imbalanz (NIESS, 1978; TORRES et al., 1999) und hohen Proteingehalten (TORRES et al., 1998) in der Diät signifikant gesteigert (DAVIS und AUSTIC, 1994 und 1997).

Der Anteil des Threonins, der entweder von der Threonindehydrogenase oder der Threonindehydratase oxidiert wird, ist offenbar beim Mensch im Gegensatz zum wachsenden Schwein und der Ratten unterschiedlich. Nach Angaben von BIRD et al. (1982) ist die Threonindehydrogenase-Aktivität in der Menschenleber deutlich niedriger als die in der Rattenleber. Die Threonindehydratase-Aktivität lag dabei sehr niedrig. Nimmt man an, daß 
die $K_{\mathrm{m}}$-Werte der zwei Enzyme der gleichen Ordnung wie die bei der Ratte sind, ist die Threonindehydrogenase in vitro das quantitativ wichtigere Enzym. Beim menschlichen Säugling wurde geschätzt, daß 44\% der gesamten Threoninoxidation durch den Threonindehydrogenase-Weg hervorgerufen wird (DARLING et al., 1999). Dies steht im Gegensatz zu den Studien mit Schweinen von BALLÈVRE et al. (1990), in denen die GlycinProduktion ca. $80 \%$ der gesamten Threoninoxidation umfaßte. Das Ferkel wächst ca. viermal so schnell wie der menschliche Säugling (PENCHARZ et al., 1996). Infolge ihrer höheren Wachstumsgeschwindigkeit können Schweine demnach auch einen höheren Bedarf an Glycin für die Proteinsynthese haben. Bei erwachsenen Menschen beläuft sich die gesamte Threoninoxidation über den TDG-Weg auf nur 7-11\%, gemessen mit Hilfe einer konstanten Infusion über 4 Stunden mit L- $\left[1-{ }^{13} \mathrm{C}\right]$ Threonin und $\left[{ }^{15} \mathrm{~N}\right]$ Glycin (DARLING et al., 2000). Diese altersbedingten Unterschiede können mit einem relativ höheren metabolischen Bedarf an Glycin beim Säugling zusammenhängen.

\subsubsection{Die Lokalisation der Threoninoxidation in verschiedenen Geweben}

Die Aktivitäten von Threonindehydratase und Threoninaldolase sind hauptsächlich in der Rattenleber (KARASEK und GREENBERG, 1957) zu finden. Die ThreonindehydrogenaseAktivität beschränkt sich nicht ausschließlich auf die Rattenleber. Bei Ratten ist auch eine spezifische Aktivität von TDG im Gehirn, in den Nieren und im Herz (10 bis $30 \%$ der Leberaktivität) beobachtet worden. (GREEN und ELLIOTT, 1964). DAVIS und AUSTIC (1994) zeigten bei Ratten, daß eine TDG-Aktivität in vielen Geweben (z.B Leber, Pankreas, Gehirn, Muskel, Milz, Nieren, Herz und Darm) verbreitet ist. Wegen des relativen Masseanteils der Organe befinden sich ca. 87\% der Gesamtkörper TDG-Aktivität in der Rattenleber (BIRD und NUNN, 1983).

Le FLOC'H et al. (1995) stellten fest, dass bei einer diätischen Unterversorgung mit Threonin ein großer Teil der Threoninoxidation extrahepatisch verlaufen kann. In vitro-Messungen der spezifischen Aktivität von TDG in den unterschiedlichen Geweben von Schweinen haben gezeigt, daß das Enzym besonders in der Leber und im Pankreas vorkommt. In den anderen Geweben konnte praktisch keine Aktivität ermittelt werden. Dieses Resultat wurde in vivo mit der Messung einer höheren Glycinanreicherung und einer höheren spezifischen Radioaktivität in diesen Geweben als im Plasma nach einer Infusion mit markiertem Threonin bestätigt (Le FLOC'H et al., 1997). Dies ist in Übereinstimmung mit den Daten aus Experimenten von Le 
FLOC'H et al. (1995 und 1996). Obgleich die spezifischen Aktivitäten der TDG in vitro in der Leber und im Pankreas ähnlich waren, finden sich in der Schweineleber mehr als $90 \%$ der Gesamtaktivität. Folglich kann angenommen werden, daß die Leber das Gewebe ist, in dem die größte Menge an Threonin in vivo oxidiert wird, wenn die Versorgung mit Threonin nicht limitierend ist (Le FLOC'H et al., 1997).

Die Rolle des Pankreas im Threoninstoffwechsel beim Küken ist von DAVIS und AUSTIC (1982a) beschrieben worden. Bei dieser Spezies lag die spezifische Aktivität von TDG im Pankreas fünffach höher als in der Leber. DAVIS und AUSTIC (1982a und 1994) zeigten ebenfalls, daß die TDG-Aktivität beim Küken in den gleichen Geweben wie bei der Ratte lokalisiert ist und die Aktivität in der Leber und im Pankreas im Vergleich mit anderen Geweben sehr hoch ist.

\subsection{Der Threoninstoffwechsel in Beziehung zum Threonin-Versorgungsgrad}

Eine bedarfsdeckende Threoninversorgung ist für Erhaltung und Wachstum notwendig. Die Threoninoxidation stellt einen irreversiblen Verlust von Threonin aus Futter- und Körperproteinen dar. Bei Schweinen begrenzt die Threoninversorgung oft das Wachstum (FULLER et al., 1989). Kenntnisse zum Threoninstoffwechsel sind deshalb notwendig, um eine optimale Threoninversorgung bei geringer Oxidationsrate im Einklang mit einer zweckmäßigen Ausschöpfung des Leistungspotentials zu erreichen.

\subsubsection{Küken}

Für Küken liegen nur wenige Untersuchungsbefunde zu diesem Thema vor, von denen zunächst zwei besonders wichtige Versuche genauer dargestellt werden sollen.

In Untersuchungen von DAVIS und AUSTIC (1982b) zeigte sich bei einer Erhöhung des Threoningehaltes von 0,6 auf $1,8 \%$ in der Kükendiät kein signifikanter Anstieg der TDGAktivität. Die Ergänzung von L-Threonin zur Basaldiät hatte auch keinen signifikanten Effekt auf Lebendmassezunahme bzw. Futteraufnahme der Küken im Vergleich zur Basaldiät (Tabelle 1). 
Tab. 1: Einfluss unterschiedlicher Threoningaben auf Wachstum und Threonindehydrogenase-Aktivität in der Leber von Küken (modifiziert nach DAVIS und AUSTIC 1982b).

\begin{tabular}{|c|c|c|c|c|c|}
\hline \multirow{2}{*}{$\begin{array}{c}\text { Ergänzung } \\
\text { zur }\end{array}$} & \multirow{2}{*}{$\begin{array}{l}\text { Lebendmasse- } \\
\text { zunahme (g/d) }\end{array}$} & \multirow{2}{*}{$\begin{array}{c}\text { Futter- } \\
\text { aufnahme } \\
\text { (g/d) }\end{array}$} & \multicolumn{2}{|c|}{ Thr-Konzentration } & \multirow{2}{*}{$\begin{array}{c}\text { TDG- } \\
\text { Aktivität* }\end{array}$} \\
\hline & & & $\begin{array}{c}\text { Plasma } \\
(\mu \mathrm{mol} / \mathrm{dl})\end{array}$ & $\begin{array}{c}\text { Leber } \\
(\mu \mathrm{mol} / \mathrm{g})\end{array}$ & \\
\hline $\begin{array}{ll} & \text { Basaldiät } \\
\text { - } & \mathbf{2 0 , 6 \%} \text { XP } \\
\text { - } & \mathbf{0 , 6 \%} \text { Thr** }\end{array}$ & $9,19^{\mathrm{a}}$ & $18,0^{\mathrm{ab}}$ & 17,4 & 0,815 & 0,42 \\
\hline$+0,2 \%$ L-Thr & $9,86^{\mathrm{a}}$ & $18,2^{\mathrm{a}}$ & 46,6 & 1,215 & 0,47 \\
\hline$+0,4 \%$ L-Thr & $9,59^{\mathrm{a}}$ & $17,9^{\mathrm{ab}}$ & 106,6 & 1,950 & 0,57 \\
\hline$+0,8 \%$ L-Thr & $9,82^{\mathrm{a}}$ & $18,1^{\mathrm{a}}$ & 318,5 & 2,805 & 0,72 \\
\hline$+1,2 \%$ L-Thr & $10,02^{\mathrm{a}}$ & $18,3^{\mathrm{a}}$ & 576,5 & 3,860 & 0,57 \\
\hline
\end{tabular}

* $\mu$ mol Aminoacetonbildung pro $30 \mathrm{~min} / \mathrm{g}$ Leber ** Threonin in der Basaldiät ist erstlimitierend.

Die TDG-Aktivität von Küken, die die Basaldiät oder die Basaldiät ergänzt mit kristallinem Threonin erhielten, zeigte keine signifikanten Unterschiede. Die Ergänzung von 1,14\% kristallinem L-Threonin zur Basaldiät hatte auch keinen Effekt auf die Lebendmassezunahme oder Futteraufnahme der Küken im Vergleich zur Basaldiät. Die Küken, die mit der proteinreichen Diät oder der proteinreichen Diät abzüglich 0,15\% kristallinem L-Threonin gefüttert wurden, hatten höhere Lebendmassezunahmen und eine bedeutend höhere TDGAktivität im Vergleich zur Basaldiät oder der Basaldiät plus 1,14\% Threonin (Tab. 2).

Die Verabreichung einer Futtermischung mit hohem Proteingehalt führte zu einem Anstieg der hepatischen TDG-Aktivität von Küken (AOYAMA und MOTOKAWA, 1981). Demnach wird die hepatische TDG-Aktivität beim Küken vom Proteingehalt des Futters, nicht aber vom Threoningehalt im Futter beeinflusst (DAVIS und AUSTIC, 1997). 
Tab. 2: Einfluss unterschiedlicher Threonin- und Rohprotein-Gaben auf Wachstum und Threonindehydrogenase-Aktivität in der Leber von Küken (modifiziert nach DAVIS und AUSTIC 1997).

\begin{tabular}{|c|c|c|c|}
\hline Gruppe & $\begin{array}{c}\text { Lebendmasse- } \\
\text { zunahme (g/ } 72 \text { h) }\end{array}$ & $\begin{array}{c}\text { Futteraufnahme } \\
\qquad(\mathrm{g} / 72 \mathrm{~h})\end{array}$ & TDG-Aktivität* \\
\hline $\begin{array}{l}\text { Basaldiät } \\
\text { - } 22 \% \text { XP } \\
\text { - } \quad 0,6 \% \text { Thr }\end{array}$ & 14 & 40 & 48 \\
\hline $\begin{array}{c}\text { Basaldiät } \\
+1,14 \% \text { Thr } \\
(1,74 \% \text { Gesamt-Thr })\end{array}$ & 15 & 40 & 63,7 \\
\hline $\begin{array}{c}\text { Hoch-Protein } \\
51 \% \text { XP } \\
(1,74 \% \text { Gesamt-Thr })\end{array}$ & $18 * *, \mathrm{a}$ & $33^{* *, b}$ & $206,7 * *, b$ \\
\hline $\begin{array}{c}\text { Hoch-Protein } \\
\bullet \quad 51 \% \text { XP } \\
-0,15 \% \text { Thr } \\
(1,59 \% \text { Gesamt-Thr) }\end{array}$ & $19 * *, \mathrm{a}$ & $35^{* *, \mathrm{~b}}$ & $206,6^{* *, b}$ \\
\hline
\end{tabular}

**Die Werte sind signifikant unterschiedlich von dem entsprechenden Wert für die Basal-Diät Gruppe: $P<0,01$; ${ }^{\mathrm{a}, \mathrm{b}}$ Die Werte sind signifikant unterschiedlich von dem entsprechenden Wert für die Basaldiät ${ }^{\mathrm{a}}, P<0,05$; ${ }^{\mathrm{b}}, P<0,01$. ; * nmol Aminoaceton- plus Glycinbildung pro $15 \mathrm{~min} / \mathrm{mg}$ Protein 


\subsubsection{Laborratte}

Aus einem Rattenversuch berichten KANG-LEE und HARPER (1978), dass die beobachtete Änderung der Threoninoxidation Abhängigkeiten vom Threoningehalt im Futter aufweist (Abb. 1).

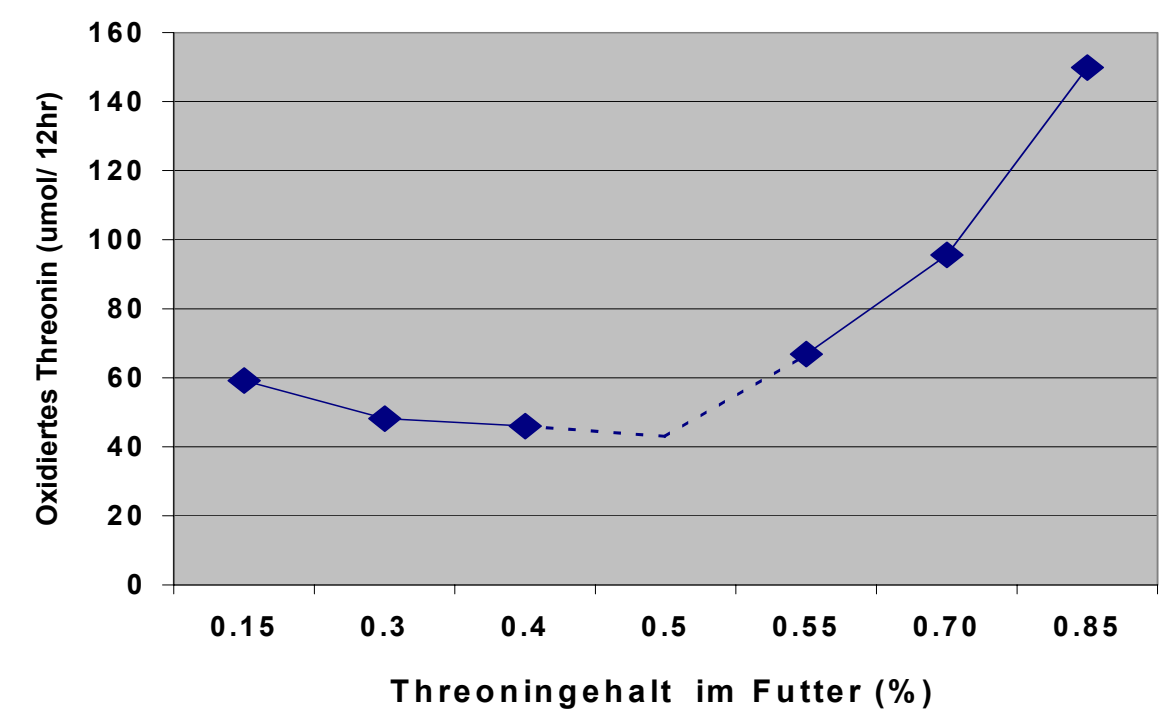

\section{Abb. 1: Effekt steigender Threoningehalte auf die in vivo Threoninoxidation bei Ratten (modifiziert nach KANG-LEE und HARPER 1978).}

Wie gezeigt werden konnte, verringert sich in diesen Untersuchungen die oxidierte Threoninmenge stufenweise bis zu einem Threoningehalt von ca. 0,5\%, dann erhöht sie sich deutlich mit zunehmender Threoninsupplementation. Die Threoninmenge für maximales Wachstum lag im Bereich ansteigender Threoninoxidation. KANG-LEE und HARPER (1978) zeigten unter Einsatz von L-[U- $\left.{ }^{14} \mathrm{C}\right]$ Threonin auch, dass bei Ratten eine niedrige Oxidationsrate für Threonin in einem Versorgungsbereich für maximales Wachstum (ca. 0,5\% Threonin) gegeben ist. Bei höherer Threoninversorgung stieg die Oxidationsrate von Threonin an. Die Threonindehydratase-Aktivität in der Leber erhöhte sich bei einem Threoninanstieg im Futter nicht. Im Gegenteil, die TDH-Aktivität tendierte dazu, bei Threoninzunahme in den Futtermischungen abzusinken. CHU und HEGSTED (1976) fanden, daß bei Ratten die TDH-Aktivität durch die Höhe der Threoninaufnahme nicht beeinflußt wird, sondern durch einen Anstieg der Proteinaufnahme erhöht wird. KANG-LEE und HARPER (1977) haben auch gezeigt, dass Histidin nur geringfügig oxidiert wird, bis die Histidinversorgung für maximales Wachstum ausreichend ist. Die Oxidation erhöht sich schnell bei einer Histidinaufnahme über dieses Niveau hinaus. Ähnliche Beobachtungen sind 
mit Lysin von BROOKES et al. (1972, 1973), mit Methionin von AGUILAR et al. (1974) und mit Phenylalanin von KIM et al. (1983) gemacht worden.

Auf der anderen Seite zeigte BLOXAM (1975), daß Threonin bei niedriger Konzentration nicht oxidiert wird, wenn sich die Raten für die Gluconeogenese und Harnstoffbildung durch eine Threoninkonzentration über dem physiologischen Bereich erhöhen. Nach YAMASHITA und ASHIDA (1971) wird bei Ratten, wenn sie mit Threonin und Lysin exzessiv versorgt wurden, mehr Threonin als Lysin desaminiert.

Bei Ratten konnte in in vitro Versuchen von BIRD und NUNN (1983) kein Anstieg der hepatischen TDG-Aktivität nach Versorgung mit hohen Proteingehalten in der Futtermischung gefunden werden.

\subsubsection{Schwein}

Nach Angaben von Le FLOC'H et al. (1996) ist die in vivo Gesamt-Threoninoxidation zu Glycin beim Schwein, errechnet aus den Plasmawerten über die Anreicherung und die spezifische Radioaktivität, niedrig und weitgehend konstant. Dies wird beobachtet, wenn die geschätzte absorbierte Threoninmenge niedriger als bei $4 \mathrm{~g} /$ Tag (LT-Gruppe) liegt. Bei höherer Threoninresorption stieg die Threoninoxidation deutlich an (Abbildung 2).

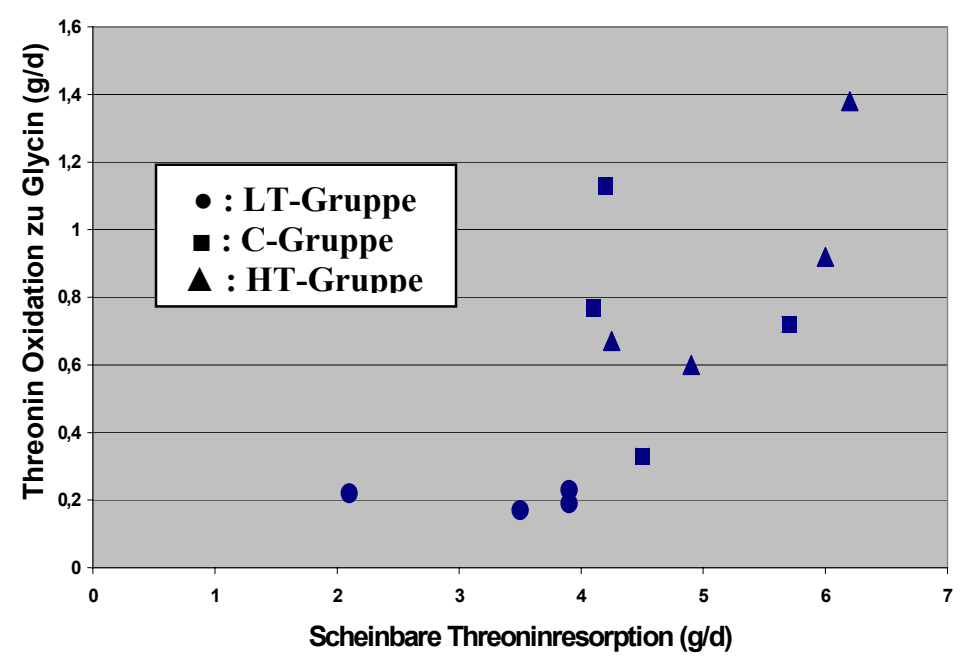

Abb. 2.: Einfluß der scheinbar resorbierten Threoninmenge auf die in vivo Threoninoxidation zu Glycin bei wachsenden Schweinen; Niedrig-Threonin-Diät (LTGruppe; 4,71g/ kg Diät)(•), Kontroll-Diät (C-Gruppe; 5,94g/ kg Diät)(ロ), HochThreonin-Diät (HT-Gruppe; 7,11g/ kg Diät)( $\Delta)$ (modifiziert nach Le FLOC'H et al. 1996). 
Wie aus Tabelle 3 hervorgeht, zeigt die TDG-Aktivität (in vitro) bei einer Hoch-Threonin Diät (HT-Gruppe) trotz der exzessiven Threoninaufnahme im Vergleich zu der NiedrigThreonin-Diät (LT-Gruppe) und Kontroll-Diät (C-Gruppe) keine signifikanten Veränderungen. Es war nicht möglich, eine Erhöhung der TDG-Aktivität durch Threoninüberschuss auszulösen. Die TDG-Aktivität, die in der LT-Gruppe gemessen wurde, war in der Leber und im Pankreas der Schweine niedriger als in der C-Gruppe (Tab. 3). Dies könnte eine Konsequenz der niedrigeren TDG-Bereitstellung sein, die aus AminosäurenImbalancen bei Threoninmangel resultiert (Le FLOC'H et al., 1996).

Tab. 3. Threonin-Oxidationsraten zu Glycin und TDG-Aktivitäten bei niedrigen Threonin-Gehalten (LT-Gruppe), einer Kontroll-Diät (C-Gruppe) und hohen Threonin-Gehalten (HT-Gruppe) in der Futtermischung (modifiziert nach Le FLOC'H et al. 1996).

\begin{tabular}{|c|c|c|c|c|}
\hline \multirow{2}{*}{ Diäten } & \multirow{2}{*}{$\begin{array}{l}\text { Thr-Oxidations- } \\
\text { Rate zu Glycin* }\end{array}$} & \multirow{2}{*}{$\begin{array}{c}\text { Plasma Threonin } \\
\text { Flux } * *\end{array}$} & \multicolumn{2}{|c|}{ TDG-Aktivität*** } \\
\hline & & & Leber & Pancreas \\
\hline $\mathbf{L T}$ & $2,43^{b}$ & $161^{\mathrm{c}}$ & $2,10^{b}$ & 1 \\
\hline $\mathbf{C}$ & $9,13^{\mathrm{a}}$ & $215^{b}$ & $3,75^{\mathrm{a}}$ & 3,1 \\
\hline HT & $10,45^{\mathrm{a}}$ & $268^{\mathrm{a}}$ & $3,2^{\mathrm{ab}}$ & 2,9 \\
\hline
\end{tabular}

* Die TDG-Aktivität wird als die Rate der Aminoacetonbildung ausgedrückt ( $\mu \mathrm{mol} / \mathrm{min} / \mathrm{g}$ Gewebe).

**Plasma Threonin Flux, berechnet aus der Anreicherung im Plasma, während der Infusion von L- $\left[1-{ }^{13} \mathrm{C}\right]$

***Threonin errechnet $(\mu \mathrm{mol} / \mathrm{kg} / \mathrm{h})$.

\subsubsection{Mensch}

ZHAO et al. (1986) untersuchten die Threoninoxidation durch die Bildung von markiertem $\mathrm{CO}_{2}$ mit Hilfe einer konstanten Infusion von L- $\left[1-{ }^{13} \mathrm{C}\right]$ Threonin bei gesunden, erwachsenen Männern und unterschiedlicher Aufnahme von Threonin. Die Raten der Threoninoxidation fielen mit verringerter Threoninaufnahme, wobei ein relativ konstantes Niveau bei einer Aufnahme von $20 \mathrm{mg} \mathrm{kg}^{-1} \cdot \mathrm{Tag}^{-1}$ erreicht wurde. Bei Erhöhung der Threoninaufnahme über den minimalen Bedarf, erhöhte sich der Anteil an markiertem ${ }^{13} \mathrm{CO}_{2}$ linear (Tab. 4). Es wurde keine Erhöhung an markiertem $\left[{ }^{13} \mathrm{C}\right]$ Glycin im Plasma während der Infusion von L-[1$\left.{ }^{13} \mathrm{C}\right]$ Threonin beobachtet. ZHAO et al. (1986) stellten fest, daß die Konvertierung von Threonin zu Glycin durch den TDG-Weg nicht von Bedeutung ist. 
Tab. 4. Plasma Threoninflux und Threoninoxidation bei adulten Männern in Beziehung zum Threonin-Versorgungsgrad (modifiziert nach ZHAO et al. 1986)

\begin{tabular}{|c|c|c|c|c|c|c|c|}
\hline \multicolumn{7}{|c|}{ Threonin Aufnahme (mg/ kg/ d) } \\
\hline & $\mathbf{3}$ & $\mathbf{1 0}$ & $\mathbf{2 0}$ & $\mathbf{3 0}$ & $\mathbf{4 0}$ & $\mathbf{8 0}$ & $\mathbf{1 0 0}$ \\
\hline $\begin{array}{c}\text { Plasma- } \\
\text { Threoninflux }\end{array}$ & $41 \pm 9$ & $40 \pm 7$ & $59 \pm 7$ & $72 \pm 8$ & $92 \pm 21$ & $177 \pm 8$ & $180 \pm 37$ \\
\hline $\begin{array}{c}\text { Threonin- } \\
\text { Oxidation }\end{array}$ & $4 \pm 2$ & $4 \pm 1$ & $5 \pm 2$ & $10 \pm 1$ & $11 \pm 3$ & $25 \pm 4$ & $28 \pm 8$ \\
\hline
\end{tabular}

Flux und Oxidation werden als $\mu \mathrm{mol} / \mathrm{kg} / \mathrm{h}$ ausgedrückt.

Tabelle 5 zeigt den Abbau von Threonin $\mathrm{zu} \mathrm{CO}_{2}$ und Glycin bei hohem Überschuss an Nahrungs-Threonin, das entweder als freie Aminosäure (+Thr) oder als proteingebundenes Threonin (+P-Thr) gegeben wurde, bei sechs gesunden adulten Männern nach einer konstanten Infusion von L- $\left[1-{ }^{13} \mathrm{C}\right]$ Threonin und $\left[{ }^{15} \mathrm{~N}\right]$ Glycin über 4 Stunden.

Tab. 5. Der Threoninkatabolismus zu Glycin und $\mathrm{CO}_{2}$ bei adulten Männern, (modifiziert nach DARLING et al., 2000; $n=6$ ).

\begin{tabular}{|c|c|c|c|c|}
\hline \multicolumn{5}{|c|}{ Diäten } \\
\hline & Kontrolle & + Thr & + P-Thr & SD \\
\hline Threoninaufnahme* & $50^{\mathrm{b}}$ & $126^{\mathrm{a}}$ & $126^{\mathrm{a}}$ & 8 \\
\hline Plasma Threoninflux* & $99^{\mathrm{c}}$ & $197^{\mathrm{a}}$ & $154^{\mathrm{b}}$ & 16 \\
\hline Plasma Glycinflux* & 147 & 129 & 134 & 17 \\
\hline $\begin{array}{l}\text { - Raten der Thr-Oxidation } \\
\text { zu Glycin* } \\
\text { - } \% \text { des Gesamtabbaues }\end{array}$ & 10 & 3,5 & 3,4 & 1,3 \\
\hline $\begin{array}{l}\text { Raten der Thr- } \\
\text { Oxidation zu } \mathrm{CO}_{2} * \\
\text { - } \% \text { des Gesamtabbaues }\end{array}$ & $15^{\mathrm{b}}$ & $49^{\mathrm{a}}$ & $45^{\mathrm{a}}$ & 5,9 \\
\hline
\end{tabular}


Die Threoninaufnahmen lagen bei den Diäten + Thr und + P-Thr höher als bei der Kontrolldiät. Bei den Männern, die die Diät +P-Thr verzehrten, lagen Plasmathreoninflux und Plasmathreoninkonzentration niedriger als bei der + Thr-Diät. Die Threoninoxidation $\mathrm{zu}^{\mathrm{CO}_{2}}$ und Glycin war nicht unterschiedlich. Es gab keinen Unterschied bezüglich der Raten der Threoninoxidation zu $\mathrm{CO}_{2}$ bei den Männern, die die +Thr-Diät anstelle der +P-Thr-Diät verzehrt hatten. Die Threoninoxidation zu $\mathrm{CO}_{2}$ erhöhte sich jedoch um das Dreifache bei +Thr- und +P-Thr-Diäten im Vergleich zur Kontrolldiät. Der Threoninabbau zu Glycin zeigte, daß er bei +Thr- und +P-Thr-Diäten im Vergleich mit der Kontrolldiät höher lag. Der TDGWeg umfaßte nur 7-10\% des Gesamtkatabolismus von Threonin und ist folglich ein eher unbedeutender Weg bei erwachsenen Menschen. Bei Säuglingen erfolgt jedoch etwa 44\% der Threoninoxidation über den TDG-Weg (DARLING et al., 1999). Insgesamt werden 90-93\% des gesamten Threonins zu $\mathrm{CO}_{2}$ abgebaut. Dieser Befund war vom Niveau der Threoninaufnahme abhängig und unabhängig von der Proteinaufnahme (DARLING et al., 2000).

Ausgehend vom vorliegenden Kenntnisstand sollte der Threoninstoffwechsel in Beziehung zum Protein- und Threoninversorgungsgrad unter den Bedingungen Threonin limitierter Diäten bei Küken und Laborratten einer weiteren Untersuchung unterzogen werden und mit Ergebnissen zur Threoninwirksamkeitsmessung in Bilanzversuchen verglichen werden. 


\section{EIGENE UNTERSUCHUNGEN}

Die vorgenommenen Untersuchungen beim Küken waren Teil eines Untersuchungskomplexes zur Ermittlung von Proteinansatzvermögen und Threoninumsatz (RIMBACH, Diss. in Vorbereitung). In der vorliegenden Arbeit erfolgt deshalb eine Darstellung methodischer Grundsätze und Ergebnisse in dem Umfang, wie sie zum unmittelbaren Verständnis der Untersuchungsbefunde erforderlich sind.

\subsection{Versuchszielstellung}

Ziel der Untersuchungen war, den Einfluss unterschiedlicher Protein- und Threoninversorgung bei Küken und Laborratte auf die Threonindehydrogenaseaktivität der Leber zu prüfen. In Anlehnung an methodische Arbeiten aus der Literatur sollten hierfür Weiterentwicklungen von in vitro Enzymaktivitätsmessungen erfolgen. $\mathrm{Da}$ die Glycinakkumulation in der Leber in diesem Zusammenhang eine wichtige Verwertungsgröße darstellt, sollte deren Variation in Abhängigkeit von Alter und Glycinversorgung besonders betrachtet werden.

Zur Lösung der Problemstellung wurden insgesamt 3 Bilanzversuche beim Küken, 2 Bilanzversuche an der Laborratte sowie 2 Wachstumsversuche beim Küken durchgeführt. Tabelle 6 gibt eine Übersicht zum experimentellen Teil der vorliegenden Arbeit. 
Tab. 6: Übersicht zur Versuchsplanung

\begin{tabular}{|c|c|c|c|}
\hline $\begin{array}{c}\text { Versuch } \\
\text { Nr. }\end{array}$ & Art des Versuchs & $\begin{array}{c}\text { Tierart und } \\
\text { Herkünfte }\end{array}$ & $\begin{array}{c}\text { Haupt- } \\
\text { Proteinträger }\end{array}$ \\
\hline $\mathbf{1}$ & $\begin{array}{c}\text { Bilanzversuch mit } \\
\text { XP-Steigerungsstufen }\end{array}$ & $\begin{array}{c}\text { Küken, } \\
\text { Cobb 500 }\end{array}$ & HP-Sojaextraktionsschrot \\
\hline $\mathbf{2}$ & $\begin{array}{c}\text { Wachstumsversuch mit XP- } \\
\text { und Thr-Steigerungsstufen }\end{array}$ & $\begin{array}{c}\text { Küken, } \\
\text { Cobb 500 }\end{array}$ & Weizenkleber + Weizen \\
\hline $\mathbf{3}$ & $\begin{array}{c}\text { Bilanzversuch mit XP- und } \\
\text { Thr-Steigerungsstufen }\end{array}$ & $\begin{array}{c}\text { Küken, } \\
\text { Cobb 500 }\end{array}$ & HP-Sojaextraktionsschrot \\
\hline $\mathbf{4}$ & $\begin{array}{c}\text { Wachstumsversuch } \\
\text { zur Prüfung der }\end{array}$ & $\begin{array}{c}\text { Küken, } \\
\text { Cobb 500 }\end{array}$ & Sojaextraktionsschrot, Fisch- \\
mehl, Mais und Weizen \\
\hline $\mathbf{5}$ & $\begin{array}{c}\text { Bilanzversuch mit Glycin- } \\
\text { und Thr- Steigerungsstufen }\end{array}$ & $\begin{array}{c}\text { Küken, } \\
\text { Cobb 500 }\end{array}$ & Weizenkleber + Weizen \\
\hline $\mathbf{6}$ & $\begin{array}{c}\text { Bilanzversuch mit } \\
\text { XP-Steigerungsstufen }\end{array}$ & $\begin{array}{c}\text { Laborratte, } \\
\text { Wistar }\end{array}$ & Kasein \\
\hline \multirow{2}{*}{$\begin{array}{c}\text { Bilanzversuch mit XP- } \\
\text { und Thr-Steigerungsstufen }\end{array}$} & $\begin{array}{c}\text { Laborratte, } \\
\text { Wistar }\end{array}$ & Weizenkleber \\
\hline
\end{tabular}

\subsection{Tierhaltung}

\subsubsection{Küken}

Die Versuche wurden mit männlichen Küken (Geschlechtertrennung durch Federsexen) des Genotyps Cobb 500 (Lieferant: WIMEX Agrarprodukte Dessau) durchgeführt. Am Schlupftag wurden die Küken übernommen.

\subsubsection{Bilanzversuche}

Die Durchführung der Bilanzversuche erfolgte im Zeitraum vom Juni 1998 bis Januar 2001. Die Bilanzmessungen wurden im Alter vom 15. - 25. Lebenstag (Versuch 1), 10. - 20. Lebenstag (Versuch 3) bzw. 5. - 15. Lebenstag (Versuch 5) mit einer Vor- und Sammelperiode von jeweils 5 Tagen (6 Tiere je Gruppe) vorgenommen. Die Tiere wurden bis 
zur Versuchsphase in Gruppen gehalten. Zum Versuchsbeginn repräsentierten die ausgewählten Tiere hinsichtlich Körpermasseentwicklung den Mittelwert der zur Verfügung stehenden Tiergruppen. Die Bilanzversuche erfolgten in speziellen Stoffwechselkäfigen bei Einzeltierhaltung. Eine stabile Raumheizung und Dauerbeleuchtung von 24 Stunden wurde in der gesamten Versuchszeit gewährleistet. Während der Versuchsperioden lagen die Raumtemperaturen bei $28^{\circ}-29^{\circ} \mathrm{C}$ für Bilanzversuch 1 bzw. 2 und bei $29^{\circ}-31^{\circ} \mathrm{C}$ für Bilanzversuch 3. Die Fütterung war restriktiv und in Pelletform. Wasser stand jederzeit zur Verfügung. Die Exkrementsammlung erfolgte dreimal täglich ohne Säurevorlage. Die Exkremente wurden unmittelbar nach der Sammlung bei $-18^{\circ} \mathrm{C}$ bis zur Analyse eingefroren.

\subsubsection{Wachstumsversuche}

Die Wachstumsversuche wurden im Zeitraum Juni 1999 bis Mai 2000 durchgeführt. Die Versuchszeiträume lagen in der Zeit vom 17. - 30. Lebenstag (Versuch 2) bzw. 7. - 49. Lebenstag (Versuch 4). Die Tiere wurden bis zur Eingewöhnungsphase in Gruppen gehalten. Zum Versuch repräsentierten die ausgewählten Tiere den Mittelwert der zur Verfügung stehenden Tiergruppen. Die Tiere wurden in Gruppenkäfigen gehalten. Jede Gruppe hatte jeweils 3 Subgruppen, die zu je 10 Tieren eingeteilt waren. Jeder Käfig bestand aus einer Fläche von $100 \mathrm{~cm}$ x $90 \mathrm{~cm}$ mit Futtertrögen und Rinnentränken. Während der ersten Woche lag die Raumtemperatur bei $31^{\circ}-32^{\circ} \mathrm{C}$, während der zweiten und dritten Woche bei $28^{\circ}$ $30^{\circ} \mathrm{C}$ und ab der vierten Woche lag sie bei etwa $26^{\circ}-27^{\circ} \mathrm{C}$. Der Versuchsraum war gegen Außenlicht abgeschirmt und wurde während des Versuches 24 Stunden lang dauerbeleuchtet. Die Tiere wurden in der Versuchsperiode ad libitum gefüttert. Wasser stand zur freien Aufnahme zur Verfügung.

\subsubsection{Laborrattenversuche}

Als Versuchstiere dienten männliche Albinoratten eines ingezüchteten Wistar Stammes aus dem Klinikum der Universität Göttingen. Für die Versuche (Versuch 6 und 7) wurden $4-6$ Wochen alte Ratten in einem Lebendmassebereich von etwa 115 - 145 g verwendet. 


\subsubsection{Bilanzversuche}

Die Ratten wurden im Alter von 21 Tagen vom Muttertier abgesetzt und bis zum Versuchsbeginn in Gruppen gehalten. 5 Tage vor der Vorperiode erfolgte die Überführung der Tiere in Stoffwechselkäfige nach HORSZCZARUK und BOCK (1963), um sich einzugewöhnen. Es wurde in der Vorperiode angestrebt, eine möglichst geringe Lebendmasseabweichung zwischen den Gruppen zu bekommen. Während der Gewöhnungsphase wurden die Tiere ad libitum mit einem Standardfutter (Altromin GmbH) in Kuchenform gefüttert. Danach wurde das Versuchsfutter restriktiv in Mehlform verabreicht. Die Versuchsperiode bestand aus einer 5-tägigen Vorperiode und 6-tägigen Sammelperiode. Während der Sammelperiode wurden Kot und Harn in einer Vorlage 5\%iger Schwefelsäure getrennt täglich einmal gesammelt und anschließend bis zur Analyse bei $-18^{\circ} \mathrm{C}$ eingefroren. Die Tiere erhielten täglich zur gleichen Zeit (9 Uhr) ihre Tagesration. Die Raumtemperatur wurde bei $21-22{ }^{\circ} \mathrm{C}$ konstant gehalten und die relative Luftfeuchtigkeit lag bei etwa $60 \%$. Der Versuchsraum war auf einen Hell- und Dunkelrhythmus von jeweils 12 Stunden eingestellt (MÜLLER, 1964; NEHRING et al., 1967; MADRY, 1989).

\subsection{Futterkomponenten und Futterherstellung}

\subsubsection{Futterkomponenten}

Die Rohrnährstoff- und Energiegehalte der Futtermischungen in den Bilanz- und Wachstumsversuchen wurden nach den NRC-Empfehlungen für Geflügel (NRC, 1994) und für Laborratten (NRC, 1995) ausgerichtet.

In den Bilanzversuchen beim Küken wurden Sojaextraktionsschrot und Weizenkleber als Proteinträger eingesetzt, in den Wachstumsversuchen Sojaextraktionsschrot, Weizenkleber und Fischmehl. In den Bilanzversuchen bei Laborratten fanden Kasein und Weizenkleber als Proteinträger Anwendung. Die Nährstoffgehalte der Hauptkomponenten sind in den Tabellen 7 und 8 dargestellt. 
Tab. 7: Nährstoffgehalte der in den Versuchen verwendeten Futtermittel (\% TS)

\begin{tabular}{|l|c|c|c|c|c|c|c|}
\hline Futtermittel & TS (\%) & XA & XP & XF & XL & Zucker & Stärke \\
\hline $\begin{array}{l}\text { HP-Sojaextrak- } \\
\text { tionsschrot }\end{array}$ & 88,0 & 6,7 & 55,2 & 3,9 & 1,3 & 11,5 & 7,2 \\
\hline Weizenkleber & 88,0 & 1,2 & 84,2 & 0,5 & 1,7 & 0,4 & 7,8 \\
\hline Fischmehl & 91,0 & 21,6 & 67,5 & 1,0 & 6,8 & $-*$ & $-^{*}$ \\
\hline Kasein & 94,0 & 5,0 & 92,0 & $-*$ & 1,5 & 0,5 & -* $^{*}$ \\
\hline Mais & 88,0 & 1,7 & 10,6 & 2,6 & 4,6 & 1,9 & 69,5 \\
\hline Weizen & 88,0 & 1,9 & 13,8 & 2,9 & 2,0 & 3,2 & 67,5 \\
\hline
\end{tabular}

* -, nicht bestimmt

Tab. 8: Aminosäurezusammensetzung der Hauptkomponenten der Futtermischungen (g/ kg TS)

\begin{tabular}{|c|c|c|c|c|c|c|}
\hline Aminosäure & $\begin{array}{c}\text { HP-Sojaextrak- } \\
\text { tionsschrot }\end{array}$ & $\begin{array}{c}\text { Weizen- } \\
\text { kleber }\end{array}$ & Fischmehl & Kasein & Mais & Weizen \\
\hline Lys & 35,6 & 20,7 & 55,1 & 83,1 & 2,8 & 4,3 \\
\hline Thr & 21,8 & 21,1 & 30,0 & 40,9 & 3,5 & 4,3 \\
\hline Met & 7,5 & 11,9 & 20,2 & 28,7 & 2,0 & 2,4 \\
\hline Cys & 8,6 & 19,8 & 6,4 & 4,4 & 2,2 & 3,3 \\
\hline Ser & 27,7 & 37,4 & 28,2 & 55,5 & 4,7 & 6,8 \\
\hline Glu & 101,6 & 281,0 & 91,4 & 210,6 & 17,7 & 41,6 \\
\hline Pro & 28,2 & 121,5 & 31,0 & 109,0 & 8,6 & 14,7 \\
\hline Gly & 23,9 & 27,4 & 47,0 & 19,0 & 3,8 & 6,1 \\
\hline Ala & 24,3 & 22,4 & 44,8 & 28,2 & 7,2 & 5,5 \\
\hline Val & 27,0 & 38,5 & 34,7 & 66,9 & 4,7 & 6,4 \\
\hline Leu & 43,6 & 57,4 & 51,9 & 93,2 & 11,9 & 9,9 \\
\hline Ile & 26,4 & 29,5 & 29,5 & 50,0 & 3,3 & 5,0 \\
\hline Tyr & 20,7 & 33,6 & 23,6 & 50,7 & 3,6 & 4,4 \\
\hline Arg & 41,5 & 32,2 & 41,1 & 37,1 & 4,5 & 7,3 \\
\hline Phe & 32,2 & 53,6 & 29,0 & 48,8 & 4,8 & 6,9 \\
\hline His & 14,5 & 25,3 & 21,4 & 33,9 & 3,0 & 3,6 \\
\hline
\end{tabular}




\subsubsection{Futterherstellung}

Die Herstellung der Futtermischungen für die Geflügelversuche erfolgte mit Chargenmischern unterschiedlichen Fassungsvermögens der Fa. Lödige (Typ M20MK bzw. Typ FM130D1MZ). Vor der Futterpelletierung (Pelletpresse Typ 3530 der Fa. Lister) erfolgte ein Wasserzusatz entsprechend dem jeweiligen Wasserbindungsvermögen. Das pelletierte Futter kam mit einem mittleren Pelletdurchmesser von 2,2 mm zum Einsatz. Die Futtermischungen für Laborratten wurden in einem Labormischer der Fa. Lödige hergestellt (Typ AD71NZ4) und in Mehlform verabreicht.

\subsection{Versuchsmischungen und Durchführung der Versuche}

In Tabelle 8 wurde die Aminosäurezusammensetzung der Hauptkomponenten der Futtermischungen, die in den Versuchen eingesetzt wurden, bereits dargestellt. Die den jeweiligen Versuchsfragen zugeordneten Futtermischungen werden nachfolgend bei der Beschreibung der Einzelversuche detailliert beschrieben.

Zur Einstellung der jeweils gewünschten Aminosäureverhältnisse diente das ideale ASMuster nach BAKER und HAN (1994) als Orientierung für die Untersuchungen beim Küken.

Für die Untersuchungen an der Laborratte diente das ideale AS-Muster nach GAHL et al. (1991) zum Vergleich.

Der AS-Ausgleich erfolgte über kristalline Aminosäuren und wird in den Einzelversuchen detailliert ausgewiesen.

\subsubsection{Versuch 1 (Bilanzversuch Küken, N-Steigerungsversuch mit HP- Sojaextraktionsschrot)}

In diesem Versuch sollten gestaffelte N-Gehalte im Futter in ihrer Wirkung auf die TDGAktivität untersucht werden. 6 Proteinstufen $(5,5 \%$ - 33,0\%) wurden in diesem Versuch verwendet. Die eingesetzten Futtermischungen sind in Tabelle 9 aufgeführt. 
Tab. 9: Zusammensetzung der Futtermischungen im N-Steigerungsversuch mit Küken (g/ kg FS)

\begin{tabular}{|c|c|c|c|c|c|c|}
\hline Futtermischung & $\begin{array}{c}\mathbf{5 , 5 0 \%} \\
\mathrm{XP}\end{array}$ & $\begin{array}{l}11,00 \% \\
\text { XP }\end{array}$ & $\begin{array}{c}16,50 \% \\
X P\end{array}$ & $\begin{array}{l}22,00 \% \\
\text { XP }\end{array}$ & $\begin{array}{l}27,50 \% \\
\text { XP }\end{array}$ & $\begin{array}{l}33,00 \% \\
\text { XP }\end{array}$ \\
\hline $\begin{array}{l}\text { HP-Sojaextraktions- } \\
\text { schrot }\end{array}$ & 112,00 & 224,00 & 336,00 & 448,00 & 560,00 & 672,00 \\
\hline Sojaöl & 15,00 & 15,00 & 15,00 & 15,00 & 115,00 & 150,00 \\
\hline Kartoffelquellstärke & 802,68 & 695,59 & 588,09 & 480,49 & 276,48 & 130,76 \\
\hline Cellulosepulver & 18,00 & 14,50 & 11,00 & 7,50 & 0,40 & 0 \\
\hline Premix* & 10,00 & 10,00 & 10,00 & 10,00 & 10,00 & 10,00 \\
\hline МСP & 28,51 & 25,00 & 21,50 & 18,00 & 14,50 & 11,00 \\
\hline $\mathrm{CaCO}_{3}$ & 10,30 & 11,10 & 11,90 & 12,70 & 13,50 & 14,30 \\
\hline $\mathrm{NaCl}$ & 0,90 & 0,90 & 0,80 & 0,70 & 0,60 & 0,50 \\
\hline$\overline{\mathrm{MgO}}$ & 0,70 & 0,10 & 0 & 0 & 0 & 0 \\
\hline L-Lys·HCl & 0,45 & 0,90 & 1,34 & 1,79 & 2,24 & 2,70 \\
\hline DL-Met & 1,46 & 2,91 & 4,37 & 5,82 & 7,28 & 8,74 \\
\hline $\begin{array}{l}\text { Aminosäuren- } \\
\text { verhältnis** }\end{array}$ & \multicolumn{6}{|c|}{$\begin{array}{l}\text { Lys }[1]: \text { Met+Cys }[0,79]: \text { Thr }[0,56]: \operatorname{Trp}[0,19]: \\
\operatorname{Arg}[1,06]: \text { Gly }[0,61]: \text { Gly+Ser }[1,31]\end{array}$} \\
\hline $\mathrm{ME}_{\mathrm{N}}(\mathrm{MJ} / \mathrm{kg} \mathrm{T})^{* * *}$ & 14,16 & 14,39 & 13,73 & 13,37 & 14,85 & 14,50 \\
\hline
\end{tabular}

** Threonin war als limitierende Aminosäure eingestellt.

*** Schätzformel WPSA (1984) für N-korrigierte umsetzbare Energie.

* Zusammensetzung des Premix (Fa. Deutsche Vilomix) pro kg : 175 g Ca, 80 g Na.

Zusatzstoffe pro kg Premix : 1.200.000 I.E. Vitamin A, 300.000 I.E. Vitamin $\mathrm{D}_{3}, 3.000 \mathrm{mg}$

Vitamin E, $200 \mathrm{mg}$ Vitamin $\mathrm{B}_{1}, 480 \mathrm{mg}$ Vitamin $\mathrm{B}_{2}, 360 \mathrm{mg}$ Vitamin $\mathrm{B}_{6}, 1.500 \mathrm{mg}$ Vitamin $\mathrm{B}_{12}$, $300 \mathrm{mg}$ Vitamin $\mathrm{K}_{3}, 2.700 \mathrm{mg}$ Nikotinsäure, $900 \mathrm{mg}$ Calcium-Pantothenat, $90 \mathrm{mg}$ Folsäure,

$5.000 \mathrm{mg}$ Biotin, $80.000 \mathrm{mg}$ Cholinchlorid, $12.000 \mathrm{mg}$ Mangan, $8.000 \mathrm{mg}$ Zink, 5.000 mg Eisen,

$3.000 \mathrm{mg}$ Kupfer, 120 mg Jod, 55 mg Kobalt, 42 mg Selen, 10.000 mg BHT, 12.500 mg Monensin-Na.

Das Prinzip der Versuchsdurchführung wurde unter 3.2.1.1 beschrieben. Es standen insgesamt 36 Tiere in 6 Gruppen zu je 6 Tieren zur Verfügung. Diese Untersuchung erfolgte im Zeitabschnitt vom 15. - 25. Lebenstag. Am Ende des Bilanzversuches wurden alle Küken durch cervicale Dislokation getötet und die Lebern entnommen, um die TDG-Aktivität zu bestimmen. Die weitere Behandlung der Lebern ist unter 3.5.1 dargestellt. 


\subsubsection{Versuch 2 (Wachstumsversuch Küken, 2 Protein- und 2 Threoninstufen mit Weizen/Weizenkleber)}

In diesem Versuch sollten 2 Protein- und 2 Threoninstufen in ihrer Wirkung auf die TDGAktivität untersucht werden. Die verwendeten Basaldiäten sind in Tabelle 10 aufgeführt. Als Proteinträger wurden Weizenkleber und Weizen verwendet. Die AS-Zusammensetzung der Basalmischungen wurde durch AS-Zusätze nach dem Ideal-Protein von BAKER und HAN (1994) optimiert. Um Glycinmangel auszuschließen, wurde Glycin in beiden Proteinstufen zugesetzt (Glycin+Serin insgesamt 1,90 \% der FS; SCHUTTE et al., 1997).

Tab. 10: Zusammensetzung der Basalmischungen (g/ kg FS)

\begin{tabular}{|c|c|c|}
\hline Futtermischung & $18,50 \%$ XP & $22,50 \% X P$ \\
\hline Weizen & 588,80 & 739,20 \\
\hline Weizenkleber & 94,20 & 118,30 \\
\hline Weizenstärke & 213,30 & 30,10 \\
\hline Sojaöl & 28,00 & 40,00 \\
\hline Premix** & 10,00 & 10,00 \\
\hline MCP & 20,50 & 18,00 \\
\hline $\mathrm{CaCO}_{3}$ & 12,00 & 13,00 \\
\hline $\mathrm{NaCl}$ & 3,00 & 3,00 \\
\hline MgO & 0,40 & 0 \\
\hline Celite & 10,00 & 10,00 \\
\hline L-Thr & 0,93 & 0 \\
\hline L-Lys•HCI & 6,14 & 7,71 \\
\hline DL-Met & 1,49 & 1,87 \\
\hline L-Trp & 0,24 & 0,30 \\
\hline L-Arg & 2,83 & 3,62 \\
\hline L-Ile & 0,97 & 1,20 \\
\hline L-Gly & 7,20 & 3,70 \\
\hline $\begin{array}{l}\text { Aminosäuren- } \\
\text { verhältnis* }\end{array}$ & $\begin{array}{c}\text { Lys }[1]: \text { Thr }[0,53]: \\
\text { Gly }[1,30]: \text { Gly+Ser } \\
{[2,02]}\end{array}$ & $\begin{array}{c}\text { Lys [1]: Thr }[0,44]: \\
\text { Gly }[0,89]: \text { Gly+Ser } \\
{[1,61]}\end{array}$ \\
\hline $\mathrm{ME}_{\mathrm{N}}(\mathrm{MJ} / \mathrm{kg} \mathrm{T})$ & 15,40 & 15,06 \\
\hline
\end{tabular}

* Threonin war als limitierende Aminosäure eingestellt.; Lys [1] : Met+Cys [0,75] : Trp [0,19] : Arg $[1,05]$ in den Basalmischungen. ** vergl. Tab.9 
Tab. 11: XP-, Threonin-, Glycin- und Seringehalt der Futtermischungen (\% FS)

\begin{tabular}{|l|c|c|c|c|}
\hline Futtermischung & A (Basal) & B & C (Basal) & D \\
\hline XP & \multicolumn{2}{|c|}{18,5} & \multicolumn{2}{|c|}{22,5} \\
\hline Gly & \multicolumn{2}{|c|}{1,22} & \multicolumn{2}{|c|}{1,05} \\
\hline Gly + Ser & \multicolumn{2}{|c|}{1,90} & 0,52 & 0,67 \\
\hline Thr & 0,50 & 0,65 & 0,45 & 0,60 \\
\hline dThr* & 0,45 & 0,60 & \multicolumn{2}{|c|}{1,90} \\
\hline
\end{tabular}

* wahr verdauliches Threonin (berechnet nach AminoDat 1.1, Degussa 1997)

Der Wachstumsversuch wurde im Zeitraum vom 17. - 30. Lebenstag durchgeführt. Parallel zum Wachstumsversuch erfolgte eine Bilanzmessung (Sammelperiode im Alter vom 20. - 25. Lebenstag). Aus den Ergebnissen des Bilanzversuches wurde die Thr-Wirksamkeit (bc ${ }^{-1}$ ) abgeleitet (GEBHARDT, 1980; LIEBERT et al., 1991; RIMBACH und LIEBERT, 2000; RIMBACH et al., 2000). Das Verfahren der Versuchsdurchführung wurde in Kapitel 3.2.1.2 beschrieben.

Am Ende der 14-tägigen Wachstumsperiode wurden die Küken durch cervicale Dislokation getötet und 6 Lebern je Gruppe entnommen, um die TDG-Aktivität zu bestimmen (vergl. 3.5.1).

\subsubsection{Versuch 3 (Bilanzversuch Küken, 2 Protein- und 2 Threoninstufen mit HP- Sojaextraktionsschrot)}

In diesem Versuch sollte die Frage geklärt werden, ob der im Vergleich zur Proteinkomponente Weizen/Weizenkleber (Versuch 2) höhere Thr-Gehalt der Komponente HP-Sojaextraktionsschrot Auswirkungen auf die TDG-Aktivität zeigt. Hierzu wurden analog zu Versuch 2 jeweils 2 Protein- bzw. Threoninstufen geprüft (Tab. 13). Die verwendeten Basaldiäten sind in Tabelle 12 aufgeführt. 
Tab. 12: Zusammensetzung der Basalmischungen (g/ kg FS)

\begin{tabular}{|c|c|c|}
\hline Futtermischung & $16,50 \% \times P$ & $22,00 \% \mathrm{XP}$ \\
\hline $\begin{array}{l}\text { HP-Sojaextraktions- } \\
\text { Schrot }\end{array}$ & 336,00 & 448,00 \\
\hline Sojaöl & 15,00 & 15,00 \\
\hline Kartoffelquellstärke & 587,77 & 480,05 \\
\hline Cellulosepulver & 11,00 & 7,50 \\
\hline Premix** & 10,00 & 10,00 \\
\hline МCP & 21,50 & 18,00 \\
\hline $\mathrm{CaCO}_{3}$ & 11,90 & 12,70 \\
\hline $\mathrm{NaCl}$ & 0,80 & 0,70 \\
\hline L-Lys·HCI & 1,63 & 2,25 \\
\hline DL-Met & 4,40 & 5,80 \\
\hline Aminosäurenverhältnis* & \multicolumn{2}{|c|}{$\begin{array}{c}\text { Lys }[1]: \text { Met+Cys }[0,79]: \text { Thr }[0,55]: \operatorname{Trp}[0,19]: \\
\text { Arg }[1,06]: \text { Gly }[0,60]: \text { Gly+Ser }[1,29]\end{array}$} \\
\hline $\mathrm{ME}_{\mathrm{N}}(\mathrm{MJ} / \mathrm{kg} \mathrm{T})$ & 13,73 & 13,37 \\
\hline
\end{tabular}

* Threonin war als limitierende Aminosäure eingestellt. ** vergl. Tab.9

Tab. 13: XP-, Threonin-, Glycin- und Seringehalte der Futtermischungen (\% FS)

\begin{tabular}{|l|c|c|c|c|}
\hline $\begin{array}{l}\text { Futter- } \\
\text { mischung }\end{array}$ & A (Basal) & B & C (Basal) & D \\
\hline XP & \multicolumn{2}{|c|}{16,50} & \multicolumn{2}{|c|}{22,00} \\
\hline Gly & \multicolumn{2}{|c|}{0,70} & \multicolumn{2}{|c|}{0,94} \\
\hline Gly + Ser & \multicolumn{2}{|c|}{1,52} & 0,86 & 1,05 \\
\hline Thr & 0,65 & 0,79 & \multicolumn{2}{|c|}{2,03} \\
\hline
\end{tabular}

Es wurden 24 Tiere in 4 Gruppen zu je 6 Tieren aufgestellt. Der Versuch erfolgte im Zeitraum vom 10. - 20. Lebenstag. Am Ende dieser Periode wurden die Lebern entnommen, um die TDG-Aktivität zu bestimmen. Die weitere Behandlung der Leber erfolgte entsprechend dem Kapitel 3.5.1. 


\subsubsection{Versuch 4 (Wachstumsversuch Küken, praxisübliche Futtermischungen)}

Zur Klärung des Alterseinflusses auf die TDG-Aktivität wurde auf praxisübliche Futtermischungen im Rahmen einer Phasenfütterung zurückgegriffen (Tab. 14). Die Untersuchung erfolgte im Zeitraum 7. - 49. Lebenstag.

Tab. 14: Zusammensetzung der Futtermischungen (g/ kg FS)

\begin{tabular}{|c|c|c|c|}
\hline Futtermischung & $\begin{array}{c}22,74 \% \text { XP } \\
\text { (Starter) }\end{array}$ & $\begin{array}{c}20,27 \% \text { XP } \\
\text { (Mast 1) }\end{array}$ & $\begin{array}{c}18,60 \% \text { XP } \\
\text { (Mast 2) }\end{array}$ \\
\hline Weizen & 400,00 & 410,00 & 350,70 \\
\hline Mais & 200,00 & 250,00 & 350,00 \\
\hline $\begin{array}{l}\text { Sojaextraktions- } \\
\text { schrot }\end{array}$ & 240,00 & 200,00 & 160,00 \\
\hline Fischmehl & 80,00 & 60,00 & 60,00 \\
\hline Sojaöl & 50,00 & 50,00 & 50,00 \\
\hline Premix & 10,00 & 10,00 & 10,00 \\
\hline $\mathrm{CaCO}_{3}$ & 8,00 & 8,00 & 8,00 \\
\hline MCP & 9,00 & 9,00 & 9,00 \\
\hline $\mathrm{NaCl}$ & 1,20 & 1,10 & 1,10 \\
\hline DL-Met & 1,50 & 1,70 & 1,00 \\
\hline L-Trp & 0,30 & 0,20 & 0,20 \\
\hline $\mathrm{ME}_{\mathrm{N}}(\mathrm{MJ} / \mathrm{kg} \mathrm{T})$ & 14,44 & 14,67 & 14,89 \\
\hline
\end{tabular}

Die Lebern wurden am 7., 21., 35. und 49 Lebenstag entnommen, um die TDG-Aktivität zu bestimmen. Die weitere Behandlung der Lebern erfolgte entsprechend dem Kapitel 3.5.1. 


\subsubsection{Versuch 5 (Bilanzversuch Küken, 2 Glycin- und 2 Threoninstufen mit Weizen/Weizenkleber)}

In diesem Versuchskomplex war die Wirkung von Threoninzulagen bei differenziertem Glycinniveau auf die TDG-Aktivität in der Kükenleber zu prüfen. Die verwendeten Futtermischungen sind in Tabelle 15 dargestellt. Die untersuchten Threonin- bzw. Glycinstufen sind in Tabelle 16 zusammengefaßt. Als Proteinträger wurden Weizenkleber und Weizen verwendet. Die Gehalte von Glycin und Serin (Tab. 16) lagen jeweils bei 1,90\% (Futtermischung A und B) bzw. 1,55\% (Futtermischung C und D).

Tab. 15: Zusammensetzung der Futtermischungen (g/ kg FS)

\begin{tabular}{|c|c|c|c|c|}
\hline Futtermischung & $\mathbf{A}$ & B & C & D \\
\hline XP-Gehalt & \multicolumn{4}{|c|}{$22 \% \times P$} \\
\hline Weizen & 400,00 & 400,00 & 400,00 & 400,00 \\
\hline Weizenkleber & 170,00 & 170,00 & 170,00 & 170,00 \\
\hline Weizenstärke & 328,97 & 327,44 & 332,47 & 330,94 \\
\hline Sojaöl & 18,00 & 18,00 & 18,00 & 18,00 \\
\hline Prämix & 10,00 & 10,00 & 10,00 & 10,00 \\
\hline $\mathrm{CaCO}_{3}$ & 10,00 & 10,00 & 10,00 & 10,00 \\
\hline MCP & 25,00 & 25,00 & 25,00 & 25,00 \\
\hline $\mathrm{NaCl}$ & 3,00 & 3,00 & 3,00 & 3,00 \\
\hline L-Lys·HCl & 8,70 & 8,70 & 8,70 & 8,70 \\
\hline DL-Met & 1,63 & 1,63 & 1,63 & 1,63 \\
\hline L-Gly & 3,50 & 3,50 & 0 & 0 \\
\hline L-Thr & 0 & 1,53 & 0 & 1,53 \\
\hline L-Trp & 0,35 & 0,35 & 0,35 & 0,35 \\
\hline L-Arg & 4,30 & 4,30 & 4,30 & 4,30 \\
\hline L-Ile & 1,00 & 1,00 & 1,00 & 1,00 \\
\hline L-Val & 0,55 & 0,55 & 0,55 & 0,55 \\
\hline L-Glu & 15,00 & 15,00 & 15,00 & 15,00 \\
\hline $\begin{array}{l}\text { Aminosäuren- } \\
\text { verhältnis* }\end{array}$ & $\begin{array}{c}\text { Lys }[1]: \\
\text { Thr }[0,43]: \\
\text { Gly }[0,86]: \\
\text { Gly+Ser }[1,64]\end{array}$ & $\begin{array}{c}\text { Lys }[1]: \\
\text { Thr }[0,56]: \\
\text { Gly }[0,86]: \\
\text { Gly+Ser }[1,64]\end{array}$ & $\begin{array}{c}\text { Lys [1] : } \\
\text { Thr }[0,43]: \\
\text { Gly }[0,56]: \\
\text { Gly+Ser }[1,34]\end{array}$ & $\begin{array}{c}\text { Lys [1]: } \\
\text { Thr }[0,56]: \\
\text { Gly }[0,56]: \\
\text { Gly+Ser }[1,34]\end{array}$ \\
\hline $\mathrm{ME}_{\mathrm{N}}(\mathrm{MJ} / \mathrm{kg} \mathrm{T})$ & 14,89 & 14,89 & 14,89 & 14,89 \\
\hline
\end{tabular}


Tab. 16: Glycin-, Serin- und Threoningehalte der Futtermischungen (\% FS)

\begin{tabular}{|l|c|c|c|c|}
\hline Futtermischung & A & B & C & D \\
\hline Gly & \multicolumn{2}{|c|}{ mit Glycin-Zulage (0,98) } & \multicolumn{2}{|c|}{ ohne Glycin-Zulage (0,64) } \\
\hline Gly + Ser & \multicolumn{2}{|c|}{1,90} & \multicolumn{2}{|c|}{1,55} \\
\hline Thr & 0,49 & 0,64 & 0,49 & 0,64 \\
\hline dThr* & 0,45 & 0,60 & 0,45 & 0,60 \\
\hline
\end{tabular}

* wahr verdauliches Threonin (berechnet nach AminoDat 1.1, Degussa 1997)

Dieser Versuch erfolgte im Altersabschnitt vom 5. - 15. Lebenstag. Am Ende dieser Periode wurden die Lebern entnommen, um die TDG-Aktivität zu bestimmen. Die weitere Behandlung der Leber erfolgte entsprechend dem Kapitel 3.5.1.

\subsubsection{Versuch 6 (Bilanzversuch Laborratte, N-Steigerungsversuch mit Kasein)}

In diesem Versuch sollten gesteigerte N-Gaben in ihrer Wirkung auf die TDG-Aktivität bei Laborratten untersucht werden, um ggf. tierartabhängige Unterschiede feststellen zu können. Mit den Futtermischungen sollten in diesem Versuch 5 Proteinstufen von 0 - 24\% erreicht werden. Die verwendeten Futtermischungen sind in Tabelle 17 dargestellt. 
Tab. 17: Zusammensetzung der Futtermischungen (g/ kg FS)

\begin{tabular}{|c|c|c|c|c|c|}
\hline Futtermischung & 0\% XP & $6 \% \times P$ & $12 \% \times P$ & $18 \% \times P$ & $24 \% \times P$ \\
\hline Kasein & 0 & 65,00 & 131,00 & 196,00 & 261,00 \\
\hline Weizenstärke & 730,00 & 650,76 & 567,80 & 475,90 & 384,20 \\
\hline Rohzucker & 100,00 & 100,00 & 100,00 & 100,00 & 100,00 \\
\hline Cellulose & 50,00 & 50,00 & 50,00 & 50,00 & 50,00 \\
\hline Sojaöl & 40,00 & 50,00 & 60,00 & 80,00 & 100,00 \\
\hline Mineralmischung** & 60,00 & 60,00 & 60,00 & 60,00 & 60,00 \\
\hline Vitaminmischung*** & 20,00 & 20,00 & 20,00 & 20,00 & 20,00 \\
\hline DL-Met & 0 & 0,80 & 4,30 & 7,80 & 11,20 \\
\hline L-Ile & 0 & 0,34 & 0,70 & 1,10 & 1,40 \\
\hline L-Phe & 0 & 2,70 & 5,40 & 8,00 & 10,70 \\
\hline L-Trp & 0 & 0,40 & 0,80 & 1,20 & 1,50 \\
\hline $\begin{array}{l}\text { Aminosäuren- } \\
\text { verhältnis* }\end{array}$ & \multicolumn{5}{|c|}{$\begin{array}{l}\text { Lys }[1]: \text { Met/Cys }[1,07]: \operatorname{Thr}[0,49]: \operatorname{Trp}[0,22]: \text { Ile }[0,67]: \\
\text { Phe }[1,11]: \text { Gly }[0,23]: \text { Gly+Ser }[0,9]\end{array}$} \\
\hline ME (MJ/ kg T) & 15,66 & 15,67 & 15,66 & 15,92 & 16,21 \\
\hline
\end{tabular}

* Threonin war als limitierende Aminosäure eingestellt.

** Inhaltstoffe der Mineralmischung (Fa. Altromin) pro kg : $146.068 \mathrm{mg}$ Calcium, $97.355 \mathrm{mg}$ Phosphor, 1.734 mg Mangan, 388 mg Zink, $2.931 \mathrm{mg}$ Eisen, 85 mg Kupfer, 6,6 mg Jod, 2,1 mg Kobalt, 3,8 mg Selen, 8.783 mg Magnesium, 39.229 mg Natrium, 116.487 mg Kalium, 10.536 mg Schwefel, 63.510 mg Chlor, 3,3 mg Molybdän, $70 \mathrm{mg}$ Fluor, 0,07 mg Aluminium.

*** Inhaltstoffe der Vitaminmischung (Fa. Altromin) pro kg : 750.000 I.E. Vitamin A, 25.000 I.E. Vitamin $\mathrm{D}_{3}, 7.500 \mathrm{mg}$ Vitamin E, $1.000 \mathrm{mg}$ Vitamin $\mathrm{B}_{1}, 1.000 \mathrm{mg}$ Vitamin $\mathrm{B}_{2}, 750 \mathrm{mg}$ Vitamin $\mathrm{B}_{6}$, 1,5 mg Vitamin $B_{12}, 500 \mathrm{mg}$ Vitamin $\mathrm{K}_{3}, 2.500 \mathrm{mg}$ Nikotinsäure, $2.500 \mathrm{mg}$ Pantothensäure, $500 \mathrm{mg}$ Folsäure, $10 \mathrm{mg}$ Biotin, $50.000 \mathrm{mg}$ Cholinchlorid, $5.000 \mathrm{mg}$ P-Aminobenzoesäure, $5.000 \mathrm{mg}$ Inosit, $1.000 \mathrm{mg}$ Vitamin C, $37.100 \mathrm{mg}$ Schwefel, 1,3 mg Aluminium.

Das Verfahren der Versuchsdurchführung wurde in Kapitel 3.2.2 beschrieben. Es wurden 30 Tiere in 5 Gruppen zu je 6 Tieren aufgestellt. Die Anfangslebendmasse der Tiere zu Beginn der Vorperiode war durchschnittlich 118 $\pm 5,8 \mathrm{~g}$ und am Anfang der Sammelperiode zwischen 106-140 g in den Gruppen. Die Tiere erhielten einmal täglich ihre Tagesration (12 g FS/ d). Am Ende der 11-tägigen Bilanzperiode wurden die Laborratten mit $\mathrm{CO}_{2}$ betäubt und getötet. Die 6 Lebern je Gruppe wurden entnommen, um die TDG-Aktivität zu bestimmen. Die weitere Behandlung der Lebern erfolgte entsprechend dem Kapitel 3.5.1. 


\subsubsection{Versuch 7 (Bilanzversuch Laborratte, 2 Protein- und 3 Threoninstufen mit Weizenkleber)}

In diesem Versuch sollte der Einfluß von Threoninstaffelungen bei unterschiedlichem Proteinniveau untersucht werden. Die Futtermischungen sollten in diesem Versuch 2 Proteinund 3 Threoninstufen aufweisen (Tab. 18). Als Proteinträger wurde Weizenkleber verwendet. Die AS-Zusammensetzung wurde nach dem Ideal-Protein der NRC-Empfehlung (1995) optimiert.

Tab. 18: Zusammensetzung der Futtermischungen (g/ kg FS)

\begin{tabular}{|c|c|c|c|c|c|c|}
\hline $\begin{array}{l}\text { Futter- } \\
\text { mischung }\end{array}$ & \begin{tabular}{|c|}
$12 \%$ XP- \\
$0,28 \%$ Thr
\end{tabular} & \begin{tabular}{|c|}
$12 \%$ XP- \\
$0,42 \%$ Thr
\end{tabular} & \begin{tabular}{|c|}
$12 \%$ XP- \\
$0,72 \%$ Thr
\end{tabular} & \begin{tabular}{|c|}
$18 \%$ XP- \\
$0,42 \%$ Thr
\end{tabular} & \begin{tabular}{|c|}
$18 \%$ XP- \\
$0,52 \%$ Thr
\end{tabular} & $\begin{array}{l}18 \% \text { XP- } \\
0,72 \% \text { Thr }\end{array}$ \\
\hline Weizenkleber & 148,00 & 148,00 & 148,00 & 223,00 & 223,00 & 223,00 \\
\hline Weizenstärke & 553,36 & 551,91 & 548,91 & 474,87 & 473,82 & 471,82 \\
\hline Rohzucker & 100,00 & 100,00 & 100,00 & 100,00 & 100,00 & 100,00 \\
\hline Cellulose & 50,00 & 50,00 & 50,00 & 50,00 & 50,00 & 50,00 \\
\hline Sojaöl & 55,00 & 55,00 & 55,00 & 50,00 & 50,00 & 50,00 \\
\hline $\begin{array}{l}\text { Mineral- } \\
\text { mischung }\end{array}$ & 60,00 & 60,00 & 60,00 & 60,00 & 60,00 & 60,00 \\
\hline $\begin{array}{l}\text { Vitamin- } \\
\text { mischung }\end{array}$ & 20,00 & 20,00 & 20,00 & 20,00 & 20,00 & 20,00 \\
\hline DL-Met & 1,60 & 1,60 & 1,60 & 3,80 & 3,80 & 3,80 \\
\hline L-Thr & 0 & 1,45 & 4,45 & 0 & 1,05 & 3,05 \\
\hline L-Ile & 0,76 & 0,76 & 0,76 & 1,20 & 1,20 & 1,20 \\
\hline L-Leu & 2,58 & 2,58 & 2,58 & 3,90 & 3,90 & 3,90 \\
\hline L-Lys·HCl & 5,44 & 5,44 & 5,44 & 8,23 & 8,23 & 8,23 \\
\hline L-Phe & 1,51 & 1,51 & 1,51 & 2,30 & 2,30 & 2,30 \\
\hline L-Trp & 0,50 & 0,50 & 0,50 & 0,80 & 0,80 & 0,80 \\
\hline L-Val & 1,25 & 1,25 & 1,25 & 1,90 & 1,90 & 1,90 \\
\hline $\begin{array}{l}\text { Aminosäuren- } \\
\text { verhältnis* }\end{array}$ & $\begin{array}{l}\text { Lys [1]: } \\
\text { Thr }[0,40]\end{array}$ & $\begin{array}{l}\text { Lys [1]: } \\
\text { Thr }[0,61]\end{array}$ & $\begin{array}{l}\text { Lys [1]: } \\
\text { Thr }[1,05]\end{array}$ & $\begin{array}{l}\text { Lys [1]: } \\
\text { Thr }[0,40]\end{array}$ & $\begin{array}{l}\text { Lys [1]: } \\
\text { Thr }[0,5]\end{array}$ & $\begin{array}{l}\text { Lys [1]: } \\
\text { Thr }[0,69]\end{array}$ \\
\hline ME (MJ/ kg T) & 16,54 & 16,46 & 16,42 & 16,46 & 16,46 & 16,37 \\
\hline
\end{tabular}

* Lys [1] : Met/Cys [1,07] : Trp [0,22] : Ile [0,67] : Phe [1,11] : Gly [0,52] : Gly+Ser [1.06] in allen Futtermischungen. 
Es wurden 36 Tiere in 6 Gruppen zu je 6 Tieren aufgestellt. Die Anfangslebendmasse zu Beginn der Vorperiode war durchschnittlich 144 $\pm 10,3 \mathrm{~g}$ und am Anfang der Sammelperiode zwischen 149-167 g in den Gruppen. Den Tieren wurde die Tagesration (14 g FS) einmalig gefüttert.

Am Ende der Periode wurden die Lebern entnommen, um die TDG-Aktivität zu bestimmen. Die weitere Behandlung der Leber erfolgte entsprechend dem Kapitel 3.5.1.

\subsection{Durchführung der Analysen}

\subsubsection{Bestimmung der Threonindehydrogenase-Aktivität}

Nach der Leberentnahme wurden die Lebern mit 0,9\% NaCl-Lösung gereinigt, in AluminiumFolie verpackt, sofort in flüssigem Stickstoff gefrostet und anschließend bei $-80^{\circ} \mathrm{C}$ tief gefroren gelagert. Nach dem Auftauen wurden $2 \mathrm{~g}$ der zerkleinerten Leber mit $18 \mathrm{~g}$ eiskalter Saccharose-Lösung (0,25 M) unter Benutzung eines Teflon-Pestle-Homogenisators (POTTER S., B. BRAUN) in einer Glasröhre homogenisiert. Die Mitochondrienfraktion konnte unter Benutzung der Methode von SCHNEIDER und HOGEBOOM (1950), die nachfolgend kurz zusammengefaßt ist, aus dem Homogenat isoliert werden.

- Die Methode von SCHNEIDER und HOGEBOOM (1950)

$20 \mathrm{~g}$ des Homogenats wurden $10 \mathrm{~min}$ bei $2.500 \mathrm{U} / \mathrm{min}(700 \mathrm{x} \mathrm{g})$ zentrifugiert, um die Kerne, unzerbrochene Leberzellen und rote Blutzellen zu sedimentieren. Das Sediment wurde einmal gewaschen, indem es in $8 \mathrm{ml} \mathrm{0,25} \mathrm{M} \mathrm{Saccharoselösung} \mathrm{resuspendiert} \mathrm{und} \mathrm{mit} \mathrm{der} \mathrm{gleichen}$ Geschwindigkeit noch einmal zentrifugiert wurde. Dieses Sediment wurde verworfen. Der erste Überstand und der gewaschene Überstand wurden zweimal $10 \mathrm{~min}$ bei $6.800 \mathrm{U} / \mathrm{min}$ $(5.000 \mathrm{x} \mathrm{g})$ zentrifugiert, um die Mitochondrien zu sedimentieren. Die Sedimente wurden gesammelt. Durch Resuspendierung in $8 \mathrm{ml} \mathrm{0,25} \mathrm{M} \mathrm{Saccharoselösung} \mathrm{wurde} \mathrm{zweimal}$ gewaschen und die Überstände und das Resuspendierte $10 \mathrm{~min}$ bei $15.000 \mathrm{U} / \mathrm{min}(24.000 \mathrm{x} \mathrm{g})$ noch einmal sedimentiert. Dieses Sediment wurde in Puffer resuspendiert und als Mitochondrienfraktion definiert. 
In den vorliegenden Untersuchungen wurden die Mitochondriensedimente in ca. $3 \mathrm{ml}$ Stammpufferlösung resuspendiert, um ca. $15 \mathrm{mg}$ Protein pro $0,5 \mathrm{ml}$ Mitochondrienfraktion zu erreichen (Stammpufferlösung : pH 7,4, 10 mM Tris-HCl, 10 mM KH${ }_{2} \mathrm{PO}_{4}, 110 \mathrm{mM} \mathrm{KHCO}$ und $5 \mathrm{mM} \mathrm{MgCl} 2 \cdot 6 \mathrm{H}_{2} \mathrm{O}$ ). Anschließend wurde die Mitochondrienfraktion bei $-20^{\circ} \mathrm{C}$ zwei Zyklen (Frieren + Auftauen + Frieren) der Methode von BIRD et al. (1984) unterworfen. Nach dem Auftauen wurde die Mitochondrienfraktion $(0,5 \mathrm{ml})$ in ein Kulturröhrchen überführt und anschließend in einem Wasserbad für $30 \mathrm{~min}$ bei $37^{\circ} \mathrm{C}$ unter vorheriger Zugabe von $2 \mathrm{ml}$ eines Mediums (pH 7,4: $10 \mathrm{mM}$ Tris-HCl, 10 mM KH${ }_{2} \mathrm{PO}_{4}, 110 \mathrm{mM} \mathrm{KHCO}, 5 \mathrm{mM}$ $\mathrm{MgCl}_{2} \cdot 6 \mathrm{H}_{2} \mathrm{O}, 25 \mathrm{mM}$ L-Threonin, 2,5 mM NAD ${ }^{+}, 1 \mathrm{mM} \mathrm{CoA}$ ) inkubiert. Ein Blindwert wurde ohne Inkubation unter den gleichen Bedingungen aufbereitet und der Wert nach 30 min Inkubation subtrahiert. Nach 30 min wurde die Inkubation durch die Zugabe von $1 \mathrm{ml}$ 0,92 M Trichloressigsäure gestoppt. Anschließend wurden die Röhrchen mindestens $30 \mathrm{~min}$ in Eis gestellt, um besser zu separieren. Das ausgefällte Protein konnte durch Zentrifugation (4.000 U/min, $15 \mathrm{~min}$ ) separiert und der Überstand für die Glycin- und Aminoacetonbestimmung verwendet werden. Die Enzymaktivität wurde nach Modifikation der Methode von BIRD et al. (1984) bestimmt. Das Prinzip der Enzymbestimmung erfolgte nach allgemeinen Methoden (MATTENHEIMER, 1971; BERGMEYER, 1974; SUELTER, 1990).

\section{- Aminoacetonbestimmung}

Aminoaceton wurde unter Benutzung des kolorimetrischen Schnellverfahrens nach URATA und GRANICK (1963) bestimmt. Für jede Probe waren drei Reagenzgläser $(18 \mathrm{~cm})$ vorbereitet. Jedem Reagenzglas wurde 1,0 ml Natriumacetat-Puffer $(1,0 \mathrm{M}, \mathrm{pH} 4,6)$ und 0,1 $\mathrm{ml}$ Acetylaceton zugegeben. Den Reagenzgläsern wurde $1 \mathrm{ml}$ Überstand aus den zuvor zentrifugierten Proben zugegeben und anschließend bei $100^{\circ} \mathrm{C}$ im Wasserbad $10 \mathrm{~min}$ gekocht. Danach erfolgte die Abkühlung bei Raumtemperatur. $\mathrm{Zu}$ jedem Reagenzglas wurden 2,0 ml Ehrlich's Reagenz (168 ml Eisessig, $40 \mathrm{ml}$ 70\% Perchlorsäure, 4 g p-Dimethylaminobenzaldehyd, 0,7 $\mathrm{g} \mathrm{HgCl}_{2}$ ) nach URATA und GRANICK (1963) hinzugegeben. Nach 15 min Reaktionszeit bei Raumtemperatur erfolgte die Messung der Absorption in einem Spektralphotometer (Specord S 100, Analytik Jena) mit einer Wellenlänge von $553 \mathrm{~nm}$. 
- Glycinbestimmung

Jeweils 0,2 $\mathrm{ml}$ Probenüberstand fanden für die Glycinbestimmung Verwendung. $20 \mu 1$ Norleucin (20 nmol Norleucin pro Probe) wurden als interner Standard zugegeben und die durch TDG akkumulierte Glycinmenge mit einem Aminosäureanalysator LC 3000 (Biotronik GmbH München) bestimmt.

- Proteinbestimmung

Die Proteinkonzentration in der 0,5 ml Mitochondrienfraktion wurde nach der Biuret Methode (LAYNE, 1957; COOPER, 1981; SUELTER, 1990) mit Rinderserum-Albumin als Standard bestimmt.

Herstellung der Reagenzien

1. Biuret-Reagenz : In einem $1000 \mathrm{ml}$ Glasbecher wurden $3,0 \mathrm{~g} \mathrm{CuSO}{ }_{4} \cdot 5 \mathrm{H}_{2} \mathrm{O}$ und $9,0 \mathrm{~g}$ Natrium-Kalium-Tartrat $\left(\mathrm{NaKC}_{4} \mathrm{H}_{4} \mathrm{O}_{6} \cdot 4 \mathrm{H}_{2} \mathrm{O}\right)$ mit $500 \mathrm{ml} \mathrm{0,2} \mathrm{N} \mathrm{NaOH}$-Lösung gelöst und die Lösung nach der Zulage von 5,0 g KJ mit 0,2 N NaOH-Lösung in einem $1000 \mathrm{ml}$ Meßkolben auf 11 aufgefüllt.

2. Protein Standardlösung : 0,15 g Rinderserum-Albumin wurde mit destilliertem Wasser gelöst und in einem $50 \mathrm{ml}$ Meßkolben aufgefüllt.

Proteinbestimmung mit der Biuret-Reaktion

Sieben (für Rinderserum-Albumin) und drei Reagenzröhrchen (für Proben) wurden nummeriert und in einem Ständer aufgestellt. In jedes Röhrchen (für Rinderserum-Albumin) wurde eins der folgenden Volumina einer Lösung von Rinderserum-Albumin $(3,0 \mathrm{mg} / \mathrm{ml})$ eingesetzt : $0 ; 0,2 ; 0,4 ; 0,7 ; 1,0 ; 2,0 ; 3,0 \mathrm{ml}$. Den Proben wurden jeweils $0,1 \mathrm{ml}$ Mitochondrienfraktion zugesetzt. Jedes Röhrchen wurde mit einer entsprechenden Menge destilliertem Wasser auf 3,0 ml aufgefüllt. Danach wurde 3,0 ml Biuret-Reagenzlösung in jedes Röhrchen zugegeben. Die Lösung wurde sofort mit Voltex kräftig gemischt. Die Röhrchen ruhten für 30 min bei Raumtemperatur. Nach 30 min Reaktionszeit erfolgte die Messung der Absorption in einem Spektralphotometer (Specord S 100, Analytik, Jena) mit einer Wellenlänge von $540 \mathrm{~nm}$. 
Die Proteinkonzentration der Proben wurde mit der Standard-Eichkurve von RinderserumAlbumin berechnet.

\subsubsection{Berechnung der Threonindehydrogenase-Aktivität}

Die spezifische TDG-Aktivität insgesamt besteht aus der Summe von Aminoaceton- und Glycinmenge, die während 30 min Inkubation pro mg Protein akkumuliert wurde.

- Zur Berechnung der Aminoacetonmenge fand folgende Gleichung Anwendung:

Aminoaceton $(\mathrm{nmol} / \mathrm{mg}$ Protein $)=\frac{\Delta \mathrm{E} \mathrm{der} \text { Probe } \cdot \mathrm{V} \cdot \mathrm{GV} \cdot 10^{9}}{(30 \mathrm{~min}) \varepsilon \cdot \mathrm{d} \cdot \mathrm{v} \cdot \mathrm{mg} \text { Protein }}$

$\Delta \mathrm{E}$ : Extinktionsänderung, $\varepsilon: 7,4 \cdot 10^{7}\left[\mathrm{~cm}^{2} / \mathrm{mol}\right], \mathrm{d}: 1 \mathrm{~cm}$, v: Probevolumen im Test (1 ml), V: Testvolumen (4,1 ml), GV: Gesamtvolumen der Probe $(3,5 \mathrm{ml})$.

- Zur Berechnung der Glycinmenge wurde folgende Gleichung angewendet:

Glycin $(\mathrm{nmol} / \mathrm{mg}$ Protein $)=$ gemessenes Glycin $\mathrm{nmol} / \mathrm{ml} \cdot \mathrm{GV}$

(30 min) mg Protein

GV: Gesamtvolumen der Probe (3,5 ml).

\subsubsection{N-Bestimmung}

Die Stickstoffgehalte von Futter, Exkrementen (Küken) und Kot (Laborratten) wurden mit dem Gerät FP 2000 (Fa. Leco) bestimmt. Dieses Gerät arbeitet elementaranalytisch nach dem Dumas-Verfahren. Die Stickstoffgehalte des angesäuerten Rattenharns wurden nach der KJELDAHL-Methode mit Büchi-Geräten bestimmt. Die Stickstoffgehalte wurden mit dem Faktor 6,25 in Rohproteingehalte umgerechnet.

\subsubsection{Aminosäurebestimmung}

Diese Bestimmung erfolgte grundsätzlich nach VDLUFA (1988) : Die Futterproben wurden in einem verschlossenen Glasgefäß mit 6 N Salzsäure für 24 Stunden im Trockenschrank bei $110^{\circ} \mathrm{C}$ hydrolysiert. Die Aminosäuren der Futterproteine werden durch Hydrolyse der 
Peptidbindungen aus dem Protein freigesetzt. Um Methionin und Cystein quantitativ bestimmen zu können, muss vor der Hydrolyse eine Oxidation mit Perameisensäure erfolgen. Nach der Hydrolyse wurde das Hydrolysat im Eisbad abgekühlt und mit Pufferlösung überführt. Unter weiterer Kühlung wurde die Natronlauge unter Rühren zugegeben. Danach wurde der Inhalt am $\mathrm{pH}-$ Meter mit $\mathrm{HCl}$ oder $\mathrm{NaOH}$ auf $\mathrm{pH} 2,2$ bei $25^{\circ} \mathrm{C}$ eingestellt. Dann wurde mit Pufferlösung gemischt und der interne Standard (Norleucin) zugegeben. Zu diesem Ansatz wurde der Aminosäuregehalt durch Ionenaustauscher-Chromatographie in einem Aminosäureanalysator LC 3000 (Biotronik GmbH München) gemessen.

\subsection{N-Verwertungsmodell und AS-Wirksamkeitsberechnung}

In den durchgeführten Bilanzversuchen wurden alle Parameter auf Grundlage des NVerwertungsmodells von GEBHARDT (1966) verrechnet. Dabei wurde die Beziehung zwischen Höhe der N-Aufnahme (x) und N-Retention (y) wie folgt beschrieben:

$$
\mathrm{y}=\mathrm{A}\left(1-\mathrm{e}^{-\mathrm{bx}}\right)
$$

wobei

$\mathrm{y}=($ tägliche N-Bilanz $+\mathrm{N}-$ Erhaltungsbedarf $) / \mathrm{LM}_{\mathrm{kg}}{ }^{0,67}(\mathrm{mg})$

$\mathrm{A}=$ Maximalwert für y (mg), abhängig von Genotyp and Alter

$\mathrm{b}=$ Proteinqualitätsmaß und Parameter für Anstieg der N-Wirkungskurve; abhängig von der

Proteinqualität, unabhängig von der N-Aufnahme

$\mathrm{x}=$ tägliche $\mathrm{N}$-Aufnahme/ $\mathrm{LM}_{\mathrm{kg}}{ }^{0,67}(\mathrm{mg})$

$\mathrm{e}=$ Grundzahl natürlicher Logarithmen

Nach der Logarithmierung von Gleichung (1) wurde der b-Wert als Ausdruck der Proteinqualität wie folgt berechnet:

$\mathrm{b}=[\operatorname{In} \mathrm{A}-\operatorname{In}(\mathrm{A}-\mathrm{y})]: \mathrm{x}$

$\mathrm{PNu}=100 \cdot\left[\mathrm{A}\left(1-\mathrm{e}^{-\mathrm{bx}}\right): \mathrm{x}\right]$

Zur Standardisierung der PNu-Werte (Gleichung 3) mit Hilfe des N-Verwertungsmodells wurde in den vorliegenden Kükenversuchen eine tägliche N-Aufnahme von $3500 \mathrm{mg} /$ $\mathrm{LM}_{\mathrm{kg}}{ }^{0,67}$ verwendet. Der verwendete A-Wert lag bei $3034 \mathrm{mg} \mathrm{N} / \mathrm{LM}_{\mathrm{kg}}{ }^{0,67}$ und der tägliche N- 
Erhaltungsbedarf bei $500 \mathrm{mg} \mathrm{N} / \mathrm{LM}_{\mathrm{kg}}{ }^{0,67}$. Die Anpassung an altersabhängige A-Werte erfolgte in Anlehnung an RIMBACH und LIEBERT (1999).

In den vorliegenden Rattenversuchen wurde ein Wert von $1200 \mathrm{mg} \mathrm{N} / \mathrm{LM}_{\mathrm{kg}}{ }^{0,67}$ als standardisierte tägliche N-Aufnahme verwendet. Ein Wert von $900 \mathrm{mg} \mathrm{N} / \mathrm{LM}_{\mathrm{kg}}{ }^{0,67}$ wurde als A-Wert verwendet (vgl. GEBHARDT, 1963). Als täglicher N-Erhaltungsbedarf (NEB) konnten $180 \mathrm{mg} \mathrm{N} / \mathrm{LM}_{\mathrm{kg}}{ }^{0,67}$ (PAHLE et al., 1993) zugrundegelegt werden. Auf Basis der im Limitierungsbereich bestehenden linearen Beziehung zwischen Konzentration der limitierenden Aminosäure (c) und b-Wert wurde die Kennzahl $b^{-1}$ als Ausdruck für die Bewertung der Threoninwirksamkeit herangezogen (z. B. LIEBERT 1995; RIMBACH und LIEBERT, 2000).

\subsection{Statistische Auswertung}

Biostatistische Prüfungen der Mittelwerte erfolgten im Rahmen von SPSS für Windows, Version 10,0 unter Verwendung des Student-Newman-Keuls Tests bzw. Turkey Tests bei einer Irrtumswahrscheinlichkeit von $\mathrm{p} \leq 0,05$. Unterschiedliche Hochbuchstaben der Mittelwerte kennzeichnen signifikante Mittelwertdifferenzen bei dieser Irrtumswahrscheinlichkeit. Mittelwerte wurden mit der Standardabweichung ( \pm SD) angegeben. Die Threoninwirksamkeit beim Küken wurde unter Verwendung des LSD-Tests bei einer Irrtumswahrscheinlichkeit von $\mathrm{p} \leq 0,05$ biostatistisch geprüft. 


\section{ERGEBNISSE}

In diesem Teil der Arbeit erfolgt zunächst eine konzentrierte Darstellung der Hauptergebnisse der einzelnen Versuchskomplexe. Einzelwerte der Messungen sind im Tabellenanhang ausgewiesen.

\subsection{Versuch 1 (Bilanzversuch Küken, N-Steigerungsversuch mit HP- Sojaextraktionsschrot)}

In Tabelle 19 sind die Ergebnisse der TDG-Aktivitätsmessung in der Leber nach Verabreichung von Futtermischungen mit gestaffeltem Proteingehalt zusammengefasst.

Tab. 19: TDG-Aktivität in der Kükenleber $(n=6)$, Versuch 1

\begin{tabular}{|c|c|c|c|c|}
\hline \multirow[t]{2}{*}{$\begin{array}{c}\text { XP- Stufen } \\
(\%)\end{array}$} & \multirow[t]{2}{*}{$\begin{array}{c}\text { Mittlere } \\
\text { Lebermasse (g) }\end{array}$} & \multicolumn{3}{|c|}{$\begin{array}{c}\text { TDG-Aktivität } \\
(\mathrm{nmol} / \mathbf{3 0} \mathrm{min} / \mathrm{mg} \text { Protein) }\end{array}$} \\
\hline & & Aminoaceton & Glycin & Gesamtaktivität \\
\hline $\mathbf{5 , 5}$ & $22,0 \pm 4,3$ & $0,18^{\mathrm{a}}$ & $0,77^{\mathrm{a}}$ & $0,95^{\mathrm{a}}$ \\
\hline 11,0 & $36,0 \pm 5,1$ & $0,54^{\mathrm{a}}$ & $0,71^{\mathrm{a}}$ & $1,25^{\mathrm{a}}$ \\
\hline 16,5 & $31,3 \pm 4,8$ & $1,49^{\mathrm{a}}$ & $0,98^{\mathrm{a}}$ & $2,47^{\mathrm{a}}$ \\
\hline 22,0 & $32,1 \pm 3,4$ & $8,91^{b}$ & $3,88^{\mathrm{a}}$ & $12,79^{b}$ \\
\hline 27,5 & $25,5 \pm 4,5$ & $11,03^{b}$ & $13,37^{b}$ & $24,40^{\mathrm{c}}$ \\
\hline 33,0 & $27,6 \pm 4,2$ & $28,70^{\mathrm{c}}$ & $67,20^{\mathrm{c}}$ & $95,90^{\mathrm{d}}$ \\
\hline
\end{tabular}

Unterschiedliche Hochbuchstaben kennzeichnen signifikante Unterschiede ( $\mathrm{p} \leq 0,05$; Tukey-Test)

Zur Verdeutlichung der Effekte ist der Einfluss des XP-Gehaltes der Diät auf den Verlauf der TDG-Aktivität in Abbildung 3 dargestellt. Durch die Erhöhung des XP-Gehaltes im Futter wird die TDG-Aktivität der Leber gesteigert. Bis 16,5\% XP zeigten sich keine signifikanten Veränderungen der TDG-Aktivität, bei darüber liegenden XP-Gehalten wird die Enzymaktivität, trotz limitierter Threoninversorgung im Futterprotein, signifikant gesteigert. 


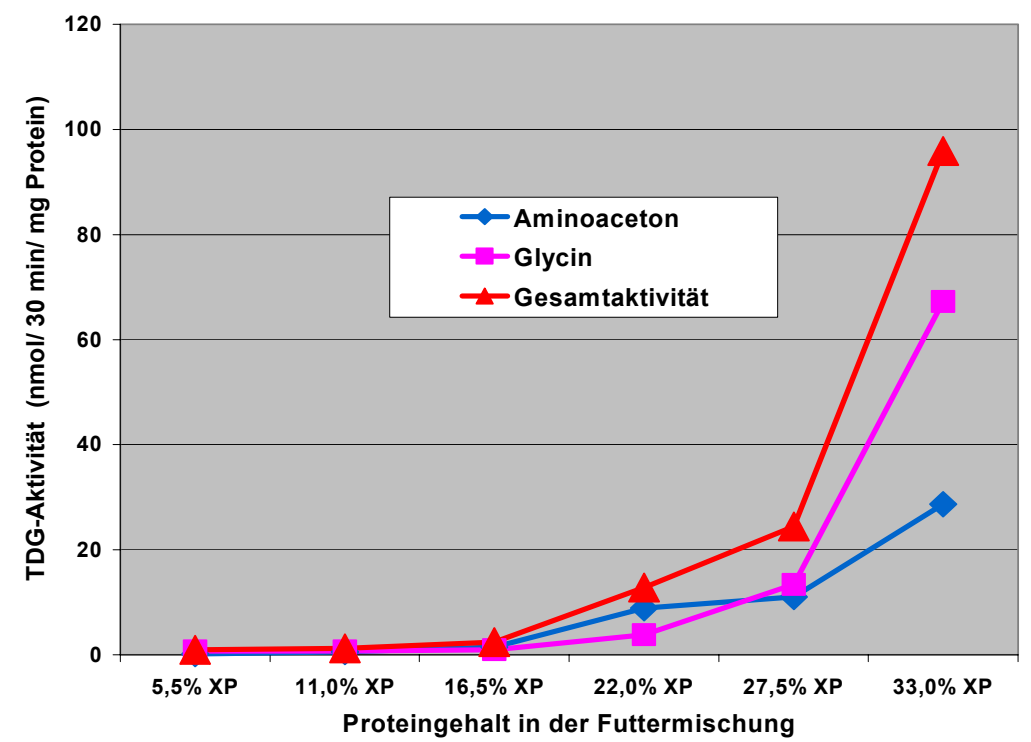

Abb. 3: Verlauf der TDG-Aktivität in der Kükenleber bei gestaffelter Proteinversorgung.

4.2 Versuch 2 (Wachstumsversuch Küken, 2 Protein- und 2 Threoninstufen mit Weizen/Weizenkleber)

Die Ergebnisse der TDG-Aktivitätsmessung fasst Tabelle 20 zusammen.

Tab. 20: TDG-Aktivität in der Kükenleber $(n=6)$, Versuch 2

\begin{tabular}{|c|c|c|c|c|}
\hline \multirow{2}{*}{$\begin{array}{c}\text { XP-/ Thr- } \\
\text { Stufen }\end{array}$} & $\begin{array}{c}\text { Mittlere } \\
\text { Lebermasse (g) }\end{array}$ & \multicolumn{3}{|c|}{ TDG-Aktivität } \\
\cline { 3 - 5 } & & Ammol/ 30 min/ mg Protein) \\
\hline $\begin{array}{c}\mathbf{1 8 , 5 \%} \text { XP } \\
\mathbf{0 , 4 5 \%} \text { dThr }\end{array}$ & $34,2 \pm 4,0$ & $2,58^{\mathrm{a}}$ & $1,71^{\mathrm{a}}$ & $4,29^{\mathrm{a}}$ \\
\hline $\begin{array}{c}\mathbf{1 8 , 5 \%} \mathbf{X P} \\
\mathbf{0 , 6 0 \%} \mathbf{d T h r}\end{array}$ & $37,8 \pm 4,8$ & $2,78^{\mathrm{a}}$ & $1,49^{\mathrm{a}}$ & $4,27^{\mathrm{a}}$ \\
\hline $\begin{array}{c}\mathbf{2 2 , 5 \%} \mathbf{X P} \\
\mathbf{0 , 4 5 \%} \mathbf{d T h r}\end{array}$ & $40,8 \pm 2,0$ & $3,9^{\mathrm{ab}}$ & $2,62^{\mathrm{a}}$ & $6,52^{\mathrm{a}}$ \\
\hline $\begin{array}{c}\mathbf{2 2 , 5 \%} \mathbf{X P} \\
\mathbf{0 , 6 0 \%} \mathbf{d T h r}\end{array}$ & $37,5 \pm 4,9$ & $5,88^{\mathrm{b}}$ & $5,57^{\mathrm{b}}$ & $11,45^{\mathrm{b}}$ \\
\hline
\end{tabular}

Unterschiedliche Hochbuchstaben kennzeichnen signifikante Unterschiede ( $\mathrm{p} \leq 0,05$; Tukey-Test) 
Zur Veranschaulichung der XP- bzw. Thr-Effekte auf die TDG-Aktivität sind die Messwerte aus Tabelle 20 in Abbildung 4 graphisch dargestellt. Die Futtermischung mit 18,5\% XP (Basaldiät) zeigte bei der Thr-Zulage von $0,15 \%$ verdaulichem Thr (dThr) keine Veränderung der TDG-Aktivität. Demgegenüber war bei $22,5 \%$ XP nach Zulage von $0,15 \%$ dThr ein signifikanter Effekt auf die TDG-Aktivität festzustellen.

Die Wirkung einer vergleichbaren Anhebung des Threoningehaltes $(0,45 \% \mathrm{dThr} \rightarrow 0,60 \%$ dThr) war also abhängig vom Proteinniveau der Futtermischung. Bei erhöhtem Proteinniveau stieg die TDG-Aktivität wesentlich stärker an.

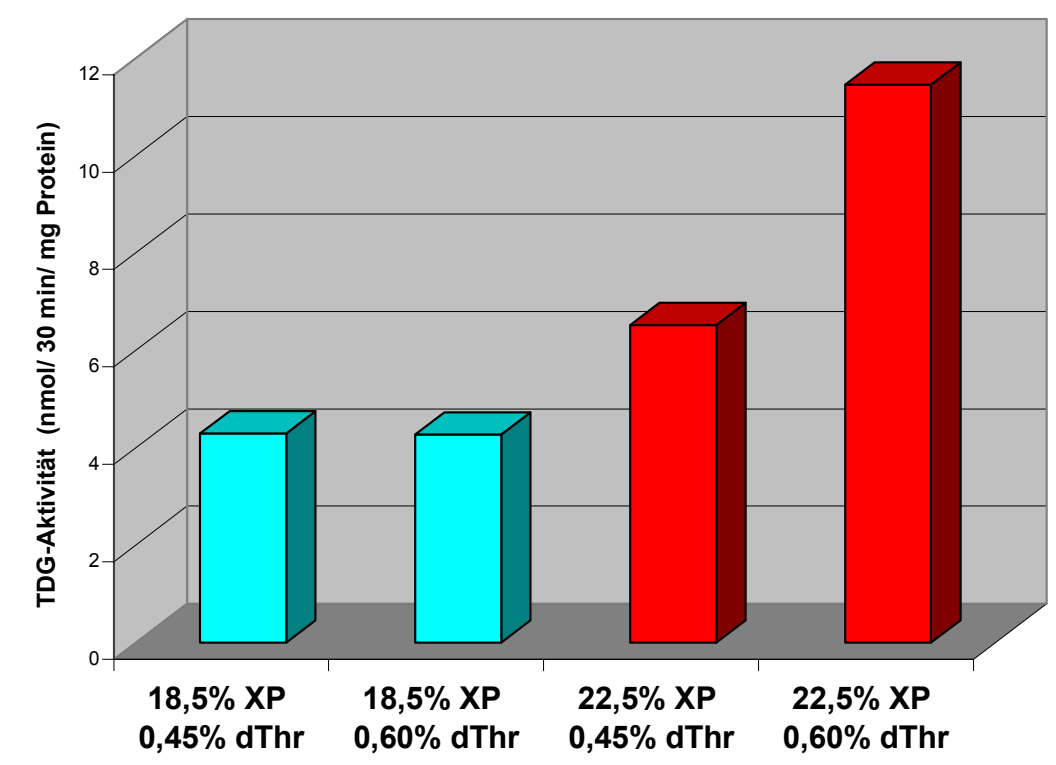

Protein- und Threoningehalte in der Futtermischung

Abb. 4: Verlauf der TDG-Aktivität in der Kükenleber bei differenziertem XP-/ThrNiveau (Versuch 2)

\subsection{Versuch 3 (Bilanzversuch Küken, 2 Protein- und 2 Threoninstufen mit HP- Sojaextraktionsschrot)}

In Tabelle 21 sind die mittleren TDG-Aktivitäten in der Kükenleber nach Verabreichung stärker differenzierter XP-Gehalte im Futter zusammengefasst. 
Tab. 21: TDG-Aktivität in der Kükenleber $(n=6)$, Versuch 3

\begin{tabular}{|c|c|c|c|c|}
\hline \multirow{2}{*}{$\begin{array}{l}\text { XP-/ Thr- } \\
\text { Stufen }\end{array}$} & \multirow{2}{*}{$\begin{array}{c}\text { Mittlere } \\
\text { Lebermasse } \\
\text { (g) }\end{array}$} & \multicolumn{3}{|c|}{$\begin{array}{c}\text { TDG-Aktivität } \\
\text { (nmol/30 } \mathrm{min} / \mathrm{mg} \text { Protein) }\end{array}$} \\
\hline & & Aminoaceton & Glycin & Gesamtaktivität \\
\hline $\begin{array}{c}16,5 \% \text { XP-0,65\% Thr } \\
(3,8 \text { g Thr/ } 16 \text { g N) }\end{array}$ & $24,2 \pm 3,8$ & $2,33^{\mathrm{a}}$ & $1,45^{\mathrm{a}}$ & $3,78^{\mathrm{a}}$ \\
\hline $\begin{array}{c}16,5 \% \text { XP-0,79\% Thr } \\
(4,7 \text { g Thr/ } 16 \text { g N) }\end{array}$ & $15,7 \pm 1,3$ & $2,42^{\mathrm{a}}$ & $1,45^{\mathrm{a}}$ & $3,87^{\mathrm{a}}$ \\
\hline $\begin{array}{c}22,0 \% \text { XP-0,86\% Thr } \\
(3,8 \text { g Thr/ } 16 \text { g N) }\end{array}$ & $18,3 \pm 1,9$ & $2,84^{\mathrm{a}}$ & $2,86^{\mathrm{ac}}$ & $5,71^{\mathrm{a}}$ \\
\hline $\begin{array}{c}22,0 \% \text { XP-1,05\% Thr } \\
(4,7 \text { g Thr/ } 16 \text { g N) }\end{array}$ & $13,1 \pm 1,6$ & $5,71^{\mathrm{b}}$ & $4,62^{\mathrm{bc}}$ & $10,33^{\mathrm{b}}$ \\
\hline
\end{tabular}

Unterschiedliche Hochbuchstaben kennzeichnen signifikante Unterschiede ( $\mathrm{p} \leq 0,05$ : Tukey-Test)

In der Abbildung 5 und Tabelle 21 wird ein Einfluß der XP-Gehalte der Diät bei gleicher ThrKonzentration im Protein auf die TDG-Aktivität deutlich. Die Thr-Zulage zur Basaldiät (16,5\%XP) von 0,65- (3,8 g Thr/ $16 \mathrm{~g} \mathrm{~N})$ auf 0,79\% Thr (4,7 g Thr/ $16 \mathrm{~g} \mathrm{~N})$ zeigte keinen Effekt auf die TDG-Aktivität. Andererseits war bei 22,0\% XP und einer Thr-Zulage von 0,86$(3,8 \mathrm{~g} \mathrm{Thr} / 16 \mathrm{~g} \mathrm{~N})$ auf 1,05\% Thr (4,7 g Thr/ $16 \mathrm{~g} \mathrm{~N})$ ein signifikanter Effekt auf die TDGAktivität nachzuweisen.

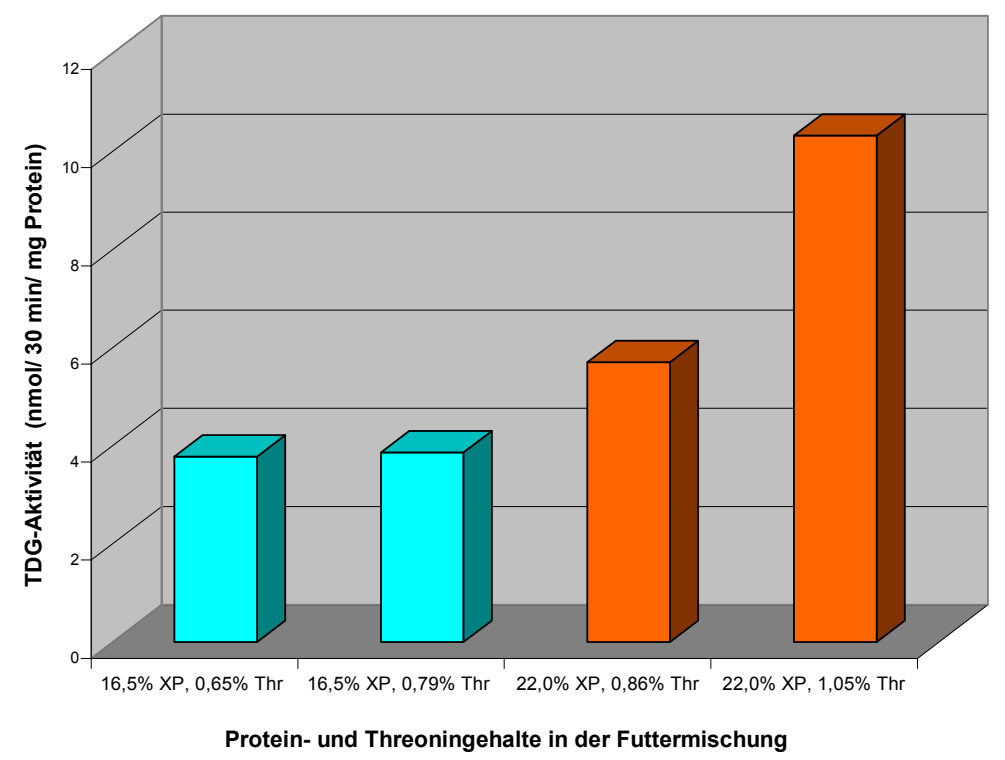

Abb. 5: Verlauf der TDG-Aktivität in der Kükenleber bei differenziertem XP-/ Thr-Niveau (Versuch 3) 


\subsection{Versuch 4 (Wachstumsversuch Küken, praxisübliche Futtermischungen)}

In Tabelle 22 sind altersabhängige Veränderungen der TDG-Aktivität in der Kükenleber aufgezeigt. Dabei ist jedoch zu berücksichtigen, dass in diesem Versuch eine altersabhängige Anpassung des XP-Niveaus vorgenommen wurde, so dass auch von diesem Faktor ein Einfluss auf die TDG-Aktivität ausgehen kann.

In der Abbildung 6 und Tabelle 22 wird der Einfluss der Altersabschnitte von Küken auf die TDG-Aktivität der Leber dargestellt. Beim Küken im Alter von 1 Woche ist die TDGAktivität auf sehr niedrigem Niveau. Beim Küken im Altersabschnitt von 3 Wochen ist die TDG-Aktivität signifikant erhöht, da Glycin und Aminoaceton im Vergleich mit anderen Gruppen deutlich stärker akkumuliert werden. Beim Küken im Altersabschnitt von 5 bis 7 Wochen ist die TDG-Aktivität wieder rückläufig und muss mit differenzierten Anforderungen an die Glycinbereitstellung weiter diskutiert werden (vgl. 5.4).

Tab. 22: TDG-Aktivität in der Kükenleber $(n=6)$, Versuch 4

\begin{tabular}{|c|c|c|c|c|c|}
\hline \multirow{2}{*}{$\begin{array}{l}\text { Alter } \\
\text { (Tag) }\end{array}$} & \multirow{2}{*}{$\begin{array}{c}\text { XP- } \\
\text { Stufen }\end{array}$} & \multirow{2}{*}{$\begin{array}{c}\text { Leber- } \\
\text { masse } \\
\text { (g) }\end{array}$} & \multicolumn{3}{|c|}{$\begin{array}{c}\text { TDG-Aktivität } \\
\text { (nmol/30 } \mathrm{min} / \mathrm{mg} \text { Protein) }\end{array}$} \\
\hline & & & Aminoaceton & Glycin & Gesamtaktivität \\
\hline 7 & $\begin{array}{l}22,70 \% \text { XP- } \\
(0,85 \% \text { Thr })\end{array}$ & $5,3 \pm 0,9$ & $1,57^{\mathrm{a}}$ & $1,27^{\mathrm{a}}$ & $2,83^{\mathrm{a}}$ \\
\hline 21 & $\begin{array}{l}20,30 \% \text { XP- } \\
(0,75 \% \text { Thr) }\end{array}$ & $23,0 \pm 4,0$ & $10,01^{\mathrm{b}}$ & $5,00^{\mathrm{b}}$ & $15,01^{\mathrm{b}}$ \\
\hline 35 & $\begin{array}{l}20,30 \% \text { XP- } \\
(0,75 \% \text { Thr })\end{array}$ & $37,0 \pm 6,0$ & $7,81^{\mathrm{bc}}$ & $2,21^{\mathrm{a}}$ & $10,02^{b c}$ \\
\hline 49 & $\begin{array}{l}18,60 \% \text { XP- } \\
(0,69 \% \text { Thr })\end{array}$ & $40,3 \pm 4,7$ & $3,79^{\mathrm{ac}}$ & $0,58^{\mathrm{a}}$ & $4,37^{\mathrm{ac}}$ \\
\hline
\end{tabular}

Unterschiedliche Hochbuchstaben kennzeichnen signifikante Unterschiede ( $p \leq 0,05$ : Tukey-Test) 


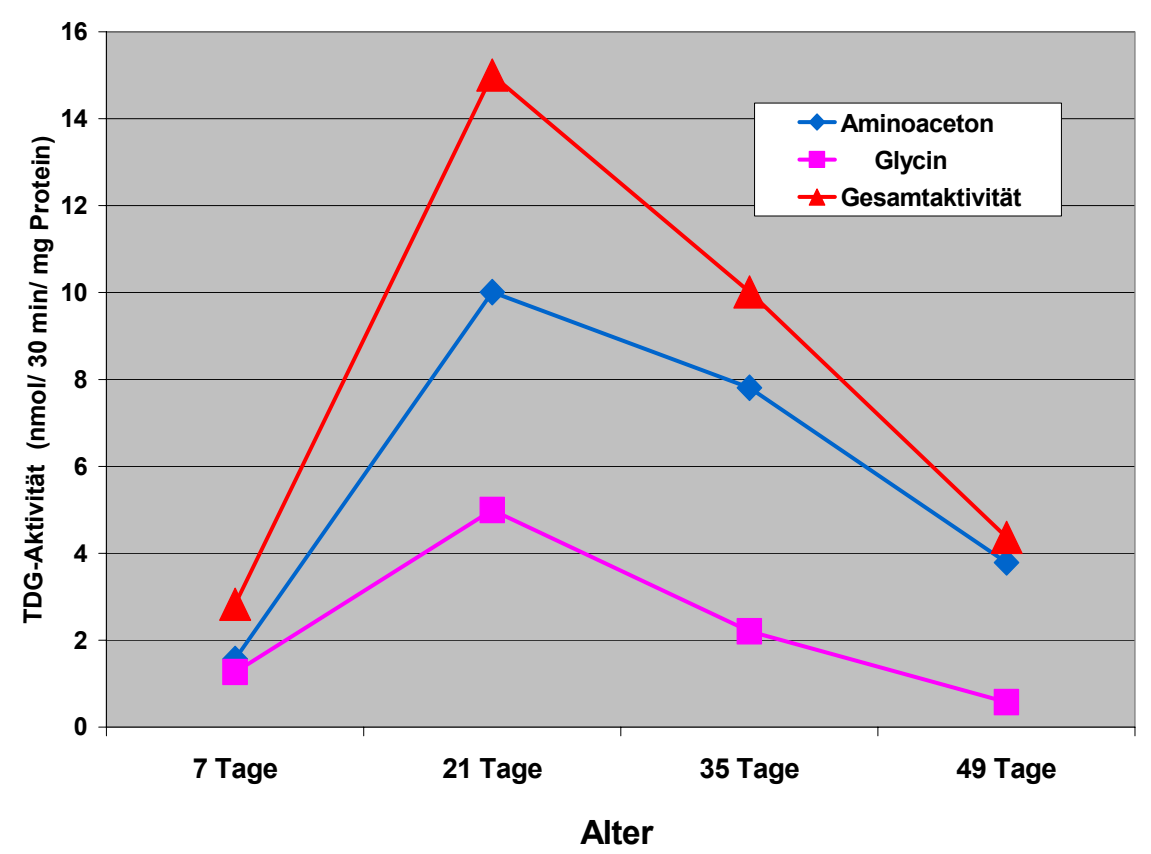

Abb. 6: TDG-Aktivität in der Kükenleber $(n=6)$ in Abhängigkeit vom Alter (Versuch 4)

\subsection{Versuch 5 (Bilanzversuch Küken, 2 Glycin- und 2 Threoninstufen mit Weizen/Weizenkleber)}

Die Ergebnisse der TDG-Aktivitätsmessung in der Kükenleber sind in Tabelle 23 zusammengefasst. 
Tab. 23: TDG-Aktivität in der Kükenleber $(n=6)$, Versuch 5

\begin{tabular}{|c|c|c|c|c|}
\hline \multirow{2}{*}{$\begin{array}{c}\text { Gly-/ Thr- } \\
\text { Stufen }\end{array}$} & \multirow{2}{*}{$\begin{array}{c}\text { Lebermasse } \\
(\mathbf{g})\end{array}$} & \multicolumn{3}{|c|}{ TDG-Aktivität } \\
$($ nmol/ 30 min/ mg Protein)
\end{tabular}

Unterschiedliche Hochbuchstaben kennzeichnen signifikante Unterschiede ( $\mathrm{p} \leq 0,05$ : Tukey-Test)

Bei vergleichbarem Rohproteingehalt der Futtermischungen (22,0\% XP) zeigte sich nach Verabreichung der Futtermischungen ohne Glycinergänzung nur tendenziell eine Steigerung der TDG-Aktivität infolge der Anhebung des Thr-Gehaltes. Demgegenüber war eine signifikante Erhöhung der TDG-Totalaktivität bei hohem Glycinniveau festzustellen.

Dieses Ergebnis ist überraschend, da bei der Glycinzulage nicht von einem erhöhten metabolischen Bedarf an Glycin als Auslöser für eine gesteigerte TDG-Aktivität ausgegangen werden kann.

In Abbildung 7 und 8 werden diese Zusammenhänge vergleichend dargestellt. 


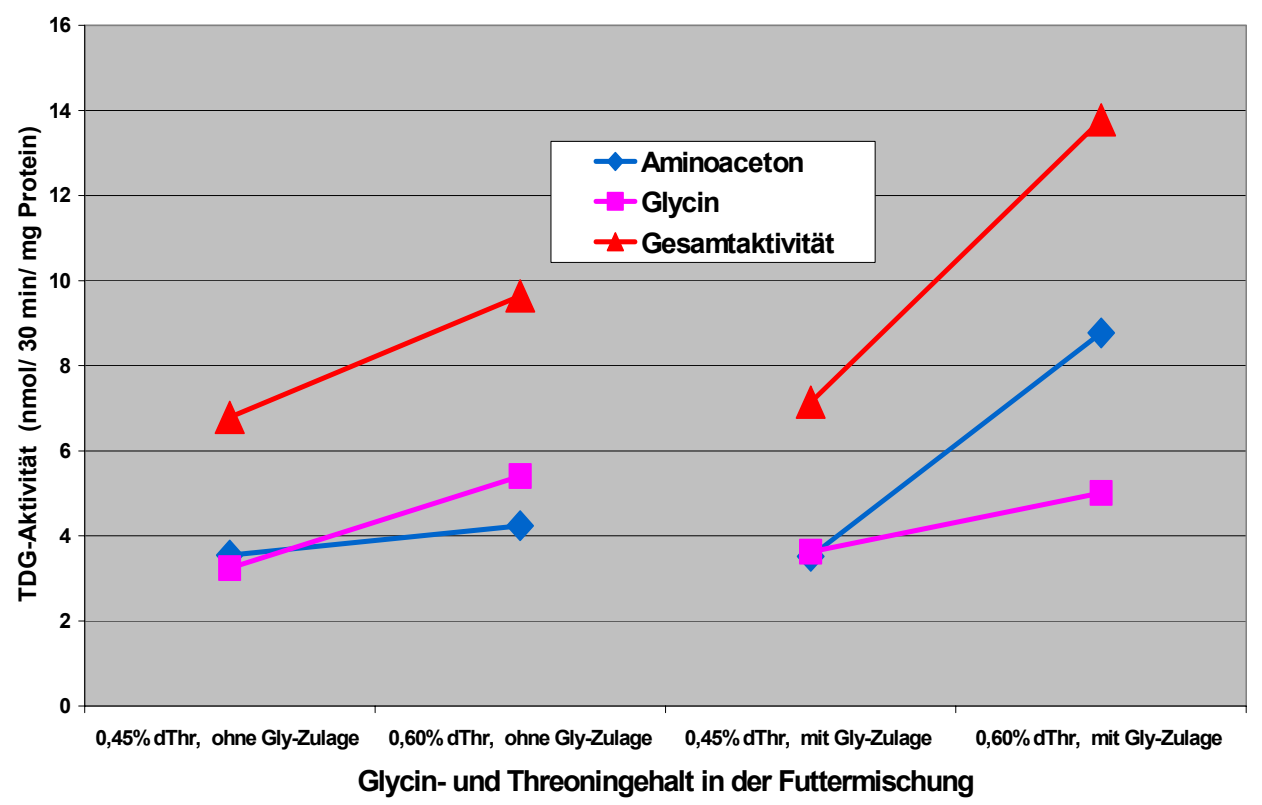

Abb. 7: TDG-Aktivität in der Kükenleber bei differenziertem Threoninniveau $(n=6)$, Versuch 5

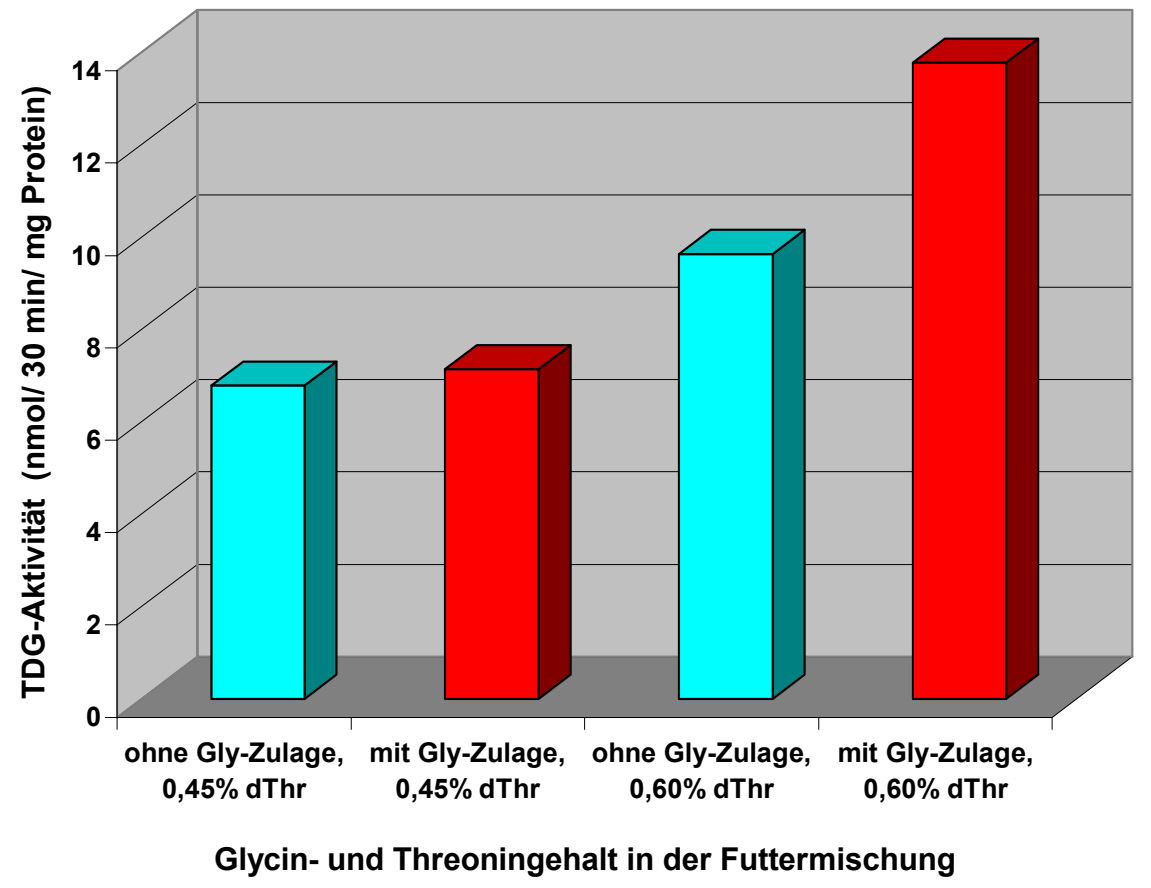

Abb. 8: TDG-Aktivität in der Kükenleber bei differenziertem Glycinniveau $(n=6)$, Versuch 5 
Nach Verabreichung der Mischungen mit 0,45\% dThr zeigte die Glycinzulage keinen signifikanten Effekt. Bei 0,60\% dThr zeigte die Akkumulation des Glycin nach Gly-Zulage nahezu keine Veränderungen. Infolge signifikanter Erhöhung der Aminoacetonakkumulation war auch ein tendenzieller Einfluss auf die Gesamtaktivität sichtbar (Abb. 8 und Tab. 23).

\subsection{Versuch 6 (Bilanzversuch Laborratte, N-Steigerungsversuch mit Kasein)}

Die Ergebnisse zur TDG-Aktivität bei Proteinstaffelung fasst Tabelle 24 zusammen.

Tab. 24: TDG-Aktivität in der Rattenleber nach gestaffelter Proteinversorgung; $(n=6)$

\begin{tabular}{|c|c|c|c|c|}
\hline $\begin{array}{c}\text { XP- } \\
\text { Gruppen }\end{array}$ & Leber- & \multicolumn{3}{|c|}{ TDG-Aktivität } \\
$\mathbf{( \% )}$ & Masse & \multicolumn{3}{|c|}{$(\mathbf{n m o l} / \mathbf{3 0}$ min/ mg Protein) } \\
\cline { 3 - 5 } & $(\mathbf{g})$ & Aminoaceton & Glycin & Gesamtaktivität \\
\hline $\mathbf{0}$ & $5,8 \pm 1,1$ & $4,37^{\mathrm{a}}$ & $1,17^{\mathrm{a}}$ & $5,54^{\mathrm{a}}$ \\
\hline $\mathbf{6}$ & $7,2 \pm 0,3$ & $10,50^{\mathrm{bc}}$ & $1,60^{\mathrm{a}}$ & $12,11^{\mathrm{bc}}$ \\
\hline $\mathbf{1 2}$ & $6.6 \pm 1,0$ & $14,25^{\mathrm{bc}}$ & $1,68^{\mathrm{a}}$ & $15,93^{\mathrm{b}}$ \\
\hline $\mathbf{1 8}$ & $8,0 \pm 0,8$ & $8,94^{\mathrm{ac}}$ & $1,29^{\mathrm{a}}$ & $10,23^{\mathrm{ac}}$ \\
\hline $\mathbf{2 4}$ & $8,4 \pm 1,1$ & $10,93^{\mathrm{bc}}$ & $1,63^{\mathrm{a}}$ & $12,56^{\mathrm{bc}}$ \\
\hline
\end{tabular}

Unterschiedliche Hochbuchstaben kennzeichnen signifikante Unterschiede( $\mathrm{p} \leq 0,05$; Tukey-Test)

In Abbildung 9 unterstreicht der Verlauf der TDG-Aktivität, dass im Bereich $0-24,0 \%$ XP keine signifikante Veränderung der Glycin-Akkumulation vorliegt. Die absolut höchste Gesamtaktivität bei 12,0\% XP resultiert aus einer sehr starken Aminoacton-Akkumulation. Nach stufenweiser Erhöhung der Gesamtaktivität bis 12,0\% XP, wird bei höherem XP-Gehalt tendenziell ein Rückgang des Thr-Katabolismus angezeigt. Dieser Befund überrascht und bedarf der Diskussion (vgl. 5.). 


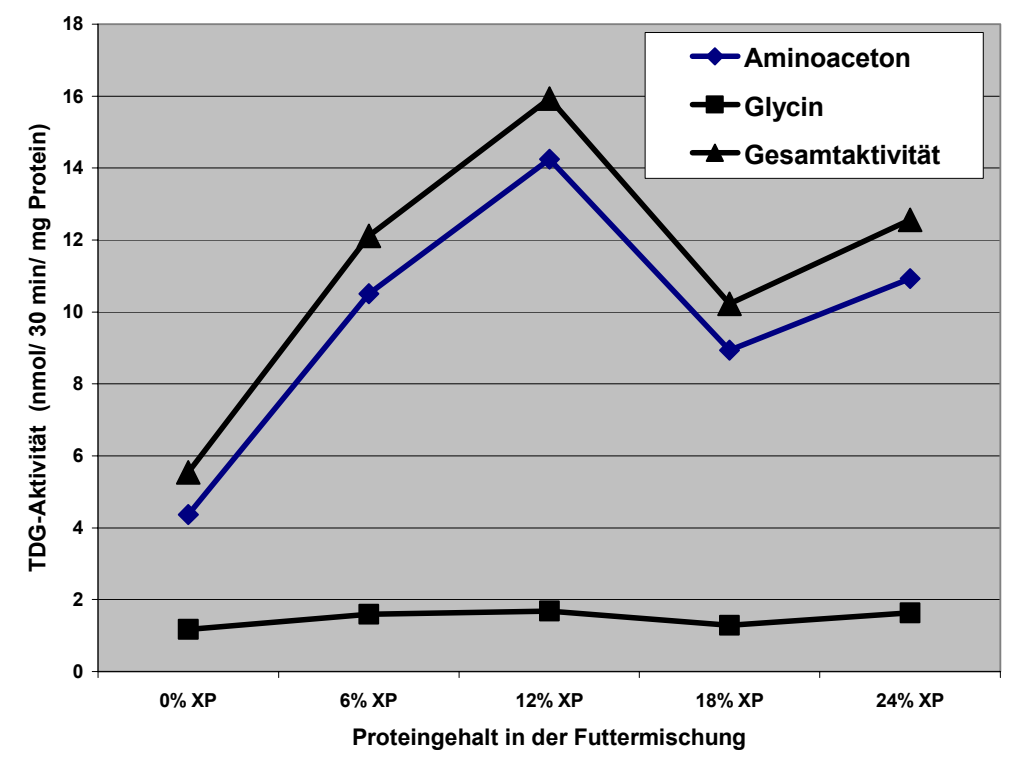

Abb. 9: Verlauf der TDG-Aktivität in der Rattenleber nach Proteinstaffelung $(n=6)$; Versuch 6

\subsection{Versuch 7 (Bilanzversuch Laborratte, 2 Protein- und 3 Threoninstufen mit Weizenkleber)}

Tabelle 25 fasst die Ergebnisse nach Thr-Staffelung bei abgestuftem Proteingehalt zusammen und stellt einen Vergleich zu Thr-Wirksamkeitsparametern her.

Die gestaffelte Thr-Zufuhr erhöhte bei 12,0\% XP schrittweise die TDG-Aktivität. Analoge Beobachtungen waren bei 18,0\% XP festzustellen. Bei beiden Proteinstufen führte die höchste Thr-Zulage im Vergleich zum Basisniveau zu signifikanter Steigerung der TDG-Aktivität und zeigten eine erhöhte Thr-Katabolisierung an. Die Wirksamkeitsparameter indizieren bei der jeweils höchsten Thr-Stufe den Bereich einer deutlichen Thr-Überversorgung und weisen demzufolge einen signifikanten Rückgang auf. Bei mittlerer Thr-Zulage war eine Verschlechterung der Thr-Wirksamkeit noch nicht zu beobachten. Die Glycinakkumulation war in allen Versuchsgruppen sehr niedrig und zeigte faktisch keine Beziehung zu den Diätveränderungen. Lediglich bei $18,0 \%$ XP und maximaler Thr-Zulage war ein signifikanter Effekt $\mathrm{zu}$ erkennen, der jedoch insgesamt auf relativ niedrigem Niveau der Glycinakkumulation lag. 
Tab. 25: TDG-Aktivität in der Rattenleber nach Threoninstaffelung und Threoninwirksamkeit $(\mathrm{n}=6)$; Versuch 7

\begin{tabular}{|c|c|c|c|c|c|}
\hline \multirow{2}{*}{$\begin{array}{c}\text { XP-/ Thr- } \\
\text { Stufen } \\
(\%)\end{array}$} & \multirow{2}{*}{$\begin{array}{c}\text { Thr-Wirk- } \\
\text { samkeit } \\
\text { (b/c) }\end{array}$} & \multirow{2}{*}{$\begin{array}{l}\text { Leber- } \\
\text { Masse } \\
\text { (g) }\end{array}$} & \multicolumn{3}{|c|}{$\begin{array}{c}\text { TDG-Aktivität } \\
\text { (nmol/ } 30 \mathrm{~min} / \mathrm{mg} \text { Protein) }\end{array}$} \\
\hline & & & Aminoaceton & Glycin & Gesamtaktivität \\
\hline $\begin{array}{c}12 \% \text { XP } \\
0.28 \% \text { Thr }\end{array}$ & $502^{\mathrm{ad}}$ & $9,3 \pm 0,8$ & $7,70^{\mathrm{a}}$ & $0,86^{\mathrm{a}}$ & $8,56^{\mathrm{a}}$ \\
\hline $\begin{array}{c}12 \% \text { XP } \\
0.42 \% \text { Thr }\end{array}$ & $527^{\text {ad }}$ & $9,7 \pm 0,5$ & $9,96^{\mathrm{ac}}$ & $0,91^{\mathrm{ac}}$ & $10,87^{\mathrm{ac}}$ \\
\hline $\begin{array}{c}12 \% \text { XP } \\
0.72 \% \text { Thr }\end{array}$ & $288^{b}$ & $10,1 \pm 0,6$ & $12,22^{b c}$ & $0,77^{\mathrm{a}}$ & $12,99^{b c}$ \\
\hline $\begin{array}{c}18 \% \text { XP } \\
0.42 \% \text { Thr }\end{array}$ & $578^{\mathrm{ac}}$ & $10,5 \pm 0,7$ & $10,59^{\mathrm{ac}}$ & $1,02^{\mathrm{ac}}$ & $11,60^{\mathrm{ac}}$ \\
\hline $\begin{array}{c}18 \% \text { XP } \\
0.52 \% \text { Thr }\end{array}$ & $674^{\mathrm{c}}$ & $11,1 \pm 1,2$ & $13,13^{b c}$ & $0,60^{\mathrm{a}}$ & $13,74^{b c}$ \\
\hline $\begin{array}{c}18 \% \text { XP } \\
0.72 \% \text { Thr }\end{array}$ & $445^{\mathrm{d}}$ & $10,3 \pm 1,0$ & $15,16^{\mathrm{b}}$ & $1,42^{b c}$ & $16,57^{b}$ \\
\hline
\end{tabular}

Unterschiedliche Hochbuchstaben kennzeichnen signifikante Unterschiede ( $\mathrm{p} \leq 0,05$; Tukey-Test)

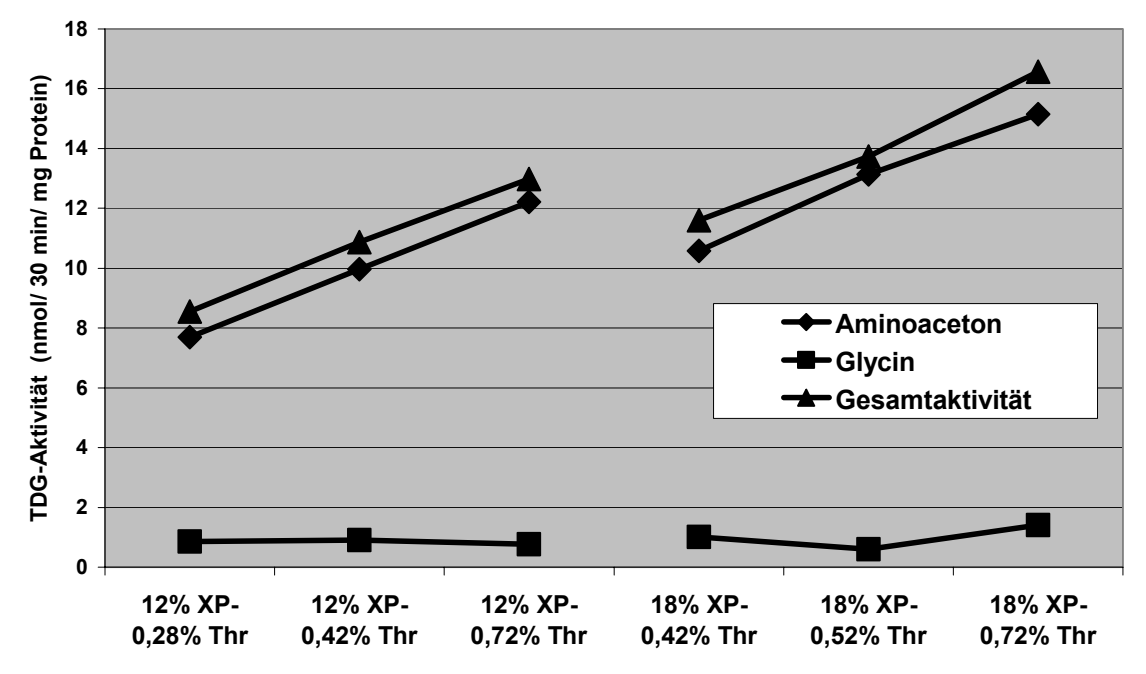

Protein- und Threoningehalte in der Futtermischung

Abb. 10: Verlauf der TDG-Aktivität in der Rattenleber bei differenziertem XP-/ThrNiveau $(\mathrm{n}=6)$; Versuch 7 
In Abbildung 11 sind relative Veränderungen und Verläufe von TDG-Aktivität und ThrWirksamkeit vergleichend dargestellt. Bei 12,0\% XP (0,28\% Thr) bzw. 12,0\% XP (0,42\% Thr) veränderte sich die Threoninwirksamkeit nicht signifikant, dies unterstützt bisherige Befunde hinsichtlich gleichbleibender AS-Wirksamkeit im Limitierungsbereich. Die TDGAktivität stieg in diesem Bereich nur tendenziell an. Hierin könnte ein vergleichbarer Verlauf von Wirksamkeit und TDG-Aktivität gesehen werden. Allerdings wird bei deutlicher Überschreitung des Limitierungsbereiches von Threonin bei 12,0\% XP (0,72\% Thr) sichtbar, dass der signifikante Wirksamkeitsrückgang nur mit einem tendenziellen kontinuierlichen weiteren Anstieg der TDG-Aktivität einhergeht. Bei 18,0\% XP sind analoge Veränderungen der genannten Parameter festzustellen. Demnach zeigt die Veränderung der TDG-Aktivität der Leber das Ende des Limitierungsbereiches von Threonin nicht in der erwarteten Deutlichkeit wie die Messung der Thr-Wirksamkeit an.

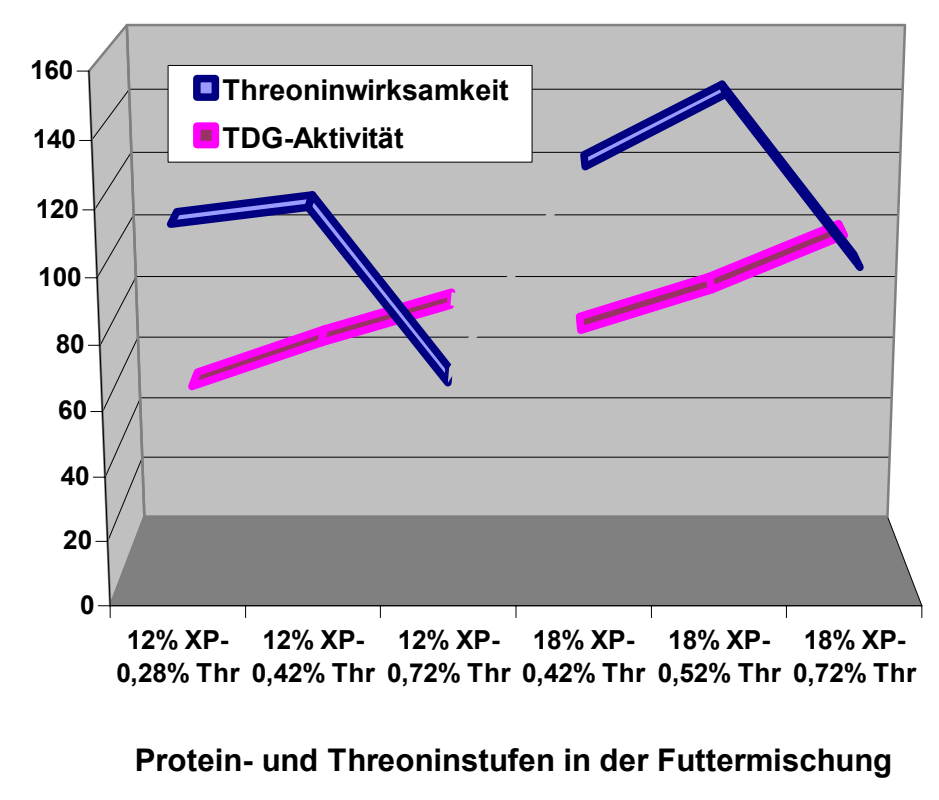

\begin{tabular}{|c|c|c|c|c|c|c|}
\hline & $\begin{array}{c}12,0 \% X P- \\
0,28 \% \mathrm{Thr}\end{array}$ & $\begin{array}{l}12,0 \% \text { XP- } \\
0,42 \% \mathrm{Thr}\end{array}$ & $\begin{array}{c}12,0 \% \mathrm{XP}- \\
0,72 \% \mathrm{Thr}\end{array}$ & $\begin{array}{c}18,0 \% \mathrm{XP}- \\
0,42 \% \mathrm{Thr}\end{array}$ & $\begin{array}{c}18,0 \% \mathrm{XP}- \\
0,52 \% \mathrm{Thr}\end{array}$ & $\begin{array}{c}18,0 \% \mathrm{XP}- \\
0,72 \% \mathrm{Thr}\end{array}$ \\
\hline Thr-Wirksamkeit & $113^{\mathrm{ad}}$ & $118^{\mathrm{ad}}$ & $65^{\mathrm{b}}$ & $130^{\mathrm{ac}}$ & $151^{\mathrm{c}}$ & $100^{\mathrm{d}}$ \\
\hline TDG-Aktivität & $52^{\mathrm{a}}$ & $66^{\mathrm{ac}}$ & $78^{\mathrm{bc}}$ & $70^{\mathrm{ac}}$ & $83^{\mathrm{bc}}$ & $100^{\mathrm{b}}$ \\
\hline
\end{tabular}

Abb. 11: Relative Veränderungen der Threoninwirksamkeit und TDG-Aktivität (18,0\% XP-0,72\% Thr = 100) bei Laborratten; $(n=6)$ 


\section{DISKUSSION}

Nach der Darstellung der Untersuchungsergebnisse soll nachfolgend der Versuch unternommen werden, die Resultate in vorliegende Arbeiten des Schrifttums einzuordnen und zu diskutieren. Da insgesamt nur eine geringe Zahl einschlägiger Arbeiten vorliegt, muss sich die Diskussion auf diese konzentrieren.

Darüber hinaus soll bei der Ergebnisdiskussion verstärkt der Zusammenhang zwischen in vitro Enzymaktivitätsmessungen zum Threoninkatabolismus und zur Threoninwirksamkeit, abgeleitet aus N-Bilanzmessungen, dargestellt werden. Dabei wird ein besonderer Schwerpunkt auf den Vergleich von relativen Veränderungen zwischen diesen Parametern gelegt, da direkte Vergleiche in Anbetracht der unterschiedlichen methodischen Ebenen nicht möglich sind.

\subsection{Zusammenhänge zwischen Proteinniveau und TDG-Aktivität beim Küken}

Durch die Erhöhung des XP-Gehaltes im Futter wurde die in vitro gemessene TDG-Aktivität der Leber erhöht (vgl. Tab. 19, Abb. 3). Dieser Befund, dass die Verabreichung einer Futtermischung mit hohem Proteingehalt zu einem Anstieg der hepatischen TDG-Aktivität führt, stimmt mit Aussagen von AOYAMA und MOTOKAWA (1981) überein. Trotz schwacher Limitanz des Threonins im Rohprotein, aber bei bedarfsgerechter XP-Versorgung und bei Versorgung über dem Bedarf wird die TDG-Aktivität erhöht. Ist der XP- und ThrGehalt der Diät deutlich unterhalb des Bedarfes, liegt die TDG-Aktivität auf sehr niedrigem Niveau. Dieses Ergebnis stimmt mit Aussagen von BENEVENGA et al. (1993) und KIM et al. (1983) überein, wonach eine minimale Oxidation von Aminosäuren bei Futterkonzentrationen, die unter dem Bedarf für hohe Wachstumsleistungen liegen, erfolgt. Andererseits resultiert eine markant steigende Aminosäure-Oxidation bei Konzentrationen, die über den Versorgungsansprüchen für intensives Wachstum liegen.

Zugleich war in vorliegenden Untersuchungen festzustellen, dass trotz bestehender Limitanz des Threonins, gemessen am Aminosäureverhältnis zu Lysin, Methionin/Cystin, Tryptophan und Arginin, der Threoninabbau ab einem XP-Gehalt von 22\% signifikant erhöht war. Dies bedeutet, dass der Threoninabbau wahrscheinlich einem allgemeinen Anstieg der unspezifischen Katabolisierungsrate folgte. Diese Beobachtung unterstützt die von DAVIS und AUSTIC (1997) mitgeteilten Befunde, wonach die zelluläre Konzentration auch anderer 
Aminosäuren neben Threonin Einfluss auf die TDG-Aktivität der Leber von Küken haben kann.

So ist für vorliegende Befunde abzuleiten, dass der beobachtete Threoninabbau durch TDG bei der Erhöhung des XP-Gehaltes trotz der Limitanz des Threonins einem allgemeinen Anstieg der unspezifischen Katabolisierungsrate zu folgen scheint und somit der stattfindende Threoninabbau vorwiegend vom XP-Niveau beeinflusst wird.

In den von RIMBACH und LIEBERT $(1999,2000)$ durchgeführten N-Bilanzmessungen im Rahmen von N-Steigerungsversuchen zeigte sich die Thr-Wirksamkeit jedoch erst beim höchsten XP-Niveau signifikant verändert. Die quantitative Bedeutung der TDGAktivitätsveränderungen ist offensichtlich begrenzt.

In Abbildung 13 wird der Zusammenhang zwischen Threoninwirksamkeit und TDG-Aktivität durch Darstellung relativer Verläufe gegenübergestellt. Der Anstieg der TDG-Aktivität zwischen $27,5 \%$ und $33 \% \quad \mathrm{XP}$ ist zugleich mit signifikant geringerer relativer Threoninwirksamkeit verbunden. Es ist anzunehmen, dass der bei 33\% XP beobachtete signifikante Rückgang der Gesamtwirksamkeit von Threonin mit einem sprunghaften Aminosäure-Katabolisierungsanstieg in Verbindung steht. Daraus lässt sich erkennen, dass beim verstärkten Abbau von Threonin durch TDG die Thr-Wirksamkeit vermindert wird. Allerdings zeigt sich auch, dass die bei niedrigen XP-Stufen beobachteten signifikanten Veränderungen der TDG-Aktivität keine signifikanten Auswirkungen auf die ThrWirksamkeit haben. Das Ergebnis unterstreicht die begrenzte quantitative Bedeutung der in vitro gemessenen TDG-Aktivität. 


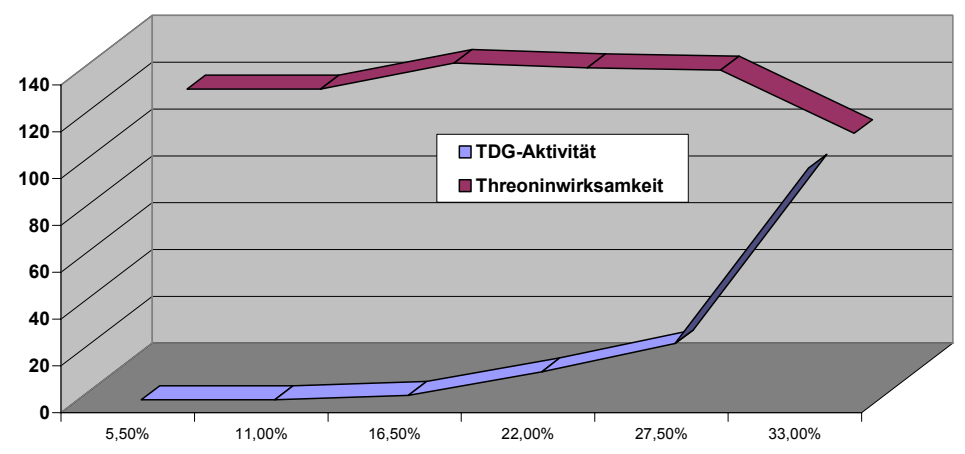

Proteinstufen in der Futtermischung

\begin{tabular}{|c|c|c|c|c|c|c|}
\hline XP & $5,50 \%$ & $11,00 \%$ & $16,50 \%$ & $22,00 \%$ & $27,50 \%$ & $33,00 \%$ \\
\hline TDG-Aktivität & $1^{\mathrm{a}}$ & $1^{\mathrm{a}}$ & $3^{\mathrm{a}}$ & $13^{\mathrm{b}}$ & $25^{\mathrm{c}}$ & $100^{\mathrm{d}}$ \\
\hline Thr-Wirksamkeit & $119^{\mathrm{a}}$ & $119^{\mathrm{a}}$ & $130^{\mathrm{a}}$ & $128^{\mathrm{a}}$ & $127^{\mathrm{a}}$ & $100^{\mathrm{b}}$ \\
\hline
\end{tabular}

\section{Abb. 13: Relative Veränderungen von Threoninwirksamkeit und TDG-Aktivität} $(33,00 \%$ XP $=100)$ nach Proteinstaffelung; $(n=6)$

\subsection{Zusammenhänge zwischen Protein- und Threoningehalt der Futtermischungen und TDG-Aktivität beim Küken (Wachstumsversuch)}

Durch eine Erhöhung des Threoningehaltes von $0,45 \%$ auf $0,60 \%$ dThr zeigte sich nach Futtermischungen mit 18,5\% XP kein Effekt auf die TDG-Aktivität in der Leber (vgl. Tab. 20). Dieses Ergebnis stimmt mit den Aussagen von DAVIS und AUSTIC (1997) bei Küken, wonach die hepatische TDG-Aktivität überwiegend vom Proteinniveau beeinflusst wird, überein. Dieser Befund unterstreicht, dass die TDG-Aktivität im Bereich unterhalb der XPBedarfsdeckung und bei Bedarfsdeckung durch eine Threoninzulage (NRC, 1994) primär vom XP-Gehalt abhängt. Bei den Mischungen mit 22,5\% XP wurde durch die Threoninanhebung von $0,45 \%$ auf $0,60 \%$ dThr eine signifikante Erhöhung der TDG-Aktivität nachgewiesen. Dieser Befund kann mit den Ergebnissen von Le FLOC'H et al. $(1994,1996)$ bei Schweinen in Verbindung gesehen werden, die die hepatische TDG-Aktivität vom Threoninniveau beeinflusst zeigten. Dies bedeutet, dass die TDG-Aktivität im Bereich der XP-Bedarfsdeckung bei Threoninzulage vom Thr-Gehalt abhängt. Bei vorliegenden 
Untersuchungen kann der Bedarfsbereich bei 0,49\% dThr und 18,5\% XP bzw. bei 0,54\% dThr und 22,5\% XP (RIMBACH, Diss. in Vorbereitung) gesehen werden. Daraus lässt sich orientierend ableiten, dass die TDG-Aktivität im Bereich unterhalb der XP-Bedarfsdeckung auch bei Threoninzulagen stärker vom XP-Gehalt abhängt, aber im Bereich optimaler XPVersorgung bei Threoninzulagen von dem erreichten Grad der Threoninbedarfsdeckung deutlich beeinflusst wird.

Die Küken zeigten auch bei einer Diät mit 0,60\% dThr einen signifikanten Anstieg der hepatischen TDG-Aktivität durch die Steigerung des XP-Gehaltes von 18,5\% auf 22,5\%. Diese Ergebnisse stimmen überein mit den Befunden von Le FLOC'H et al. (1994), die in in vitro Versuchen mit Bestimmung von Aminoaceton bei Schweinen nach einer Diät mit 0,52\% Thr einen signifikanten Anstieg der hepatischen TDG-Aktivität bei der Anhebung des XPGehaltes von $12,6 \%$ auf $15,6 \%$ zeigen konnten. Dieser Befund bedeutet, dass die TDGAktivität im Bereich der optimalen Thr-Bedarfsdeckung primär vom XP-Gehalt abhängt. Der gleiche Anstieg des XP-Gehaltes in der Diät verursachte einen wesentlich geringeren Anstieg der TDG-Aktivität bei einem Thr-Gehalt von $0,45 \%$ dThr. Diese Ergebnisse stimmen überein mit den Aussagen von Le FLOC'H et al. (1994), wonach in den genannten Versuchen beim Schwein die Diäten mit 0,42\% Thr einen wesentlich geringeren Anstieg der hepatischen TDG-Aktivität bei der Anhebung des XP-Gehaltes von 12,6\% auf 15,6\% zur Folge hatten. Dieser Befund bedeutet, dass die TDG-Aktivität im Bereich begrenzter Thr-Bedarfsdeckung stärker vom Thr-Gehalt abhängt, aber auch eine Tendenz zur Abhängigkeit vom XP-Gehalt besteht.

Parallel wurden Messungen zur Threoninwirksamkeit in den Futtermischungen vorgenommen (RIMBACH und LIEBERT, 2000). Der unveränderten TDG-Aktivität bei der Thr-Anhebung von $0,45 \%$ auf $0,60 \%$ dThr bei $18,5 \%$ XP steht eine signifikant geringere Threoninwirksamkeit gegenüber (Abb. 14 und Tab. 20). Die zugelegte Thr-Menge konnte offensichtlich nicht effizient verwertet werden, obgleich ein Zustand unterhalb der Bedarfsdeckung erwartet werden konnte. Es ist zu vermuten, dass bei 18,5\% XP im Altersabschnitt von 17. - 30. LT nicht genügend Gesamt-N (nicht-essentielle AS) vorhanden war und somit den limitierenden Faktor für die Proteinsynthese insgesamt darstellte. Die ausgebliebene Steigerung der TDG-Aktivität bei Thr-Zulage legt die Vermutung nahe, dass das zugesetzte Threonin durch die TDG nicht oxidiert, sondern durch die Threonindehydratase abgebaut worden sein könnte. Diese Annahme ist eine 
Erklärungsmöglichkeit, bleibt aber spekulativ. Der signifikante Anstieg der TDG-Aktivität bei Thr-Anhebung von $0,45 \%$ auf $0,60 \%$ dThr bei $22,5 \%$ XP ist ebenfalls mit einer signifikant geringeren Threoninwirksamkeit verbunden. Diese Ergebnisse zeigen eine vergleichbare Tendenz wie Ergebnisse von LEE und LIEBERT (2000) bei Küken, wonach der Anstieg der TDG-Aktivität mit einer signifikant geringeren Threoninwirksamkeit verbunden war. Die erhöhte TDG-Aktivität beim 22,5\% XP-0,60\% dThr gibt einen Hinweis auf das Ende des Limitierungsbereiches von Threonin in den Futtermischungen mit 22,5\% XP. Diese Folgerung wird durch eine signifikant niedrigere Threoninwirksamkeit bestätigt.

Es kann vermutet werden, dass unterhalb der XP-Bedarfsdeckung durch die Threoninzulage wahrscheinlich ein anderer Abbauweg (TDH-Weg) des Threonins die Thr-Wirksamkeit vermindert und im Bereich optimaler XP-Versorgung bei der Threoninzulage ein Abbau von überschüssigem Threonin durch die TDG erfolgt und zugleich die Thr-Wirksamkeit vermindert wird. Auch hierbei muss zunächst von einer spekulativen Betrachtung ausgegangen werden.

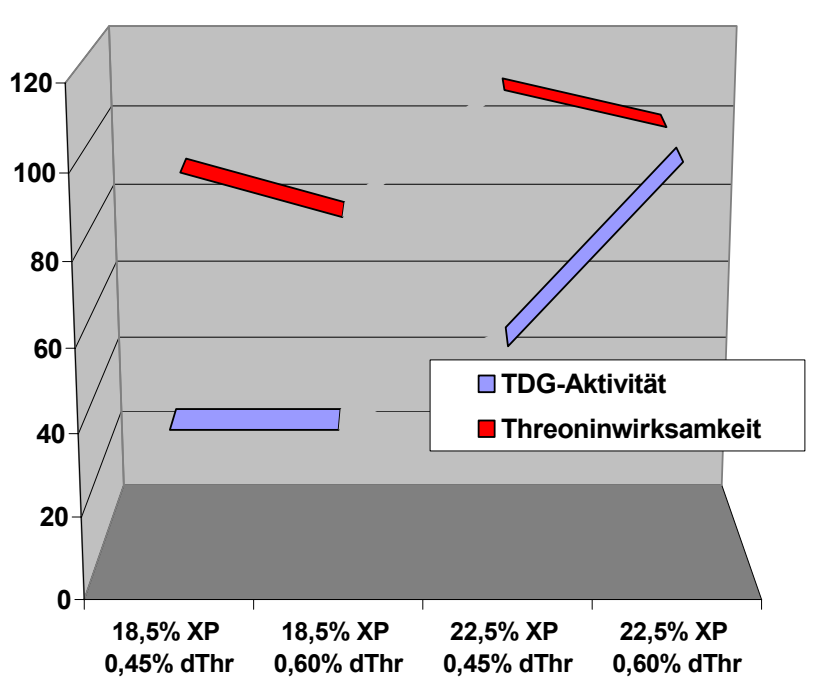

Protein- und Threoninstufen in der Futtermischung

\begin{tabular}{|c|c|c|c|c|}
\hline & $\begin{array}{c}18,5 \% \mathrm{XP}- \\
0,45 \% \mathrm{dThr}\end{array}$ & $\begin{array}{c}18,5 \% \mathrm{XP}- \\
0,60 \% \mathrm{dThr}\end{array}$ & $\begin{array}{c}22,5 \% \mathrm{XP}- \\
0,45 \% \mathrm{dThr}\end{array}$ & $\begin{array}{c}22,5 \% \mathrm{XP}- \\
0,60 \% \mathrm{dThr}\end{array}$ \\
\hline TDG-Aktivität & $37^{\mathrm{a}}$ & $37^{\mathrm{a}}$ & $57^{\mathrm{a}}$ & $100^{\mathrm{b}}$ \\
\hline Thr-Wirksamkeit & $89^{\mathrm{a}}$ & $78^{\mathrm{b}}$ & $109^{\mathrm{c}}$ & $100^{\mathrm{d}}$ \\
\hline
\end{tabular}

Abb. 14: Relative Veränderungen der Threoninwirksamkeit und TDG-Aktivität (22,5\% $\mathrm{XP}-0,60 \% \mathrm{dThr}=100$ ) bei verschiedenen Protein- und Threoninstufen in der Futtermischung; $(n=6)$ 


\subsection{Zusammenhänge zwischen Protein- und Threoningehalt der Futtermischungen und TDG-Aktivität beim Küken (Bilanzversuch)}

Durch eine Erhöhung des Thr-Gehaltes von 0,65\% (3,8 g Thr/ 16 g N) auf 0,79\% Thr (4,7 g $\mathrm{Thr} / 16 \mathrm{~g} \mathrm{~N}$ ) bei 16,5\% XP haben sich keine signifikante Effekte auf die TDG-Aktivität in der Leber gezeigt (vgl. Tab. 21). Dieses Ergebnis stimmt wiederum mit Beobachtungen von DAVIS und AUSTIC (1997) bei Küken überein, wonach die hepatische TDG-Aktivität vom Proteinniveau beeinflusst wird. Bei den Diäten mit 22,0\% XP wird durch die Threoninzulage von $0,86 \%(3,8 \mathrm{~g}$ Thr/ $16 \mathrm{~g} \mathrm{~N})$ auf 1,05\% Thr (4,7 g Thr/ $16 \mathrm{~g} \mathrm{~N})$ eine Erhöhung der TDGAktivität signifikant nachgewiesen. Dieses Ergebnis stimmt mit den Aussagen von Le FLOC'H et al. $(1994,1996)$ bei Schweinen überein. Wiederholt zeigte sich (vgl. Versuch 2), dass die TDG-Aktivität im Bereich unterhalb der XP-Bedarfsdeckung primär vom XP-Gehalt abhängt und in der Nähe der XP-Bedarfsdeckung durch die Threoninzulage beeinflusst werden kann. Damit zeigten Bilanzversuch und Wachstumsversuch übereinstimmende Befunde.

In parallel durchgeführten Bilanzmessungen (RIMBACH, Diss. in Vorbereitung) wurde die Threoninwirksamkeit ermittelt. Abbildung 15 zeigt den Zusammenhang zwischen relativer Veränderung der Threoninwirksamkeit und TDG-Aktivität. Die unveränderte TDG-Aktivität nach Anhebung des Thr-Niveaus von $0,65 \%$ auf $0,79 \%$ bei $16,5 \%$ XP steht einer signifikant geringeren Threoninwirksamkeit gegenüber (Abb. 15 und Tab. 21). Der signifikante Anstieg der TDG-Aktivität zwischen $0,86 \%$ und 1,05\% Thr bei 22,0\% XP ist auch mit signifikant geringerer Threoninwirksamkeit verbunden. Die Beziehungen zwischen Threoninabbau und Threoninwirksamkeit in diesem Bilanzversuch weisen ähnliche Verhältnisse wie im Wachstumsversuch (Versuch 2) auf. 


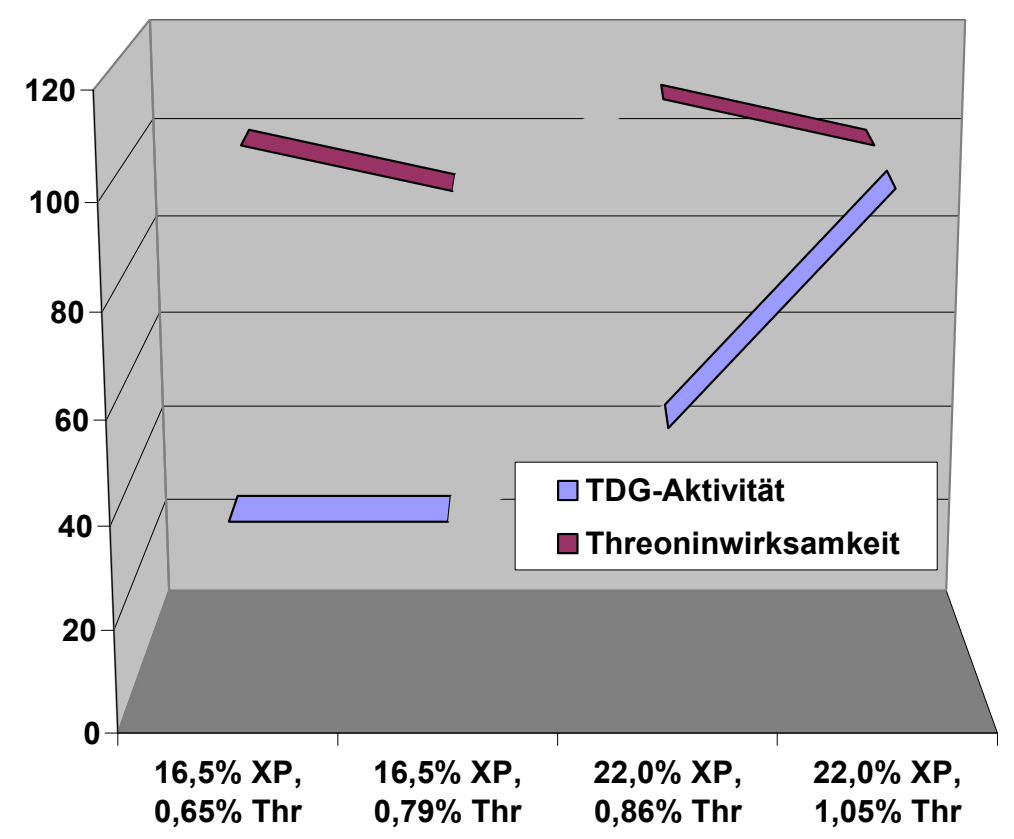

Protein- und Threoninstufen in der Futtermischung

\begin{tabular}{|c|c|c|c|c|}
\hline & $\begin{array}{c}16,5 \% \mathrm{XP}- \\
0,65 \% \mathrm{Thr}\end{array}$ & $\begin{array}{c}16,5 \% \mathrm{XP}- \\
0,79 \% \mathrm{Thr}\end{array}$ & $\begin{array}{c}22,0 \% \mathrm{XP}- \\
0,86 \% \mathrm{Thr}\end{array}$ & $\begin{array}{c}22,0 \% \mathrm{XP}- \\
1,05 \% \mathrm{Thr}\end{array}$ \\
\hline TDG-Aktivität & $37^{\mathrm{a}}$ & $37^{\mathrm{a}}$ & $55^{\mathrm{a}}$ & $100^{\mathrm{b}}$ \\
\hline Thr-Wirksamkeit & $100^{\mathrm{a}}$ & $91^{\mathrm{b}}$ & $109^{\mathrm{c}}$ & $100^{\mathrm{a}}$ \\
\hline
\end{tabular}

Abb. 15: Relative Veränderungen der Threoninwirksamkeit und TDG-Aktivität (22,0\% $\mathrm{XP}-1,05 \% \mathrm{Thr}=100$ ) bei verschiedenen Protein- und Threoninstufen in der Futtermischung; $(n=6)$

\subsection{Zusammenhänge zwischen Alter und TDG-Aktivität beim Küken}

Beim Küken lag im Alter von 7 Tagen eine sehr niedrige TDG-Aktivität vor (Tabelle 22). Dieser Befund könnte mit geringer Futteraufnahmekapazität, noch unzureichender Ausbildung des Verdauungssystems und ggf. auch der Bedeutung des Dottersackes in dieser Entwicklungsphase in Verbindung stehen.

Im Altersabschnitt von 3 Wochen wird die TDG-Aktivität insgesamt stark erhöht und Glycin vergleichsweise signifikant höher akkumuliert. Der metabolische Bedarf an Glycin ist in diesem Entwicklungsabschnitt offenbar deutlich stärker ausgeprägt. Dieser Befund stimmt 
prinzipiell mit Beobachtungen von MILLWARD (1998) in unterschiedlichen Entwicklungsphasen des Menschen überein (Abbildung 16). Daraus ist abzuleiten, dass es sich bei Erwachsenen um den minimalen obligatorischen metabolischen Bedarf für die Erhaltung und bei Säugling um den maximalen metabolischen Bedarf für schnelles Wachstum handelt. Dieser Befund stimmt auch mit den Aussagen von BALLÈVRE et al. (1991) überein, wonach Glycin für das Wachstum der Ferkel begrenzend wirken kann und durch eine Threoninergänzung eine Glycin-limitierte Diät aufgewertet wird. Die TDG-Aktivität und die akkumulierte Glycinmenge beim Küken im Altersabschnitt von 3 Wochen kann vermutlich mit höheren metabolischen Anforderungen für Glycin in Zusammenhang gebracht werden.

\section{Lysinbedarf (mg/ g Protein)}

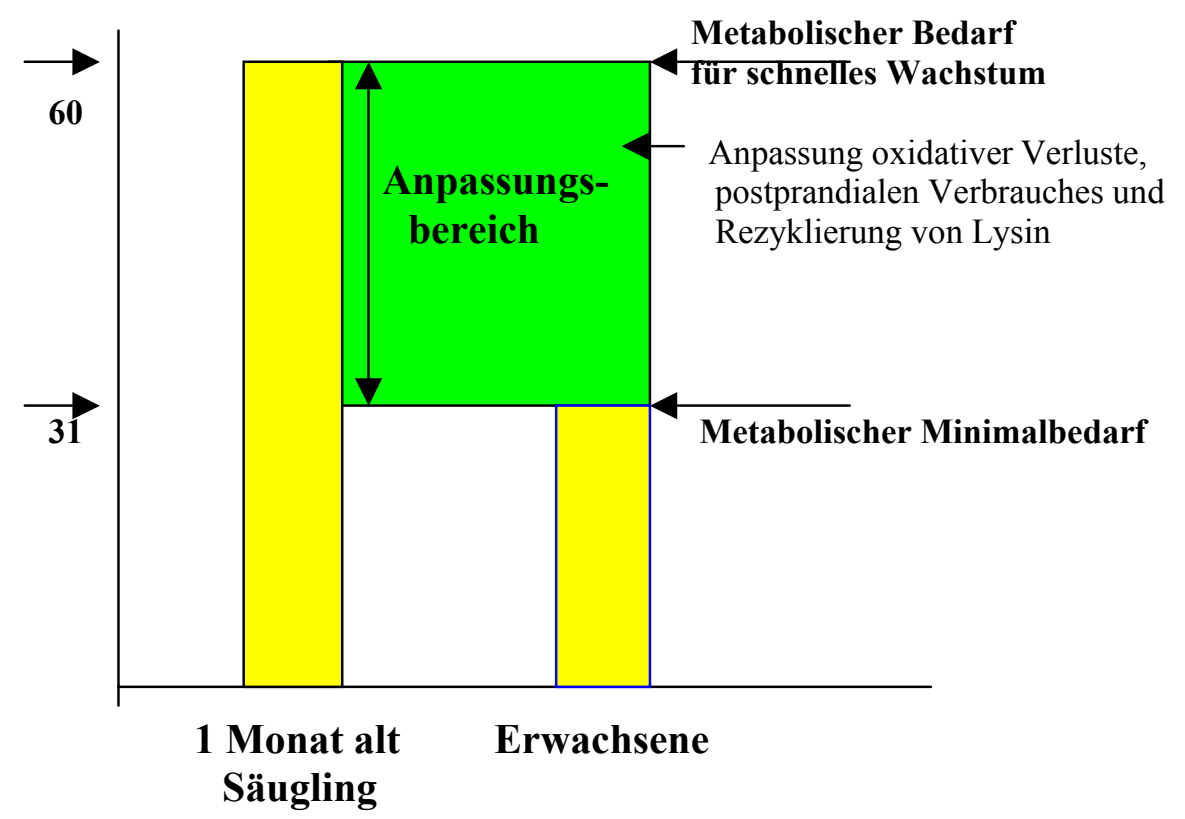

\section{Abb. 16: Aminosäuren-Bedarfsniveaus bei Säugling und Erwachsenen (modifiziert von Millward (1998)).}

Die TDG-Aktivität im Alter von über 5 Wochen und darüber liegt auf deutlich niedrigerem Niveau (Abb. 6 und Tab. 22). Dieses Ergebnis stimmt mit den Aussagen von BENEVENGA et al. (1993) und KIM et al. (1983) überein, wonach die minimale Oxidation einer Aminosäure bei Futterkonzentrationen, die unter dem Bedarf für maximales Wachstum liegen, erfolgt. Dieser Befund deutet an, dass die TDG-Aktivität beim Küken im Altersabschnitt von 5 bis 7 Wochen, vermutlich infolge eines niedrigeren metabolischen Glycinbedarfs im Vergleich mit 3 Wochen alten Tieren, verringert sein könnte. 
Hiervon wäre abzuleiten, dass im Altersabschnitt von 3 Wochen die höchsten metabolischen Anforderungen für Glycin vorliegen. Allerdings kann diese Annahme durch vorliegende Befunde nicht abschließend belegt werden.

\subsection{Zusammenhänge zwischen Glycin- und Threoningehalt der Futtermischungen und TDG-Aktivität beim Küken}

Nach dem NRC (1994) liegt der empfohlene Glycin + Serin-Gehalt bei 1,25\% für Küken bis zum 21. Lebenstag. Nach Angaben von SCHUTTE et al. (1997) kann der Bedarf an Glycin und Serin für hohe Wachstumsraten bei 1,8 - 1,9\% für Rationen mit 13,4 MJ ME/ kg und 19 - 21\% XP-Gehalt erwartet werden. Im vorliegenden Versuch betrug der Glycin + SerinGehalt jeweils 1,55\% bzw. 1,90\% (ohne bzw. mit Glycinzulage) bei 22,0\% XP für 10 - 15 Tage alte Küken.

Bei 1,55\% Gly+Ser in den Futtermischungen (ohne Glycin-Zulage) und 22,0\% XP zeigte die Akkumulation von Glycin sowie Gesamtaktivität der TDG bei Erhöhung des Thr-Gehaltes von $0,45 \%$ auf $0,60 \%$ dThr eine steigende Tendenz, jedoch ohne Signifikanz. Dieses Ergebnis stimmt mit den Aussagen von LEE und LIEBERT (2001) beim Küken überein. Die TDGAktivität war bei Threoninzulage erhöht. Bei Glycin-Zulage (1,90\% Gly+Ser) und 22,0\% XP im Futter wurde bei einer Erhöhung des Thr-Gehaltes von 0,45\% auf 0,60\% dThr die Gesamtaktivität signifikant erhöht (Abb. 7 und Tab. 23). Eine Glycin-Zulage führte offensichtlich zur Stimulierung der TDG-Aktivität.

Bei 22,0\% XP-0,45\% dThr in der Diät zeigt die Akkumulation des Glycins und die Gesamtaktivität der TDG bei Glycin-Zulage nahezu keine Veränderungen (Abb. 8 und Tab. 23). Dieser Befund unterstreicht, dass im Bereich limitierter Thr-Bedarfsdeckung die GlycinZulage auf die TDG-Aktivität keinen Einfluss hat. Bei 22,0\% XP-0,60\% dThr in der Diät zeigt die Akkumulation des Glycins durch TDG bei Glycin-Zulage fast keine Veränderungen und die Gesamtaktivität zeigt lediglich eine steigende Tendenz. Dieser Befund bedeutet, dass im Bereich der Thr-Bedarfsdeckung durch Glycin-Zulagen keine signifikante Wirkung auf die TDG-Aktivität vorliegt. 
Es lässt sich schlussfolgern, dass bei nahezu gleicher Akkumulation des Glycins und wenig erhöhter TDG-Aktivität bei Glycinzulage kein erhöhter stoffwechselphysiologischer Bedarf durch die TDG Rechnung getragen wird. Das bedeutet auch, dass die TDG nicht nur durch Thr-Zulagen, sondern zugleich durch Glycin-Zulagen stimuliert wird. Glycin sowie Glutaminsäure sind nach Le FLOC'H et al. (1994) als Substrat für die TDG teilweise verwendbar.

In parallelen Untersuchungen wurden die Effekte auf die Threoninwirksamkeit ermittelt (RIMBACH, Diss. in Vorbereitung), um die Zusammenhänge von Threoninabbau durch TDG und Threoninwirksamkeit ohne und mit Glycinzulage zu quantifizieren. In 1,55\% Gly+SerDiäten (ohne Glycin-Zulage) zeigte bei einer Erhöhung des Thr-Gehaltes von 0,45\% auf $0,60 \%$ dThr die TDG-Aktivität keine signifikanten Veränderungen, auch die Threoninwirksamkeit wurde nicht signifikant verändert. Bei einer Glycin-Zulage $(1,90 \%$ Gly+Ser-Diäten) wurde bei einer Erhöhung des Threoningehaltes von 0,45\% auf 0,60\% dThr

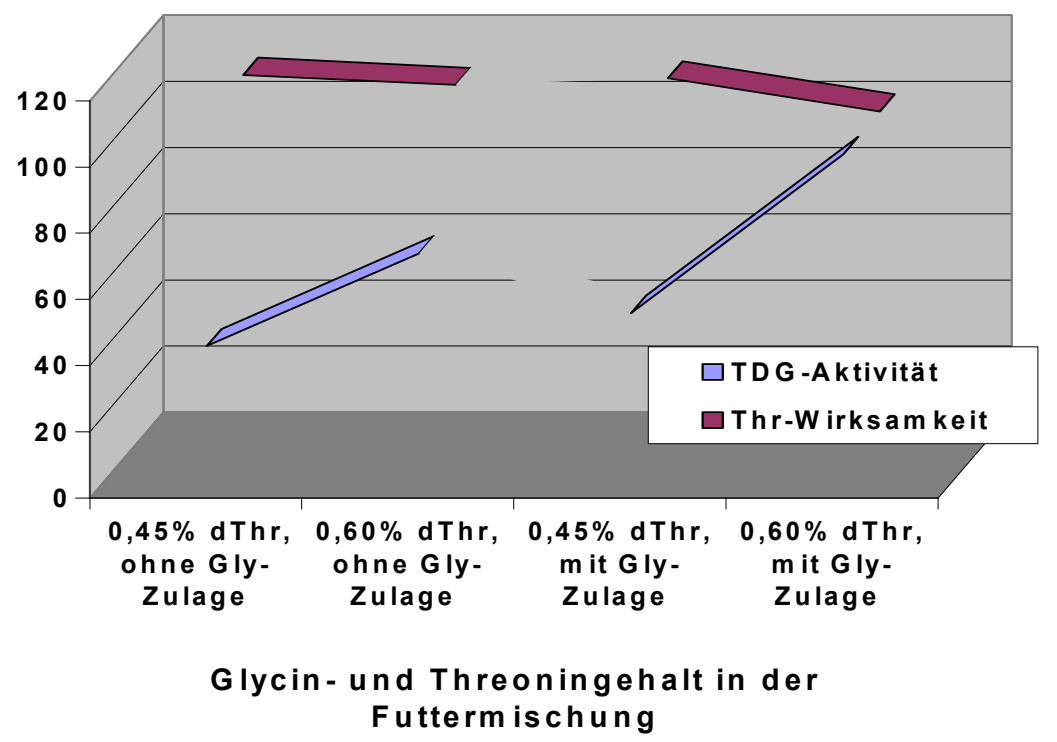

\begin{tabular}{|c|c|c|c|c|}
\hline & $\begin{array}{c}0,45 \% \mathrm{dThr} \\
\text { ohne Gly-Zulage }\end{array}$ & $\begin{array}{c}0,60 \% \mathrm{dThr} \\
\text { ohne Gly-Zulage }\end{array}$ & $\begin{array}{c}0,45 \% \mathrm{dThr} \\
\text { mit Gly-Zulage }\end{array}$ & $\begin{array}{c}0,60 \% \mathrm{dThr} \\
\text { mit Gly-Zulage }\end{array}$ \\
\hline TDG-Aktivität & $42^{\mathrm{a}}$ & $70^{\mathrm{ab}}$ & $52^{\mathrm{a}}$ & $100^{\mathrm{b}}$ \\
\hline Thr-Wirksamkeit & $111^{\mathrm{a}}$ & $108^{\mathrm{a}}$ & $110^{\mathrm{a}}$ & $100^{\mathrm{b}}$ \\
\hline
\end{tabular}

Abb. 17: Relative Veränderungen der Threoninwirksamkeit und TDG-Aktivität (0,60\% dThr mit Gly-Zulage $=100$ ) nach Glycin- und Threoninabstufungen in der Futtermischung; $(n=6)$ 
die TDG-Aktivität signifikant erhöht und die Threoninwirksamkeit signifikant vermindert (Abb. 17 und Tab. 23).

Dieser Befund stimmt trotz des unterschiedlichen Alters beim Küken mit dem Ergebnis des Versuches 2 überein, bei dem durch die Erhöhung des Threoningehaltes von 0,45\% auf 0,60\% dThr bei 22,0\% XP (1,90\% Gly + Ser-Diäten) die TDG-Aktivität signifikant erhöht wurde und die Threoninwirksamkeit signifikant abfiel.

Die tendenzielle Erhöhung der TDG-Aktivität ohne Glycin-Zulage bei Anhebung des ThrGehaltes von $0,45 \%$ auf $0,60 \%$ dThr gibt einen Hinweis auf den ThreoninLimitierungsbereich. Diese Folgerung findet Bestätigung durch nicht signifikante Veränderungen der Threoninwirksamkeit. Die signifikant erhöhte TDG-Aktivität durch Glycin-Zulage bei Erhöhung des Thr-Niveaus von 0,45\% auf 0,60\% dThr zeigt vermutlich das Ende des durch Threonin limitierten Bereichs an. Dementsprechend liegt eine signifikant niedrigere Threoninwirksamkeit vor.

In den Futtermischungen mit 0,45\% dThr zeigte die TDG-Aktivität bei Glycin-Zulage und die Threoninwirksamkeit kaum Veränderungen. In den Futtermischungen mit 0,60\% dThr wurde die Threoninwirksamkeit signifikant vermindert (Abb. 18 und Tab. 23).

Die durch Glycin-Zulage geringfügig erhöhte TDG-Aktivität bei 0,45\% dThr und nahezu unveränderte Threoninwirksamkeit lassen den Limitierungsbereich erkennen. 


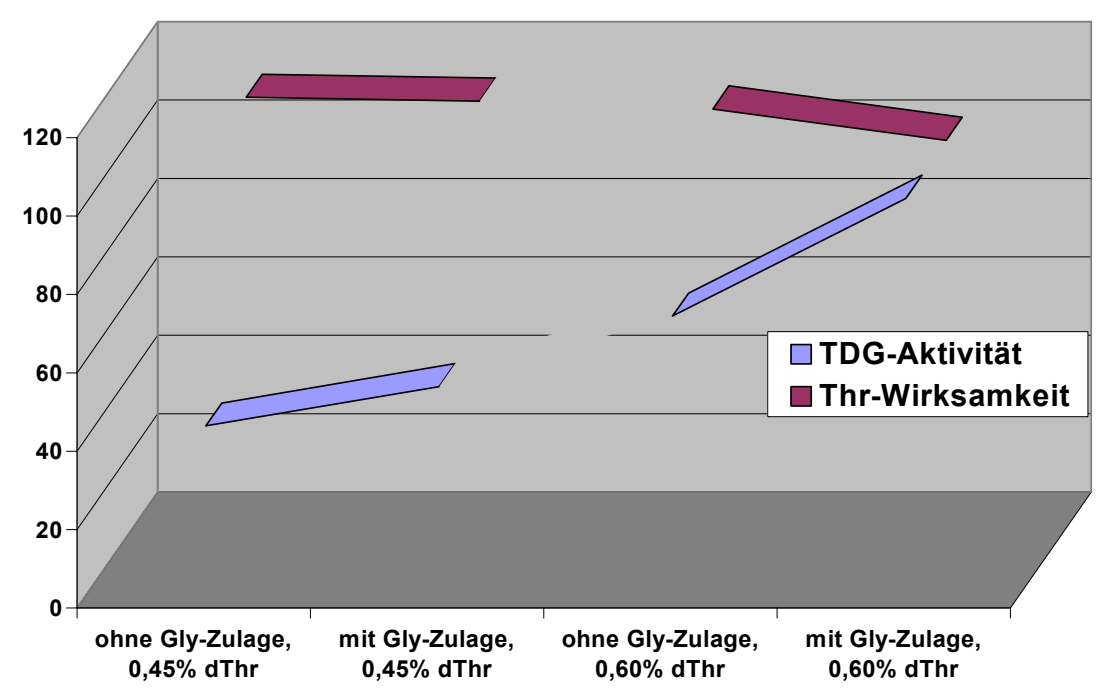

Glycin- und Threoningehalt in der Futtermischung

\begin{tabular}{|c|c|c|c|c|}
\hline & $\begin{array}{c}\text { ohne Gly-Zulage } \\
0,45 \% \mathrm{dThr}\end{array}$ & $\begin{array}{c}\text { mit Gly-Zulage } \\
0,45 \% \mathrm{dThr}\end{array}$ & $\begin{array}{c}\text { ohne Gly-Zulage } \\
0,60 \% \mathrm{dThr}\end{array}$ & $\begin{array}{c}\text { mit Gly-Zulage } \\
0,60 \% \mathrm{dThr}\end{array}$ \\
\hline TDG-Aktivität & $42^{\mathrm{a}}$ & $52^{\mathrm{a}}$ & $70^{\mathrm{ab}}$ & $100^{\mathrm{b}}$ \\
\hline Thr-Wirksamkeit & $111^{\mathrm{a}}$ & $110^{\mathrm{a}}$ & $108^{\mathrm{a}}$ & $100^{\mathrm{b}}$ \\
\hline
\end{tabular}

\section{Abb. 18: Relative Veränderungen der Threoninwirksamkeit und TDG-Aktivität (mit} Gly-Zulage, $0,60 \%$ dThr $=100)$ nach Glycin- und Threoninabstufungen; $(\mathrm{n}=6)$

Nach den Ergebnissen von Abbildung 17 und 18 werden TDG-Aktivität und Thr-Wirksamkeit in der Nähe der Thr-Bedarfsdeckung vom Glycin- wie Threoningehalt beeinflusst. Interessanterweise zeigt sich bei Darstellung relativer Werte (Abbildung 17 und 18) bei TDGAktivität und Thr-Wirksamkeit eine ausgeprägte Wirkung der Thr-Zulage.

Es lässt sich aber auch feststellen, dass die TDG-Aktivität und die Thr-Wirksamkeit in der Nähe der Thr-Bedarfsdeckung vom Glycingehalt beeinflusst werden. Diese Beobachtung bedarf weiterer experimenteller Belege.

\subsection{Zusammenhänge zwischen Proteinniveau und TDG-Aktivität bei der Laborratte}

Bei der Ratte wurde durch die Erhöhung des XP-Gehaltes im Futter die TDG-Aktivität in der Leber nicht erhöht (Abb. 9 und Tab. 24). Dass die Verabreichung einer Diät mit hohem Proteingehalt nicht zwangsläufig zu einem starken Anstieg der hepatischen TDG-Aktivität führen muss, stimmt mit Aussagen von BIRD und NUNN (1983) überein. Die Relation der 
TDG-Aktivität im Bereich von 12,0\% XP und 24,0\% XP war ähnlich der von BIRD und NUNN (1983) beobachteten. Nach den Empfehlungen des NRC (1978) liegt der Proteinbedarf für maximales Wachstum bei Ratten im Bereich von 12,0\% XP, wenn hoch verdauliches Protein mit ausgeglichenem Aminosäuremuster verwendet wird. MERCER et al. (1989) und PETERS und HARPER (1985) zeigten, dass 19\% Kasein (ca. 17\% XP) in der Diät notwendig war, um 95\% der maximalen Wachstumskapazität auszuschöpfen.

Trotz einer geringen Limitanz von Threonin im Rohprotein aber bei insgesamt bedarfsdeckender XP- und Thr-Versorgung (18,0\% XP und 0,75\% Thr) und bei Versorgung über dem Bedarf (24,0\% XP und 1,0\% Thr), wurde die TDG-Aktivität nicht signifikant erhöht. Dieser Befund bedeutet, dass die TDG-Aktivität im Bereich des optimalen XPBedarfs eine schwache Abhängigkeit vom XP-Gehalt hat. In dem optimalen XP-Bereich von 18,0\% XP war die TDG-Aktivität niedrig. Dieser Befund stimmt mit den Aussagen von KANG-LEE und HARPER (1978) überein, die bei Ratten unter Verwendung von L-[U- $\left.{ }^{14} \mathrm{C}\right]$ Threonin eine niedrige Oxidationsrate von Threonin in einem optimalen ThrVersorgungsbereich für maximales Wachstum ermittelten. Danach, bei höherer ThrVersorgung, stieg die Oxidationsrate von Threonin an.

Die Katabolisierung von Threonin verringerte sich jedoch signifikant, wenn der XP-Gehalt von 12,0\% auf 18,0\% angehoben wurde. Das Verhältnis der Gesamtmenge von Glycin und Serin bei der 18,0\%- bzw. 12,0\% XP-Diät war 1,5:1, d. h. die 18,0\% XP-Diät enthielt die 1,5fach höhere Menge an Glycin und Serin. Bei 18,0\% XP in der Diät wird Threonin durch die TDG offensichtlich in geringem Umfang zu Glycin abgebaut, da bei diesem Proteinniveau ausreichend Aminosäuren verfügbar sind, um ein entsprechendes Wachstum sicherzustellen. Nach Angaben von LEE und LIEBERT (2001) aus in vitro Studien (Inkubation mit $20 \mathrm{mM}$ Thr-Konzentration) mit Rattenlebern wurden ca. 10\% des Threonins zu Glycin abgebaut. Nach Ergebnissen von BALLÈVRE et al. (1990) mit in vivo Studien beim Schwein wurden ca. 80\% des Threonins zu Glycin abgebaut. Ferner errechneten BIRD et al. (1984), ausgehend von in vitro Studien mit intakten hepatischen Mitochondrien von Ratten, dass bei ausreichender Versorgung mit L-Threonin mindestens $65 \%$ des katabolisierten Threonins in Glycin und Acetyl-CoA umgewandelt werden. Das bedeutet, dass mindestens $60 \%$ des katabolisierten Threonins zu Glycin abgebaut werden. Hierbei zeigen sich große Unterschied zwischen in vitro- und in vivo Messungen. Die in vivo Messung mit physiologischen Konzentrationen an Threonin (ca. 0,35- und 0,2 $\mathrm{mM}$ ) ist letztendlich erforderlich, um 
genauere quantitative Kenntnisse über den Threoninabbau zu Glycin durch die TDG zu ermitteln. Trotzdem könnte nach Aussagen von BIRD et al. (1984) und BALLÈVRE et al. (1990) geschlussfolgert werden, dass ca. 60 - 80\% des Threonins zu Glycin abgebaut werden kann und dass eine de novo Synthese von Glycin aus Threonin durch den TDG-Weg für die Deckung eines höheren Bedarfs an Glycin als wichtiger metabolischer Weg in Frage kommt (LE FLOC'H et al. 1994).

XP-Überschüsse im untersuchten Bereich, so kann aus vorliegenden Untersuchungen geschlossen werden, stimulieren den Thr-Abbau bei der Ratte über den TDG-Weg nicht. Es liegen also keine Anzeichen für die zusätzliche Stimulierung des Threoninabbaues durch TDG bei differenziertem XP-Niveau vor. Dieser Befund unterscheidet sich deutlich von den Beobachtungen beim Küken.

\subsection{Zusammenhänge zwischen Protein- und Threoningehalt der Futtermischungen und TDG-Aktivität bei der Laborratte}

Durch die Erhöhung des Thr-Gehaltes von $0,28 \%$ auf $0,72 \%$ bei $12,0 \%$ XP bzw. von 0,42\% auf $0,72 \%$ bei $18,0 \%$ XP erhöhte sich der Threoninabbau signifikant (Abb. 10 und Tab. 25). Dieser Befund lässt erkennen, dass die TDG-Aktivität im Bereich minimaler und optimaler XP-Bedarfsdeckung vom Thr-Gehalt des Futters abhängt.

Im vorliegenden Versuch, in dem die Ratten mit Weizenkleber als Proteinquelle gefüttert wurden, lag die TDG-Aktivität bei 12,0\% XP (0,72\% Thr) nicht signifikant höher als bei der Diät mit 18,0\% XP (0,42\% Thr). In Versuch 6, in dem die Ratten mit Kasein als Proteinquelle ernährt wurden, lag die TDG-Aktivität bei der Diät mit 12,0\% XP (0,5\% Thr) dagegen signifikant höher als bei der Diät mit 18,0\% XP (0,75\% Thr). Dieser widersprüchliche Befund kann auch mit den verwendeten unterschiedlichen Proteinträgern zusammenhängen bzw. mit Differenzen im Thr-Niveau. Insgesamt aber sind weitere Untersuchungen erforderlich, um den genauen physiologischen Hintergrund zu eruieren.

Wie in Abb. 11 und Tab. 25 gezeigt wurde, hat die Threoninzulage von 0,42\% (Thrminimaler Bereich) auf $0,72 \%$ Thr (Thr-optimaler Bereich) bei 12,0\% XP (minimaler XPBereich) die TDG-Aktivität nicht weiter signifikant erhöht. Demgegenüber wurde bei Zulagen von $0,42 \%$ auf $0,72 \%$ Thr bei $18,0 \%$ XP (optimaler XP-Bereich) die TDG-Aktivität 
signifikant erhöht. Die beiden TDG-Aktivitäten stehen mit dem Ende des Limitierungsbereiches von Threonin in Verbindung. Diese Folgerungen wurden jeweils durch eine signifikant niedrigere Threoninwirksamkeit bestätigt.

LEE und LIEBERT (2000, 2001) zeigten bei Küken, dass der Anstieg des Threoninabbaus durch TDG mit signifikant geringerer Threoninwirksamkeit verbunden war. Das bedeutet, dass der Threoninabbau in vitro mit der gemessenen Threoninwirksamkeit in Zusammenhang stehen kann. Allerdings berechtigen die bisherigen Befunde nicht zu der Annahme, dass die in vitro gemessene TDG-Aktivität empfindlicher auf Thr-Wirksamkeitsunterschiede reagiert als die Bilanzmessung selbst. Weitere Untersuchungen sind unverzichtbar.

\subsection{Zum Threoninstoffwechsel von Laborratte und Küken in Abhängigkeit von der Protein-, Threonin- und Glycinversorgung}

Durch die Erhöhung des XP-Gehaltes im Futter wurde die Leber-TDG-Aktivität beim Küken deutlich erhöht. Bei Laborratten gab es keine Indikation für eine zusätzliche Stimulation der Threoninoxidation durch TDG bei Erhöhung des XP-Gehaltes in den Diäten (Abb. 19). Diese Erhöhung der TDG-Aktivität beim Küken könnte eine Reflexion des höheren Glycinbedarfes für die Harnsäurebildung sein. Offensichtlich liegen also tierartabhängige Reaktionen der TDG-Aktivität vor.

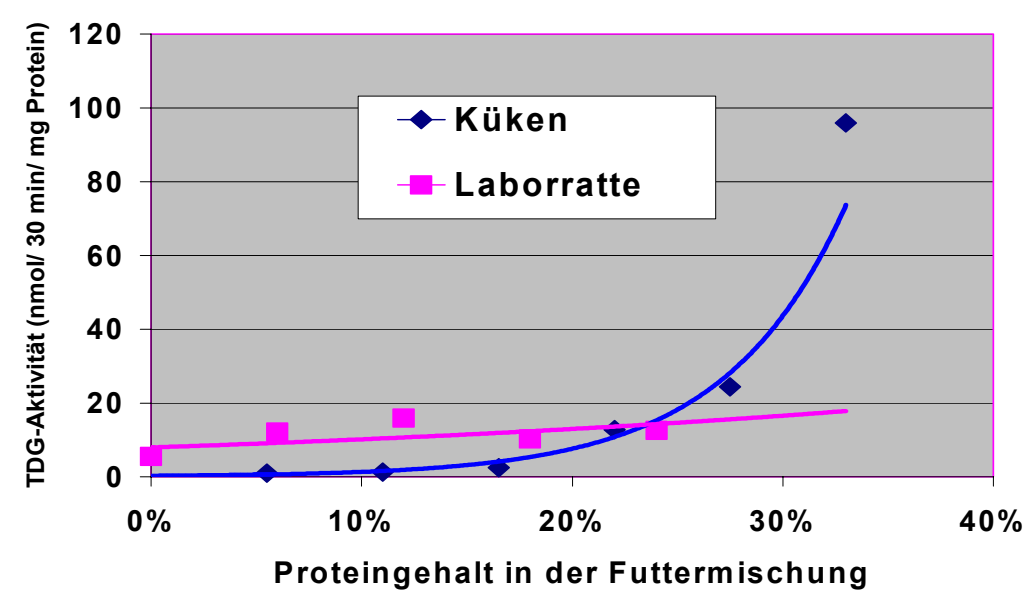

\section{Abb. 19: Verlauf der Leber TDG-Aktivität bei differenziertem Proteingehalt bei} Laborratte und Küken 
Beim Küken, im Bereich limitierter XP-Bedarfsdeckung, hängt die TDG-Aktivität bei Threoninzulage stärker vom XP-Gehalt $\mathrm{ab}$ und im Bereich optimaler XP-Versorgung verstärkt vom Thr-Gehalt; bei Laborratten im Bereich unterhalb der XP-Bedarfsdeckung hauptsächlich vom Thr-Gehalt. Beim Küken, im Bereich unterhalb optimaler XP-Versorgung, könnte die Thr-Wirksamkeit bei der vorliegenden Threoninzulage beim Abbau über den TDH-Weg des Threonins vermindert werden. Im Bereich optimaler XP-Bedarfsdeckung wird die Thr-Wirksamkeit bei einer Threoninzulage beim Abbau des Threonins durch TDG vermindert. Bei Laborratten, im Bereich minimaler- und optimaler XP-Bedarfsdeckung, wird die Thr-Wirksamkeit bei der Threoninzulage beim Abbau des Threonins durch TDG vermindert.

Die Thr-Wirksamkeit, die aus N-Bilanzmessungen mit dem exponentiellem NVerwertungsmodell abgeleitet wird, ist ein quantitatives Maß für die Thr-Verwertung. Die in vitro Messung der TDG-Aktivität ist ein qualitatives Maß für den Threoninabbau, dessen Resultat nicht durchgängig mit der in vivo Situation übereinstimmen muss. Vorliegende Befunde weisen aber durchaus eine gewisse Indikatorfunktion aus, die zur Abgrenzung des Threonin-Limitierungsbereiches genutzt werden kann.

DAVIS und AUSTIC (1997) haben gezeigt, dass auch die zelluläre Konzentration anderer Aminosäuren neben Threonin Einfluss auf die TDG-Aktivität der Leber von Küken haben kann. Dies wird unterstützt durch die Untersuchung von Le FLOC'H et al. (1994), in denen auch Glutaminsäure die TDG-Aktivität von Schweinen erhöht, die mit einem niedrigen ThrGehalt in der Diät gefüttert wurden. Dies wird auch unterstützt durch die Untersuchungen von DAVIS und AUSTIC (1982b, 1994), in denen die hepatische TDG-Aktivität nach der Zugabe spezifischer Aminosäuren oder einem Gemisch von essentiellen Aminosäuren ohne Threonin anstieg, was gleichzeitig die Möglichkeit bietet, Threonin-Imbalanzen hervorzurufen. Nach Angaben von SANCHEZ und SWENDSEID (1969) und DANIEL und WAISMAN (1969) zeigt sich auch, dass überschüssiges Methionin die hepatische Threonindehydratase-Aktivität in Ratten erhöht. Dieser Befund kann auch nach Auffassung von GOLDSTEIN et al. (1962) dadurch erklärt werden, dass Serindehydratase, Threonindehydratase und Cystathioninsynthetase (STIPANUK und BENEVENGA, 1977) Eigenschaften ein- und desselben Enzyms bei Ratten haben. Le FLOC'H et al. (1996) fanden, dass die meisten Enzyme des Aminosäurenkatabolismus nicht nur durch ein spezifisches Substrat stimuliert werden. Daraus lässt sich schließlich ableiten, dass die TDG-Aktivität nicht nur durch 
Threonin, sondern auch durch andere Aminosäuren oder auch durch andere Enzyme, die die gleichen Eigenschaften aufweisen, stimuliert werden kann. Natürlich schränkt diese Besonderheit die Spezifik der Interpretation von TDG-Veränderungen ein.

Grundsätzlich gilt dies natürlich auch für die in vitro Aktivitätsmessungen, die in vivo Verhältnisse infolge eines anderen Substrat-Enzym-Verhätlnisses nur begrenzt reflektieren können.

Als zusätzlicher Indikator zur ergänzenden Beurteilung der aktuellen Stoffwechselsituation im Komplex Thr - Gly - Ser sind jedoch, bei Beherrschung des methodischen Umfeldes, Einsatzmöglichkeiten von in vitro Enzymaktivitätsmessungen $\mathrm{zu}$ einer komplettierenden Beurteilung des Ablaufes physiologischer Prozesse des Aminosäurestoffwechsels gegeben. 


\section{ZUSAMMENFASSUNG}

Ziel der vorliegenden Arbeit war es festzustellen, ob die unterschiedliche Versorgung mit Protein (XP), Threonin (Thr) und Glycin (Gly) bei einer limitierten Threoninversorgung einen Einfluss auf die Threonindehydrogenase-Aktivität (TDG-Aktivität) in der Leber von Küken und Laborratten hat.

Dazu wurden 7 Versuche mit federgesexten männlichen Cobb-Küken und weißen WistarRatten in verschiedenen Altersstufen und Lebendmassebereichen durchgeführt:

Versuch 1: Küken vom 15. - 25. Lebenstag bei unterschiedlichen Rohproteingehalten. Die kalkulierten XP-Gehalte lagen bei 5,5\%;11,0\%; 16,5\%; 22,0\%; 27,5\% und 33,0\%.

Versuch 2: Küken vom 17. - 30. Lebenstag bei XP-Gehalten von 18,5\% und 22,5\% mit jeweils 2 Threoninstufen von $0,45 \%$ und $0,60 \%$ wahr fäcal verdaulichem Threonin.

Versuch 3: Küken vom 10. - 20. Lebenstag bei XP-Gehalten von 16,5\% und 22,0\% und einer Steigerung des Threoningehaltes von $0,65 \%$ auf $0,79 \%$ Threonin bei $16,5 \%$ XP und $0,86 \%$ auf $1,05 \%$ Threonin bei $22,0 \%$ XP.

Versuch 4: Küken vom 1. - 49. Lebenstag in Bodenhalten bei praxisnaher Phasenfütterung. Die Prüfung der Leber-Threonindehydrogenase erfolgte am 7., 21., 35. und 49. Lebenstag.

Versuch 5: Küken vom 5. - 15. Lebenstag bei einem XP-Gehalt von einheitlich 22,0\% und Glycingehalten von $0,64 \%$ und $0,98 \%$ und wahr fäcal verdaulichen Threoningehalten von $0,45 \%$ und $0,60 \%$ bei $0,64 \%$ bzw. $0,98 \%$ Glycingehalt. Die Gly+Ser-Gehalte betrugen insgesamt $1,55 \%$ bzw. $1,90 \%$.

Versuch 6: Weiße Wistar-Ratten im Lebendmassebereich von $106-140 \mathrm{~g}$ bei XP-Gehalten von $0 \%, 6,0 \%, 12,0 \%, 18,0 \%$ und $24,0 \%$. 
Vesuch 7: Weiße Wistar-Ratten im Lebendmassebereich von 149 - $167 \mathrm{~g}$ und XP-Gehalten von $12,0 \%$ und $18,0 \%$ mit unterschiedlichen Threoningehalten von $0,28 \%, 0,42 \%$ und $0,72 \%$ bei $12,0 \%$ XP bzw. $0,42 \%, 0,52 \%$ und $0,72 \%$ bei $18,0 \%$ XP.

Am Ende des jeweiligen Vesuches wurden die Lebern von jeweils 6 Tieren entnommen und für die Bestimmung der TDG-Aktivität in vitro aufbereitet.

Die Threoninwirksamkeiten wurden aus N-Bilanzversuchen mit einem exponentiellen NVerwertungsmodell abgeleitet.

Folgende Ergebnisse wurden erzielt:

1. Durch die Erhöhung der XP-Gehalte stieg die TDG-Aktivität in der Kükenleber ab 22,0\% $\mathrm{XP}$ in der Futtermischung trotz limitierter Threoninversorgung signifikant an. Die Threoninwirksamkeit war unverändert bis zu einem XP-Gehalt von 27,5\% und fiel bei 33,0\% XP signifikant ab. D. h. durch einen verstärkten Abbau von Threonin durch die TDG erfolgte eine Verminderung der Thr-Wirksamkeit bei der Futtermischungen mit hohem XP-Gehalt.

2. Bei einem XP-Gehalt von $18,5 \%$ und einem Anstieg der Thr-Konzentration von 0,45\% auf $0,60 \%$ dThr zeigte sich kein Einfluss auf die TDG-Aktivität in der Kükenleber, wohl aber bei einem XP-Gehalt von 22,5\% und einem Gehalt von $0,60 \%$ dThr war die TDGAktivität in der Kükenleber erhöht. Das könnte den Bereich angeben, in dem Threonin nicht mehr limitierend wirkt.

3. Bei einem Gehalt von $16,5 \%$ XP und einem Anstieg der Thr-Konzentration von $0,65 \%$ auf 0,79\% wurde kein Einfluss auf die TDG-Aktivität in der Kükenleber ermittelt, dagegen stieg die TDG-Aktivität bei einem Gehalt von 22,0\% XP und einer Erhöhung des ThrGehaltes von $0,86 \%$ auf $1,05 \%$ signifikant an.

4. Im Verlauf des Phasenfütterungsversuches zeigten sich altersabhängige Veränderungen der TDG-Aktivität, die mit Phasen eines besonders hohen metabolischen Bedarfes an Glycin erklärt weden können. 
5. Bei einem XP-Gehalt von 22,0\% (Gly + Ser-Gehalt 1,55\%) führte die Erhöhung des ThrGehaltes von $0,45 \%$ auf $0,60 \%$ dThr zu einer mehreren Akkumulation von Gly in den Lebermitochondrien, jedoch nicht signifikantem Anstieg der TDG-Aktivität. Bei 1,90\% Gly+Ser und 22,0\% XP stieg die TDG-Aktivität nach Thr-Zulage signifikant an. Dieser Befund weist auf das Ende des Thr-Limitierungsbereiches hin.

6. Bei Laborratten lag die TDG-Aktivität bei einer proteinfreien Ration am niedrigsten, erhöhte sich bei einer XP-Steigerung bis 12,0\% XP, verringerte sich geringfügig bis $18,0 \%$ XP und stieg von $18,0 \%$ bis $24,0 \%$ XP tendenziell an. Insgesamt beeinflusste das XP-Niveau die TDG-Aktivität aber nur zufällig.

7. Der Anstieg des Thr-Gehaltes von $0,28 \%$ auf $0,72 \%$ bei $12,0 \%$ XP bewirkte einen allmählichen Anstieg der TDG-Aktivität in den Rattenlebermitochondrien. Das trifft ebenfalls für die Futtermischung mit 18,0\% XP zu, allerdings auf einem etwas höheren Niveau. Die TDG-Aktivität wurde nahezu ausschließlich durch die Aminoacetonakkumulierung moduliert. TDG-Aktivität und Thr-Wirksamkeit zeigten das Ende des Thr-Limitierungsbereiches an. Die in vitro TDG-Aktivitäten der Leber von Küken und Laborratten wird demnach nicht nur durch die Thr-Konzentrationen im Futter sondern auch vom XP-Gehalt und damit dem Angebot anderer Aminosäuren sowie vom Alter beeinflusst. Da offensichtlich Zusammenhänge zur unspezifischen Katabolisierungsrate anderer Aminosäuren bestehen, wird die Interpretation von TDGVeränderungen (in vitro) erschwert. Bezüge zum Parameter Thr-Wirksamkeit sind mit Einschränkungen deutlich geworden und müssen, bevor quantitative Aussagen möglich sind, weiter erforscht werden. 


\section{SUMMARY}

Aim of this research was to determine the effects of different supply of crude protein (CP), threonine (Thr) and glycine (Gly) on threonine dehydrogenase activity (TDG activity) in the liver of chickens and laboratory rats under conditions of different threonine supply. A total of 7 experiments with feather-sexed male Cobb chickens and white Wistar rats were done in different age periods:

Experiment 1: Chicken day 15-25, different CP contents. The calculated CP contents were $5.5 \%, 11.0 \%, 16.5 \%, 22.0 \%, 27.5 \%$ and $33.0 \%$.

Experiment 2: Chicken day $17-30,18.5 \%$ and $22.5 \% \mathrm{CP}$ and $0.45 \%$ and $0.60 \%$ true fecal digestible threonine (dThr).

Experiment 3: Chicken day 10-20, 16.5\% and 22.0\% CP and different threonine levels.

Experiment 4: Chicken day 1-49, standard feeding program. Determination of liver threonine dehydrogenase at days 7, 21, 35 and 49.

Experiment 5: Chicken day 5-15, 22.0\% CP content, different glycine and threonine levels.

Experiment 6: White Wistar rats in live weight range from 106-140 g with CP contents of 0\%, $6.0 \%, 12.0 \%, 18.0 \%$ and $24.0 \%$.

Experiment 7: White Wistar rats in live weight range from 149-167 g and CP contents of $12.0 \%$ and $18.0 \%$ with different threonine levels.

At the end of the experiments the livers were taken from 6 animals for the in vitro TDG assay.

The threonine efficiency was calculated from results of N-balance trials with an exponential N-utilization model. 
Summary of the Results:

1. The elevation in CP content caused a significant increase in TDG activity in the livers of chickens starting at $22.0 \% \mathrm{CP}$ in the feed mixtures despite a limited threonine supply. Threonine efficiency remained unchanged up to an CP content of $27.5 \%$, dropping off significantly at $33.0 \% \mathrm{CP}$. This means that an intensified TDG-induced breakdown of threonine caused a reduction in threonine efficiency in the feed mixtures with a high CP content.

2. There was no effect on the TDG activity in the chick liver in the presence of an CP content of $18.5 \%$ and an increase in threonine concentration from $0.45 \%$ to $0.60 \%$ dThr. However, TDG activity in the chick liver was elevated at an CP content of $22.5 \%$ and a $0.60 \%$ content of $\mathrm{dThr}$. These findings might delineate the range in which threonine no longer has a limiting effect.

3. At a content of $16.5 \% \mathrm{CP}$ and an increase in the Thr concentration from $0.65 \%$ to $0.79 \%$, no influence on TDG activity was determined in the chick liver. By contrast, there was a significant increase in TDG activity when the CP content was $22.0 \%$ and the Thr content increased from $0.86 \%$ to $1.05 \%$.

4. During the course of the phase-feeding experiment, there proved to be age-dependent changes in TDG activity that can be explained as phases in which a specifically high metabolic need for glycine existed.

5. At an CP content of $22.0 \%$ (Gly + Ser content $1.55 \%)$, the elevation in Thr content from $0.45 \%$ to $0.60 \%$ dThr led to an increased accumulation of Gly in the liver mitochondria, but not to a significant increase in TDG activity. After adding Thr at $1.90 \%$ Gly + Ser and $22.0 \% \mathrm{CP}$, TDG activity increased significantly. This finding would indicate the end of the Thr limit range.

6. In laboratory rats fed on a protein-free diet, TDG activity was at its lowest, increased during an $\mathrm{CP}$ rise to $12.0 \% \mathrm{CP}$, decreased slightly down to $18.0 \% \mathrm{CP}$ and showed a trend to increase from $18.0 \%$ to $24.0 \% \mathrm{CP}$. Overall, the CP level only had a random effect on TDG activity. 
7. The increase in Thr content from $0.28 \%$ to $0.72 \%$ in the presence of $12.0 \% \mathrm{CP}$ caused a gradual increase in TDG activity in rat liver mitochondria. This similarly applied to the feed admixed with $18.0 \% \mathrm{CP}$, but at a higher level. The TDG activity was almost exclusively modulated by amino acetone accumulation. TDG activity and Thr efficiency would indicate the end of the Thr limit range. Accordingly, the in vitro TDG activity in the livers of chicks and laboratory rats is not solely affected by the Thr concentration in the feed, but also by the CP content and, hence, by the supply of other amino acids and by the animal's age. Interpretation of the TDG changes (in vitro) is difficult since there are apparent connections to the non-specific catabolism rate of other amino acids. There is obvious, albeit limited evidence of connections to the parameter of Thr efficiency. Further research is required before quantitative conclusions can be drawn. 


\section{LITERATURVERZEICHNIS}

AGUILAR, T. S. ; BENEVENGA, N. J. ; HARPER, A. E., 1974 : Effect of dietary methionine level on its metabolism in rats.

J. Nutr. 104, 761-771.

AKOPOV, M. A. ; KAGAN, Z. S. ; BEREZOV, T. T. ; FILIPTSEV, P. Y., 1979 :

Detection and properties of L-threonine-L-serine dehydratase in human liver.

Biochem. (Engl. Transl.) $\underline{43}$, 1466-1476.

AOYAMA, Y.; MOTOKAWA, Y., 1981: L- Threonine dehydrogenase of chicken liver ; purification, characterization and physiological significance.

J. Biol. Chem. 256, 12367-12373.

BAKER, D. H. ; HAN, Y., 1994 : Ideal amino acid profile for chicks during the first three weeks posthatching.

Poult. Sci. $\underline{73}$, 1441-1447.

BAKER, D. H. ; HILL, T. M. ; KLEISS, A. J., 1972 : Nutritional evidence concerning formation of glycine from threonine in the chick.

J. Anim. Sci. 34, 582-586.

BAKER, D. H. ; SUGAHARA, M. ; SCOTT, H. M., 1968 : The glycine-serine interrelationship in chick nutrition.

Poult. Sci. 47, 1376-1377.

BALlÈVRE, O. ; CADENHEAD, A. ; CALDER, A.G. ; REES, W.D. ; LOBLEY, G.E. ; FULLER, M.F. ; GARLICK, P.J., 1990 : Quantitative partition of threonine oxidation in pigs; effect of dietary threonine.

Am. J. Physiol. 259, E483-E491. 
BALlÈVRe, O. ; HOUlier, M. -L. ; PRUGNAUD, J. ; BAYLE, G. ; BERCOVICI, D. ; SEVE, B. ; ARNALZ, M.,1991 : Altered partition of threonine metabolism in pigs by protein-free feeding or starvation.

Am. J. Physiol. 261, E748-E757.

BENEVENGA, N. J. ; GAHL, M. J. ; BLEMINGS, K. P., 1993 : Role of protein synthesis in amino acid catabolism.

J. Nutr. $\underline{123}, 332-336$.

BENEVENGA, N. J. ; GAHL, M. J. ; CRENSHAW, T. D. ; FINKE, M. D., 1994 : Protein and amino acid requirements for maintenance and amino acid requirements for growth of laboratory rats.

J. Nutr. 124, 451-453.

BERGMEYER, H. U., 1974 : Methoden der enzymatischen Analyse (Band 1 und 2).

3. Auflage.

Verlag Chemie, Weinheim.

BERTOLO, R. F. P. ; CHEN, C. Z. L. ; LAW, G. ; PENCHARZ, P. B. ; BALL, R. O., 1998 : Threonine requirement of neonatal piglets receiving total parenteral nutrition is considerably lower than that of piglets receiving an identical diet intragastrically. J. Nutr. $128,1752-1759$.

BIRD, M. I. ; LORD, L. A. J. ; NUNN, P. B., 1982 : Catabolism of L-threonine in rat and human liver ; Importance of threonine dehydrogenase.

Biochem. Soc. Trans. $\underline{10}, 130$.

BIRD, M. I. ; NUNN, P. B., 1979 : Glycine formation from L-threonine in intact isolated rat liver mitochondria.

Biochem. Soc. Trans. $\underline{7}$, 1276-1277.

BIRD, M. I. ; NUNN, P. B., 1983 : Metabolic homoeostasis of L-threonine in the normally-fed rat.

Biochem. J. 214, 687-694. 
BIRD, M. I. ; NUNN, P. B. ; LORD, L. A. J., 1984 : Formation of glycine and aminoacetone from L-threonine by rat liver mitochondria.

Biochim. Biophys. Acta. $\underline{802}$, 229-236.

BLOXAM, D. L., 1975 : Restriction of hepatic gluconeogenesis and ureogenesis from threonine when at low concentrations.

Am. J. Physiol. 229, 1718-1723.

BOYLAN, S. A. ; DEKKER, E. E., 1981 : L-threonine dehydrogenase, purification and properties of the homogeneous enzyme from Escherichia coli k-12.

J. Biol. Chem. 256, 1809-1815.

BROOKES, I. M. ; OWENS, F. N. ; BROWN, R. E. ; GARRIGUS, U. S., 1973 : Amino acid oxidation and plasma amino acid levels in sheep with abomasal infusion of graded amounts of lysine.

J. Anim. Sci. $\underline{36}$, 965-970.

BROOKES, I. M. ; OWENS, F. N. ; GARRIGUS, U. S., 1972 : Influence of amino acid level in the diet upon amino acid oxidation by the rat.

J. Nutr. 102, 27-36.

CHU, S. W. ; HEGSTED, D. M., 1976 : Adaptive response of lysine and threonine degrading enzymes in adult rats.

J. Nutr. $\underline{106}, 1089-1096$.

COON, C. N. ; GROSSIE, V. B. ; COUCH, J. R., 1974 : Glycine-serine requirement for chicks.

Poult. Sci. 53, 1709-1713.

COOPER, T. G., 1981 : Protein-Bestimmung mit der Biuret-Reaktion. In : COOPER, T. G.

1. Ed. : Biochemische Arbeitsmethoden.

Walter de Gruyter Verlag, Berlin, 49-51. 
DALE, R. A., 1978 : Catabolism of threonine in mammals by coupling of L-threonine 3-dyhydrogenase with 2-amino-3-oxobutyrate-CoA ligase.

Biochim. Biophys. Acta. 544, 496-503.

DANIEL, R. G. ; WAISMAN, H. A., 1969 : Adaptation of the weaning rat to diets containing excess methionine.

J. Nutr. $\underline{99}$, 299-306.

DARLING, P. B. ; DUNN, M. ; SARWAR, G. ; BROOKES, S. ; BALL, R. O. ; PENCHARZ, P. B., 1999 : Threonine kinetics in preterm infants fed their mothers' milk or formula with various ratios of whey to casein.

Am. J. Clin. Nutr. $\underline{69}$, 105-114.

DARLING, P. B. ; GRUNOW, J. ; RAFII, M. ; BROOKES, S. ; BALL, R. O. ; PENCHARZ, P. B., 2000 : Threonine dehydrogenase is a minor degradative pathway of threonine catabolism in adult humans.

Am. J. Physiol. 278, 877-884.

DAVIS, A. J. ; AUSTIC, R. E., 1994 : Dietary threonine imbalance alters threonine dehydrogenase activity in isolated hepatic mitochondria of chicks and rats. J. Nutr. 124, 1667-1677.

DAVIS, A. J. ; AUSTIC, R. E., 1997 : Dietary protein and amino acid levels alter threonine dehydrogenase activity in hepatic mitochondria of Gallus domesticus. J. Nutr. $127,738-744$.

DAVIS, A. T. ; AUSTIC, R. E., 1982a : Threonine degrading enzymes in the chicken. Poult. Sci. $\underline{61,2107-2111 .}$

DAVIS, A. T. ; AUSTIC, R. E., 1982b : Threonine metabolism of chicks fed threonineimbalanced diets.

J. Nutr. 112, 2177-2186. 
DEVLIN, T. M., 1997 : Textbook of biochemistry with clinical correlations. 4. Ed., Wiley-Liss publishers, New York.

FREEDLAND, R. A. ; AVERY, E. H., 1964 : Studies on threonine and serine dehydrase. J. Biol. Chem. 239, 3357-3360.

FULLER, M. F. ; MCWILLIAM, R. ; WANG, T. C. ; GILES, L. R., 1989 : The optimum dietary amino acid pattern for growing pigs. 2. Requirements for maintenance and for tissue protein accretion.

Br. J. Nutr. $\underline{62}, 255-267$.

GAHL, M. J. ; FINKE, M. D. ; CRENSHAW, T. D. ; BENEVENGA, N. J., 1991 : Use of a four-parameter logistic equation to evaluate the response of growing rats to ten levels of each indispensable amino acid.

J. Nutr. 121, 1720-1729.

GEBHARDT, G., 1963 : Die Bewertung des Futtereiweißes nach dem N-Bilanzverfahren an wachsenden Tieren.

Habil.-Schrift, Halle.

GEBHARDT, G., 1966 : Die Bewertung der Eiweißqualität von Nahrungs- und Futtermitteln mit Hilfe des N-Bilanzversuches. In: HOCK, A. (Hrsg.): Vergleichende Ernährungslehre des Menschen und seiner Haustiere. Fischer Verlag, Jena, 228-348.

GEBHARDT, G., 1980 : Eiweiß- und Aminosäurenverwertung in Beziehung zum Stoffwechsel der limitierenden Aminosäure.

Arch. Anim. Nutr. 30, 63-71.

GOLDSTEIN, L. ; KNOX, W. E. ; BEHRMAN, E. J., 1962 : Studies on the nature, inducibility and assay of the threonine and serine dehydrase activities of rat liver.

J. Biol. Chem. 237, 2855-2860. 
GREEN, M. L. ; ELLIOTT, W. H., 1964 : The enzymic formation of aminoacetone from threonine and its further metabolism.

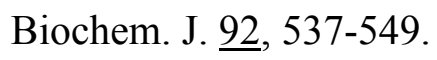

GUSTAFSON, J. M. ; DODDS, S. J. ; BURGUS, R. C. ; MERCER, L. P., 1986 :

Prediction of brain and serum free amino acid profiles in rats fed graded levels of protein.

J. Nutr. 116, 1667-1681.

HARTSHORNE, D. ; GREENBERG, D. M., 1964 : Studies on liver threonine dehydrogenase.

Arch. Biochem. Biophys. 105, 173-178.

HORSZCZARUK, F. ; BOCK, H. -D., 1963 : Eine Modifikation des von K. Schiller vorgeschlagenen Stoffwechselkäfigs für Ratten.

Z. Versuchstierkunde $\underline{2}, 126-131$.

INOUE, H. ; KASPER, C. B. ; PITOT, H. C., 1971 : Studies on the induction and repression of enzymes in rat liver.

J. Biol. Chem. 246, 2626-2632.

INOUE, H. ; PITOT, H. C., 1970 : Regulation of the synthesis of serine dehydratase isozymes.

Adv. Enz. Regul. ㅁ, 289-296.

KANG-LEE, Y. A. ; HARPER, A. E., 1977 : Effect of histidine intake and hepatic histidase activity on the metabolism of histidine in vivo.

J. Nutr. 107, 1427-1443.

KANG-LEE, Y. A. ; HARPER, A. E., 1978 : Threonine metabolism in vivo ; Effect of threonine intake and prior induction of threonine dehydratase in rats.

J. Nutr. 108, 163-175. 
KARASEK, M. A. ; GREENBERG, D. M., 1957 : Studies on the properties of threonine aldolases.

J. Biol. Chem. 227, 191-205.

KIM, K. I. ; McMILLAN, I. ; BAYLEY, H. S., 1983 : Determination of amino acid requirements of young pigs using an indicator amino acid.

Br. J. Nutr. 무, 369-382.

KIRCHGESSNER, M., 1992 : Tierernährung. 8. Auflage.

DLG-Verlag, Frankfurt (Main).

KÖHLER, R. ; GEBHARDT, G., 1979 : Untersuchungen zum Zusammenhang zwischen Proteinqualität, Höhe der Proteingabe und endogener N-Ausscheidung. Arch. Anim. Nutr. 29, 679-690.

LAVER, W. G. ; NEUBERGER, A. ; SCOTT, J. J., 1959 : $\alpha$-Amino- $\beta$-keto-acids. ; Rates of decarboxylation of the free acids and the behaviour of derivatives on titration.

J. Chem. Soc. $\underline{2}, 1483-1491$.

LAYNE, E., 1957 : Spectrophotometric and turbidimetric methods for measuring proteins, 3. Biuret Method.

Methods Enzymol. $\underline{3}, 447-454$.

LEE, C. W. ; LIEBERT, F., 2000 : Influence of protein supply on threonine dehydrogenase activity in the liver of growing chicken.

Proc. Soc. Nutr. Physiol. $\underline{9}, 113$.

LEE, C. W. ; LIEBERT, F., 2001 : Comparative study about the effect of protein supply on in vitro threonine dehydrogenase activity in the liver of laboratory rats and chicken.

Proc. Soc. Nutr. Physiol. $10,85$. 
LEE, C. W. ; RIMBACH, M. ; LIEBERT, F., 2001 : Effect of protein and threonine level in the diet on in vitro liver threonine dehydrogenase activity in the chicken.

Proc. Soc. Nutr. Physiol. $10,84$.

Le FLOC'H, N. ; OBLED, C. ; SÈVE, B., 1995 : In vivo threonine oxidation rate is dependent on threonine dietary supply in growing pigs fed low to adequate levels.

J. Nutr. 125, 2550-2562.

Le FLOC'H, N. ; OBLED, C. ; SÈVE, B.,1996 : In vivo threonine oxidation in growing pigs fed on diets with graded levels of threonine.

Br. J. Nutr. $\underline{75}$, 825-837.

Le FLOC'H, N. ; SÈVE B. ; HENRY Y., 1994 : The addition of glutamic acid or protein to a threonine-deficient diet differentially affects growth performance and threonine dehydrogenase activity in fattening pigs.

J. Nutr. 124, 1987-1995.

Le FLOC'H, N. ; THIBAULT, J-N ; SÈVE, B.,1997 : Tissue localization of threonine oxidation in pigs.

Br. J. Nutr. $\underline{77}$, 593-603.

LIEBERT, F., 1995 : Untersuchungsergebnisse zur Lysinverwertung bei wachsenden monogastrischen Tieren unter besonderer Beachtung unterschiedlicher Lysinquellen.

Arch. Anim. Nutr. 47, 373-380.

LIEBERT, F. ; WECKE, C. ; REINISCH, F. ; GEBHARDT, G., 1991 : Neue Ergebnisse und Aufgaben zur Lysinwirksamkeitsbeurteilung in Futtermitteln für Monogastriden.

Arch. Anim. Nutr. 41, 279-294. 
MADRY, M., 1989 : Versuchstierernährung. In : HEINECKE, H. (Hrsg.) : Angewandte Versuchstierkunde.

VEB Gustav Fischer Verlag, Jena, 116-144.

MALKIN, L. I. ; GREENBERG, D. M., 1964 : Purification and properties of threonine or allothreonine aldolase from rat liver.

Biochim. Biophys. Acta. $\underline{85}$, 117-131.

MATTENHEIMER, H., 1971 : Die Theorie des enzymatischen Tests. Biochemica. Boehringer, Mannheim.

MAUZERALL, D. ; GRANICK, S., 1956 : The occurrence and determination of $\delta$ aminolevulinic acid and porphobilinogen in urine.

J. Biol. Chem. 219, 435-446.

McGILVRAY, D. ; MORRIS, J. G., 1969 : Utilization of L-threonine by a species of Arthrobacter; A novel catabolic role for aminoacetone synthase.

Biochem. J. 112, 657-671.

McGILVRAY, D. ; MORRIS, J. G., 1971 : L-threonine dehydrogenase (Arthrobacter). Methods Enzymol. 17B, 580-584.

MELTZER, H. L.; SPRINSON, D. B., 1952 : The Synthesis of $4-\mathrm{C}^{14}, \mathrm{~N}^{15}$-L-threonine and a study of its metabolism.

J. Biol. Chem. 197, 461-474.

MERCER, L. P. ; MAY, H. E. ; DODDS, S. J., 1989 : The determination of nutritional requirements in rats : Mathematical modeling of sigmoidal, inhibited nutrientresponse curves.

J. Nutr. $119,1465-1471$. 
MILLWARD, D. J., 1998 : Metabolic demands for amino acids and the human dietary requirement : MILLWARD and RIVERS (1988) revisited.

J. Nutr. $\underline{128}, 2563$ S-2576S.

MÜLLER, R., 1964 : Vorschrift zur Proteinbewertung in Versuchen an wachsenden Ratten.

Z. Tierphysiol., Tierernährg. u. Futtermittelkde. $\underline{19}$, 305-308.

NAKAGAWA, H. ; KIMURA, H., 1969 : The properties of crystalline serine dehydratase of rat liver.

J. Biochem. $\underline{66}, 669-683$.

NEHRING, K. ; BOCK, H. D. ; WÜNSCHE, J., 1967 : Festlegungen zur Standardisierung der N-Bilanzmethode an wachsenden Albinoratten für die Qualitätsbeurteilung von Futterproteinen.

Sitzungsber., Dt. Akad. Landw. Wiss., Berlin, XVI, H. 9, 61-63.

NELSON, D. L. ; COX, M. M., 2000 : Lehninger principles of biochemistry. 3. Ed., Worth publishers, New York.

NIESS, E., 1978 : Ursachen und Folgen von Aminosäure-Imbalanzen beim monogastrischen Nutztier.

Kraftfutter $\underline{61}, 686-690$.

NRC (National Research Council 1978) : Nutrient requirements of laboratory animals.

3. Rev. Ed.

National Academy of sciences, Washington, D.C.

NRC (National Research Council 1994) : Nutrient requirements of poultry. 9. Rev. Ed. National Academy Press, Washington D.C.

NRC (National Research Council 1995) : Nutrient requirements of laboratory animals.

4. Rev. Ed.

National Academy Press, Washington D.C. 
PAGANI, R. ; LEONCINI, R. ; TERZUOLI, L. ; CHEN, J. ; PIZZICHINI, M. ; MARINELLO, E., 1991 : DL-Allothreonine and L-threonine aldolase in rat liver.

Biochem. Soc. Trans. 19, 346S.

PAHLE, T. ; KÖHLER, R. ; MÜLLER, M., 1993 : Bestimmung der endogenen NAusscheidungen sowie der N-Bilanz im Bereich geringer N-Aufnahmen an Ratten. Arch. Anim. Nutr. $\underline{43}$, 117-132.

PENCHARZ, P. B. ; HOUSE, J. D. ; WYKES, L. J. ; BALL, R. O., (1996) : What are the essential amino acids for the preterm and term infant? Zit. n. DARLING et al. 1999.

PETERS, J. C. ; HARPER, A. E., 1985 : Adaptation of rats to diets containing different levels of protein : Effects on food intake, plasma and brain amino acid concentrations and brain neurotransmitter metabolism.

J. Nutr. $115,382-398$.

PÜSCHNER, A. ; SIMON, O., 1988 : Grundlagen der Tierernährung. 4. Auflage. Ferdinand Enke Verlag, Stuttgart.

RANGEL-LUGO, M. ; SU, C.-L. ; AUSTIC, R. E., 1994 : Threonine requirement and threonine imbalance.

Poult. Sci. $\underline{73}$, 670-681.

RAY, M. ; RAY, S., 1985 : L-threonine dehydrogenase from goat liver. J. Biol. Chem. 260, 5913-5918.

RIMBACH, M., : Dissertation in Vorbereitung. Diss. sc. agr., Göttingen. 
RIMBACH, M. ; BUSS, B. O. ; LIEBERT, F., 2000 : Zum Einfluß des Rohprotein- und Threoningehaltes der Ration auf Parameter der scheinbaren ilealen Aminosäurenverdaulichkeit sowie der Threoningesamtwirkung in unterschiedlichen Altersabschnitten beim Broiler. In: RODEHUTSCORD, M. ; NONN, H. ; EDER, K. (Hrsg.): 6. Tagung Schweine- und Geflügelernährung.

Fachverlag Köhler, Gießen, 19 - 21.

RIMBACH, M. ; LIEBERT, F., 1999 : N-Umsatzparameter aktueller Broilergenotypen in differenzierten Altersabschnitten.

Proc. Soc. Nutr. Physiol. $\underline{8}, 49$.

RIMBACH, M. ; LIEBERT, F., 2000 : Ergebnisse zum altersabhängigen Threoninbedarf aktueller Broilergenotypen.

Proc. Soc. Nutr. Physiol. $\underline{9}, 106$.

ROGERS, Q. R. ; HARPER, A. E., 1965 : Amino acid diets and maximal growth in the rat. J. Nutr. $\underline{87}, 267-273$.

SANCHEZ, A. ; SWENDSEID, M. E., 1969 : Amino acid levels and enzyme activity in tissues of rats force-fed diets differing in methionine content.

J. Nutr. $\underline{99}, 145-151$.

SCHENCK, M. ; KOLB, E., 1990 : Grundriß der physiologischen Chemie. 8. Aufl., Gustav Fischer Verlag, Jena.

SCHIRCH, L. ; GROSS, T., 1968 : Serine transhydroxymethylase : Identification as the threonine and allothreonine aldolases.

J. Biol. Chem. 243, 5651-5655.

SCHNEIDER, W. C. ; HOGEBOOM, G. H., 1950 : Intracellular distribution of enzymes.

V. Further studies on the distribution of cytochrome $\mathrm{c}$ in rat liver homogenates.

J. Biol. Chem. 183, 123-128. 
SCHUTTE, J. B. ; SMINK, W. ; PACK, M., 1997 : Requirement of young broiler chicks for glycine + serine.

Arch. Geflügelk. 61, 43-47.

STIPANUK, M. H. ; BENEVENGA, N. J., 1977 : Effect of cystine on the metabolism of methionine in rats.

J. Nutr. 107, 1455-1467.

SUELTER, C. H., 1990 : Experimentelle Enzymologie.

Gustav Fischer Verlag, Stuttgart.

TORRES, N. ; BERISTAIN, L. ; BOURGES, H. ; TOVAR, A. R., 1999 : Histidineimbalanced diets stimulate hepatic histidase gene expression in rats.

J. Nutr. 129 , 1979-1983.

TORRES, N. ; MARTÍNEZ, L. ; ALEMÁN, G. ; BOURGES, H. ; TOVAR, A. R., 1998 : Histidase expression is regulated by dietary protein at the pretranslational level in rat liver.

J. Nutr. $128,818-824$.

TRESSEL, T. ; THOMPSON, R. ; ZIESKE, L. R. ; MENENDEZ, M. I. T. S. ; DAVIS, L., 1986 : Interaction between L-threonine dehydrogenase and aminoacetone synthetase and mechanism of aminoacetone production.

J. Biol. Chem. 261, 16428-16437.

URATA, G. ; GRANICK, S., 1963 : Biosynthesis of $\alpha$-aminoketones and the metabolism of aminoacetone.

J. Biol. Chem. 238, 811-820.

VDLUFA, 1988 : Bestimmung von Aminosäuren. In: Methodenbuch 3, 2. Erg. 1-5. 
WILSON, D. C. ; RAFII, M. ; BALL, R. O. ; PENCHARZ, P. B., 2000 : Threonine requirement of young men determined by indicator amino acid oxidation with use of L- $\left[1-{ }^{13} \mathrm{C}\right]$ phenylalanine.

Am. J. Clin. Nutr. 71, 757-764.

WPSA., 1984 : The prediction of apparent metabolizable energy values for poultry in compound feeds.

Wld's Poult. Sci. J. $\underline{40}, 181-182$.

YAMASHITA, K. ; ASHIDA, K., 1971 : Effect of excessive levels of lysine and threonine on the metabolism of these amino acids in rats.

J. Nutr. 101, 1607-1614.

YEUNG, Y. G., 1986 : L-Threonine aldolase is not a genuine enzyme in rat liver. Biochem. J. 237, 187-190.

ZHAO, X. ; WEN, Z. M. ; MEREDITH, C. N. ; MATTHEWS, D. E. ; BIER, D. M. ; YOUNG, V. R., 1986 : Threonine kinetics at graded threonine intakes in young men.

Am. J. Clin. Nutr. $\underline{43}$, 795-802. 


\section{ABKÜRZUNGSVERZEICHNIS}

\begin{tabular}{|c|c|}
\hline Abb. & Abbildung \\
\hline Ala & Alanin \\
\hline Arg & Arginin \\
\hline AS & Aminosäure \\
\hline $\mathrm{Ca}$ & Calcium \\
\hline Cys & Cystin \\
\hline $\mathrm{d}$ & Tag \\
\hline dThr & wahr verdauliches Threonin \\
\hline FS & Frischsubstanz \\
\hline $\mathrm{g}$ & Erdbeschleunigung \\
\hline Glu & Glutaminsäure \\
\hline Gly & Glycin \\
\hline His & Histidin \\
\hline Ileu & Isoleucin \\
\hline $\mathrm{Kg}^{0,67}$ & metabolische Körpergröße \\
\hline Leu & Leucin \\
\hline LM & Lebendmasse \\
\hline LSD & List significant difference \\
\hline LT & Lebenstag \\
\hline Lys & Lysin \\
\hline M & Molarität \\
\hline $\mathrm{ME}_{\mathrm{N}-\mathrm{korr}}$ & N-korrigierte umsetzbare Energie \\
\hline Met & Methionin \\
\hline $\min$ & Minute \\
\hline MJ & Megajoule \\
\hline MW & Mittelwert \\
\hline $\mathrm{n}$ & Anzahl \\
\hline $\mathrm{N}$ & Stickstoff, Normalität \\
\hline $\mathrm{p}$ & Irrtumswarscheinlichkeit \\
\hline $\mathrm{P}$ & Phosphor \\
\hline Phe & Phenylalanin \\
\hline Pro & Prolin \\
\hline
\end{tabular}




$\begin{array}{ll}\text { XA } & \text { Rohasche } \\ \text { XL } & \text { Rohfett } \\ \text { XF } & \text { Rohfaser } \\ \text { XP } & \text { Rohprotein } \\ \text { SD } & \text { Standardabweichung } \\ \text { Ser } & \text { Serin } \\ \text { SPSS } & \text { Statistik-Programmpakete } \\ \text { TA } & \text { Threoninaldolase } \\ \text { Tab. } & \text { Tabelle } \\ \text { TDG } & \text { Threonindehydrogenase } \\ \text { TDH } & \text { Threonindehydratase } \\ \text { Thr } & \text { Threonin } \\ \text { Trp } & \text { Tryptophan } \\ \text { TS } & \text { Trockensubstanz } \\ \text { Tyr } & \text { Tyrosin } \\ \text { U/min } & \text { Umdrehung pro Minute } \\ \text { Val } & \text { Valin } \\ \text { Vit. } & \text { Vitamin }\end{array}$




\section{TABELLENANHANG}

Tab. A1: TDG-Aktivität in der Kükenleber $(n=6)$, Versuch 1

\begin{tabular}{|c|c|c|c|c|}
\hline \multirow[t]{2}{*}{ XP-Stufen (\%) } & \multirow[t]{2}{*}{ Lebermasse (g) } & \multicolumn{3}{|c|}{ TDG-Aktivität (nmol/ $30 \mathrm{~min} / \mathrm{mg}$ Protein) } \\
\hline & & Aminoaceton & Glycin & Gesamtaktivität \\
\hline \multirow[t]{6}{*}{$\mathbf{5 , 5 0}$} & 20,49 & $\overline{0,09}$ & 0,75 & 0,84 \\
\hline & 28,71 & 0,06 & 0,85 & 0,91 \\
\hline & 26,05 & 0,07 & 0,75 & 0,82 \\
\hline & 18,49 & 0,29 & 0,70 & 0,99 \\
\hline & 19,35 & 0,29 & 0,74 & 1,03 \\
\hline & 18,86 & 0,25 & 0,85 & 1,10 \\
\hline MW & 21,99 & 0,18 & 0,77 & 0,95 \\
\hline SD & 4,31 & 0,11 & 0,06 & 0,11 \\
\hline \multirow[t]{6}{*}{11,00} & 38,93 & 0,75 & 0,72 & 1,47 \\
\hline & 37,93 & 0,68 & 0,71 & 1,39 \\
\hline & 39,76 & 0,31 & 0,54 & 0,85 \\
\hline & 38,95 & 0,28 & 0,89 & 1,17 \\
\hline & 34,30 & 0,68 & 0,70 & 1,38 \\
\hline & 26,35 & 0,52 & 0,72 & 1,24 \\
\hline MW & 36,04 & $\mathbf{0 , 5 4}$ & 0,71 & 1,25 \\
\hline SD & 5,12 & $\mathbf{0 , 2 0}$ & $\mathbf{0 , 1 1}$ & $\mathbf{0 , 2 2}$ \\
\hline \multirow{6}{*}{16,5} & 30,11 & 1,27 & 0,95 & 2,22 \\
\hline & 34,82 & 1,54 & 0,87 & 2,41 \\
\hline & 22,22 & 1,40 & 1,39 & 2,79 \\
\hline & 34,41 & 1,94 & 0,88 & 2,82 \\
\hline & 32,65 & 1,25 & 0,93 & 2,18 \\
\hline & 33,66 & 1,55 & 0,88 & 2,43 \\
\hline MW & 31,31 & 1,49 & 0,98 & 2,48 \\
\hline SD & 4,76 & 0,25 & 0,20 & 0,27 \\
\hline \multirow[t]{6}{*}{22,00} & 27,81 & 9,11 & 3,07 & 12,18 \\
\hline & 36,22 & 7,89 & 2,65 & 10,54 \\
\hline & 30,45 & 9,12 & 3,08 & 12,2 \\
\hline & 34,61 & 10,07 & 2,35 & 12,42 \\
\hline & 29,26 & 9,38 & 4,61 & 13,99 \\
\hline & 34,10 & 7,88 & 7,52 & 15,4 \\
\hline MW & 32,08 & 8,91 & 3,88 & 12,79 \\
\hline SD & 3,36 & $\mathbf{0 , 8 7}$ & 1,95 & 1,68 \\
\hline \multirow[t]{6}{*}{27,50} & 21,97 & 8,13 & 7,29 & 15,42 \\
\hline & 18,37 & 11,03 & 13,37 & 24,4 \\
\hline & 27,08 & 9,53 & 18,98 & 28,51 \\
\hline & 30,43 & 7,53 & 10,17 & 17,7 \\
\hline & 26,52 & 14,79 & 12,72 & 27,51 \\
\hline & 28,36 & 15,16 & 17,67 & 32,83 \\
\hline MW & 25,46 & 11,03 & 13,37 & 24,40 \\
\hline SD & 4,46 & 3,29 & 4,42 & 6,68 \\
\hline \multirow[t]{6}{*}{ 33,00 } & 28,35 & 28,81 & 64,62 & 93,43 \\
\hline & 34,22 & - & - & - \\
\hline & 29,18 & 26,68 & 63,01 & 89,69 \\
\hline & 26,49 & 28,62 & 62,99 & 91,61 \\
\hline & 21,48 & 30,62 & 77,87 & 108,49 \\
\hline & 25,96 & 28,75 & 67,51 & 96,26 \\
\hline MW & 27,61 & 28,70 & 67,20 & 95,90 \\
\hline SD & 4,20 & 1,40 & 6,24 & 7,44 \\
\hline
\end{tabular}

- Ausreißer 
Tab. A2: TDG-Aktivität in der Kükenleber $(n=6)$, Versuch 2

\begin{tabular}{|c|c|c|c|c|}
\hline \multirow{2}{*}{$\begin{array}{l}\text { XP-/ Thr- } \\
\text { Stufen }\end{array}$} & \multirow[t]{2}{*}{ Lebermasse (g) } & \multicolumn{3}{|c|}{ TDG-Aktivität (nmol/ 30 min/ mg Protein) } \\
\hline & & Aminoaceton & Glycin & Gesamtaktivität \\
\hline \multirow{6}{*}{$\begin{array}{l}18,5 \% \text { XP- } \\
0,45 \% \text { dThr }\end{array}$} & 40,96 & 2,93 & 2,68 & 5,61 \\
\hline & 30,71 & - & - & - \\
\hline & 29,80 & 1,16 & 1,01 & 2,17 \\
\hline & 34,70 & 1,66 & 1,87 & 3,53 \\
\hline & 34,13 & 4,04 & 0,68 & 4,72 \\
\hline & 35,02 & 3,10 & 2,30 & 5,40 \\
\hline MW & 34,22 & 2,58 & 1,71 & 4,29 \\
\hline SD & 3,95 & 1,16 & 0,85 & 1,43 \\
\hline \multirow{6}{*}{$\begin{array}{c}18,5 \% \text { XP- } \\
0,60 \% \text { dThr }\end{array}$} & 44,39 & - & - & - \\
\hline & 41,11 & 1,61 & 0,16 & 1,77 \\
\hline & 31,51 & 2,87 & 0,92 & 3,79 \\
\hline & 38,07 & 4,38 & 2,04 & 6,42 \\
\hline & 33,49 & 3,57 & 1,77 & 5,34 \\
\hline & 38,04 & 1,49 & 2,54 & 4,03 \\
\hline MW & 37,77 & 2,78 & 1,49 & 4,27 \\
\hline SD & 4,75 & 1,25 & 0,95 & 1,75 \\
\hline \multirow{6}{*}{$\begin{array}{c}22,5 \% \text { XP- } \\
0,45 \% \text { dThr }\end{array}$} & 39,61 & 6,66 & 4,41 & 11,07 \\
\hline & 38,61 & 4,01 & 3,53 & 7,54 \\
\hline & 39,76 & 1,65 & 1,47 & 3,12 \\
\hline & 42,85 & 5,04 & 4,13 & 9,17 \\
\hline & 40,39 & 4,71 & 0,56 & 5,27 \\
\hline & 43,62 & 1,34 & 1,61 & 2,95 \\
\hline MW & 40,81 & 3,90 & 2,62 & 6,52 \\
\hline SD & 1,98 & 2,06 & 1,61 & 3,31 \\
\hline \multirow{6}{*}{$\begin{array}{c}22,5 \% \text { XP- } \\
0,60 \% \text { dThr }\end{array}$} & 32,53 & 3,88 & 4,53 & 8,41 \\
\hline & 34,53 & 7,60 & 6,68 & 14,28 \\
\hline & 36,25 & 6,76 & 4,43 & 11,19 \\
\hline & 45,25 & 8,31 & 7,15 & 15,46 \\
\hline & - & 5,62 & 6,54 & 12,16 \\
\hline & 38,82 & 3,10 & 4,10 & 7,20 \\
\hline MW & 37,48 & 5,88 & 5,57 & 11,45 \\
\hline SD & 4,92 & 2,07 & 1,36 & 3,22 \\
\hline
\end{tabular}

- Ausreißer 
Tab. A3: TDG-Aktivität in der Kükenleber $(n=6)$, Versuch 3

\begin{tabular}{|c|c|c|c|c|}
\hline \multirow{2}{*}{$\begin{array}{c}\text { XP-/ Thr- } \\
\text { Stufen }\end{array}$} & \multirow[t]{2}{*}{ Lebermasse (g) } & \multicolumn{3}{|c|}{ TDG-Aktivität (nmol/ 30 min/ mg Protein) } \\
\hline & & Aminoaceton & Glycin & Gesamtaktivität \\
\hline $16,5 \%$ XP- & 19,30 & 2,11 & 0,82 & 2,93 \\
\hline \multirow[t]{5}{*}{$0,65 \%$ Thr } & 26,60 & 4,65 & 1,46 & 6,11 \\
\hline & 20,70 & 1,12 & 1,9 & 3,02 \\
\hline & 27,00 & 2,74 & 1,63 & 4,37 \\
\hline & 27,20 & 1,01 & 1,45 & 2,46 \\
\hline & 24,20 & 2,32 & 1,46 & 3,78 \\
\hline MW & 24,20 & 2,33 & 1,45 & 3,78 \\
\hline SD & $3, \mathbf{4 0}$ & 1,33 & $\mathbf{0 , 3 6}$ & 1,33 \\
\hline $16,5 \%$ XP- & 16,20 & 2,88 & 1,26 & 4,14 \\
\hline \multirow[t]{5}{*}{ 0,79\% Thr } & 15,40 & 0,96 & 0,58 & 1,54 \\
\hline & 17,20 & 3,16 & 2,94 & 6,10 \\
\hline & 13,60 & 4,01 & 1,02 & 5,03 \\
\hline & - & 1,11 & 1,45 & 2,56 \\
\hline & 16,00 & 2,43 & 1,44 & 3,87 \\
\hline MW & 15,70 & 2,42 & 1,45 & $\mathbf{3 , 8 7}$ \\
\hline SD & 1,30 & 1,34 & $\mathbf{0 , 8 9}$ & 1,84 \\
\hline $22,0 \%$ XP- & 18,00 & 2,84 & 2,86 & 5,70 \\
\hline \multirow[t]{5}{*}{$0,86 \%$ Thr } & 19,80 & 2,45 & 2,56 & 5,01 \\
\hline & 19,70 & 3,24 & 1,53 & 4,77 \\
\hline & 17,00 & 4,63 & 4,20 & 8,83 \\
\hline & 20,00 & 3,20 & 3,75 & 6,95 \\
\hline & 15,40 & 0,69 & 2,28 & 2,97 \\
\hline MW & 18,30 & 2,84 & 2,86 & 5,71 \\
\hline SD & 1,90 & 1,44 & 1,09 & 2,24 \\
\hline $22,0 \%$ XP- & 12,50 & - & - & - \\
\hline \multirow[t]{5}{*}{ 1,05\% Thr } & 13,00 & 6,52 & 5,37 & 11,89 \\
\hline & 14,20 & 5,75 & 3,31 & 9,06 \\
\hline & 10,70 & 3,28 & 2,76 & 6,04 \\
\hline & 13,10 & 6,47 & 4,04 & 10,51 \\
\hline & 14,80 & 6,54 & 7,62 & 14,16 \\
\hline MW & 13,10 & 5,71 & 4,62 & 10,33 \\
\hline SD & 1,40 & 1,40 & 1,94 & 3,05 \\
\hline
\end{tabular}

- Ausreißer 
Tab. A4: TDG-Aktivität in der Kükenleber $(n=6)$, Versuch 4

\begin{tabular}{|c|c|c|c|c|c|}
\hline \multirow{2}{*}{$\begin{array}{l}\text { Alter } \\
\text { (Tag) }\end{array}$} & \multirow{2}{*}{$\begin{array}{c}\text { XP- } \\
\text { Stufen }\end{array}$} & \multirow[t]{2}{*}{ Lebermasse (g) } & \multicolumn{3}{|c|}{ TDG-Aktivität (nmol/ $30 \mathrm{~min} / \mathrm{mg}$ Protein) } \\
\hline & & & Aminoaceton & Glycin & Gesamtaktivität \\
\hline 7 & $\begin{array}{l}22,7 \% \text { XP- } \\
0,85 \% \text { Thr }\end{array}$ & $\begin{array}{l}6,40 \\
4,00 \\
6,00 \\
5,30 \\
5,70 \\
4,60 \\
\mathbf{5 , 3 0} \\
\mathbf{0 , 9 0} \\
\end{array}$ & $\begin{array}{l}1,47 \\
2,92 \\
2,20 \\
0,54 \\
1,56 \\
0,71 \\
\mathbf{1 , 5 7} \\
\mathbf{0 , 9 0} \\
\end{array}$ & $\begin{array}{l}1,48 \\
0,50 \\
0,76 \\
3,20 \\
1,28 \\
0,39 \\
\mathbf{1 , 2 7} \\
\mathbf{1 , 0 4} \\
\end{array}$ & $\begin{array}{l}2,95 \\
3,42 \\
2,96 \\
3,74 \\
2,83 \\
1,10 \\
\mathbf{2 , 8 3} \\
\mathbf{0 , 9 2}\end{array}$ \\
\hline 21 & $\begin{array}{l}\text { 20,3\% XP- } \\
0,75 \% \text { Thr }\end{array}$ & $\begin{array}{c}25,50 \\
29,50 \\
19,50 \\
22,00 \\
20,00 \\
21,00 \\
\mathbf{2 3 , 0 0} \\
\mathbf{4 , 0 0}\end{array}$ & $\begin{array}{c}- \\
14,10 \\
14,42 \\
5,41 \\
4,83 \\
11,29 \\
\mathbf{1 0 , 0 1} \\
\mathbf{4 , 6 3}\end{array}$ & $\begin{array}{c}- \\
5,50 \\
6,44 \\
2,60 \\
4,31 \\
6,15 \\
\mathbf{5 , 0 0} \\
\mathbf{1 , 5 7}\end{array}$ & $\begin{array}{c}- \\
19,60 \\
20,86 \\
8,01 \\
9,14 \\
17,44 \\
\mathbf{1 5 , 0 1} \\
\mathbf{6 , 0 1}\end{array}$ \\
\hline 35 & $\begin{array}{l}20,3 \% \text { XP- } \\
0,75 \% \text { Thr }\end{array}$ & $\begin{array}{c}41,00 \\
53,70 \\
32,30 \\
43,70 \\
32,30 \\
40,60 \\
\mathbf{4 1 , 0 0} \\
\mathbf{8 , 0 0} \\
\end{array}$ & $\begin{array}{c}7,82 \\
4,29 \\
7,82 \\
12,88 \\
9,85 \\
4,21 \\
\mathbf{7 , 8 1} \\
\mathbf{3 , 3 2} \\
\end{array}$ & $\begin{array}{l}2,20 \\
1,76 \\
2,20 \\
2,51 \\
3,82 \\
0,75 \\
\mathbf{2 , 2 1} \\
\mathbf{1 , 0 0}\end{array}$ & $\begin{array}{c}10,02 \\
6,05 \\
10,02 \\
15,39 \\
13,67 \\
4,96 \\
\mathbf{1 0 , 0 2} \\
\mathbf{4 , 0 9}\end{array}$ \\
\hline 49 & $\begin{array}{l}18,6 \% \text { XP- } \\
0,69 \% \text { Thr }\end{array}$ & $\begin{array}{c}37,50 \\
38,30 \\
46,40 \\
33,90 \\
44,50 \\
41,30 \\
\mathbf{4 0 , 3 0} \\
\mathbf{4 , 7 0}\end{array}$ & $\begin{array}{c}3,16 \\
- \\
4,87 \\
3,78 \\
1,61 \\
5,52 \\
\mathbf{3 , 7 9} \\
\mathbf{1 , 5 3}\end{array}$ & $\begin{array}{c}0,38 \\
- \\
0,09 \\
0,59 \\
1,00 \\
0,84 \\
\mathbf{0 , 5 8} \\
\mathbf{0 , 3 6}\end{array}$ & $\begin{array}{c}3,54 \\
- \\
4,96 \\
4,37 \\
2,61 \\
6,36 \\
\mathbf{4 , 3 7} \\
\mathbf{1 , 4 2}\end{array}$ \\
\hline
\end{tabular}

- Ausreißer 
Tab. A5: TDG-Aktivität in der Kükenleber $(n=6)$, Versuch 5

\begin{tabular}{|c|c|c|c|c|}
\hline \multirow{2}{*}{$\begin{array}{c}\text { Gly- / Thr- } \\
\text { Stufen }\end{array}$} & \multirow[t]{2}{*}{ Lebermasse (g) } & \multicolumn{3}{|c|}{ TDG-Aktivität (nmol/ 30 min/ mg Protein) } \\
\hline & & Aminoaceton & Glycin & Gesamtaktivität \\
\hline \multirow{6}{*}{$\begin{array}{l}0,64 \% \text { Gly- } \\
0,45 \% \text { dThr }\end{array}$} & 6,40 & 2,34 & 3,15 & 5,49 \\
\hline & 6,90 & 3,38 & 5,34 & 8,72 \\
\hline & 8,90 & 2,49 & 2,00 & 4,49 \\
\hline & 7,10 & 1,71 & 2,40 & 4,11 \\
\hline & 7,00 & 5,22 & 2,73 & 7,95 \\
\hline & 6,30 & 6,17 & 3,83 & 10,00 \\
\hline MW & 7,10 & $3, \mathbf{5 5}$ & 3,24 & 6,79 \\
\hline SD & 0,90 & 1,77 & 1,21 & 2,43 \\
\hline \multirow{6}{*}{$\begin{array}{l}0,64 \% \text { Gly- } \\
0,60 \% \text { dThr }\end{array}$} & 11,90 & 5,36 & 6,51 & 11,88 \\
\hline & 11,10 & 3,46 & 5,55 & 9,00 \\
\hline & 10,10 & 2,77 & 2,22 & 4,99 \\
\hline & 12,60 & 4,93 & 5,58 & 10,50 \\
\hline & 9,70 & 6,17 & 8,38 & 14,55 \\
\hline & 11,70 & 2,77 & 4,16 & 6,94 \\
\hline MW & 11,20 & 4,24 & 5,40 & 9,64 \\
\hline SD & 1,10 & 1,44 & 2,09 & 3,44 \\
\hline \multirow{6}{*}{$\begin{array}{l}0,98 \% \text { Gly- } \\
0,45 \% \text { dThr }\end{array}$} & 6,60 & 2,88 & 1,95 & 4,83 \\
\hline & 6,10 & 5,54 & 6,56 & 12,10 \\
\hline & 6,20 & 2,61 & 2,71 & 5,33 \\
\hline & 6,50 & 3,11 & 1,90 & 5,02 \\
\hline & 5,20 & 4,44 & 4,82 & 9,27 \\
\hline & 7,00 & 2,54 & 3,76 & 6,30 \\
\hline MW & 6,30 & 3,52 & 3,62 & 7,14 \\
\hline SD & 0,60 & 1,21 & 1,82 & 2,93 \\
\hline \multirow{6}{*}{$\begin{array}{l}0,98 \% \text { Gly- } \\
0,60 \% \text { dThr }\end{array}$} & 14,40 & 11,69 & 5,04 & 16,73 \\
\hline & 14,60 & 4,35 & 4,32 & 8,67 \\
\hline & - & - & - & - \\
\hline & 13,00 & 15,56 & 3,93 & 19,49 \\
\hline & 14,40 & 5,51 & 3,93 & 9,44 \\
\hline & 15,70 & 6,74 & 7,84 & 14,58 \\
\hline MW & 14,40 & 8,77 & 5,01 & 13,78 \\
\hline SD & 1,00 & 4,05 & 1,64 & 4,05 \\
\hline
\end{tabular}

- Ausreißer 
Tab. A6: TDG-Aktivität in der Rattenleber $(n=6)$, Versuch 6

\begin{tabular}{|c|c|c|c|c|}
\hline \multirow[t]{2}{*}{ XP-Stufen (\%) } & \multirow[t]{2}{*}{ Lebermasse (g) } & \multicolumn{3}{|c|}{ TDG-Aktivität (nmol/ $30 \mathrm{~min} / \mathrm{mg}$ Protein) } \\
\hline & & Aminoaceton & Glycin & Gesamtaktivität \\
\hline \multirow{6}{*}{$\mathbf{0}$} & 4,10 & 6,19 & 1,17 & 7,36 \\
\hline & 4,90 & 4,35 & 0,70 & 5,05 \\
\hline & 5,90 & 3,31 & 1,75 & 5,06 \\
\hline & 6,60 & 4,96 & 0,83 & 5,79 \\
\hline & 6,90 & 3,04 & 1,40 & 4,44 \\
\hline & 6,30 & 4,36 & 1,18 & 5,54 \\
\hline MW & 5,80 & 4,37 & 1,17 & 5,54 \\
\hline SD & 1,10 & 1,14 & 0,38 & 1,01 \\
\hline \multirow{6}{*}{6} & 7,50 & 11,00 & 1,54 & 12,54 \\
\hline & 7,00 & 12,36 & 1,52 & 13,88 \\
\hline & 7,40 & 10,50 & 1,60 & 12,10 \\
\hline & 6,70 & 7,03 & 1,70 & 8,73 \\
\hline & 7,20 & 14,03 & 2,30 & 16,33 \\
\hline & 7,30 & 8,14 & 0,93 & 9,07 \\
\hline MW & 7,20 & 10,51 & 1,60 & 12,11 \\
\hline SD & $\mathbf{0 , 3 0}$ & 2,60 & 0,44 & 2,89 \\
\hline \multirow{6}{*}{12} & 10,30 & 13,33 & 1,34 & 14,67 \\
\hline & 7,00 & 15,63 & 1,63 & 17,26 \\
\hline & 6,10 & 14,69 & 1,70 & 16,39 \\
\hline & 7,00 & 19,03 & 2,44 & 21,47 \\
\hline & 5,20 & - & - & - \\
\hline & 7,70 & 8,59 & 1,29 & 9,88 \\
\hline MW & 7,20 & 14,25 & 1,68 & 15,93 \\
\hline SD & 1,70 & $\mathbf{3 , 8 0}$ & 0,46 & 4,21 \\
\hline \multirow{6}{*}{18} & 8,70 & 5,39 & 1,37 & 6,76 \\
\hline & 7,90 & 8,33 & 2,02 & 10,35 \\
\hline & 9,30 & 9,34 & 1,94 & 11,28 \\
\hline & 7,30 & 7,36 & 0,46 & 7,82 \\
\hline & 7,60 & 12,96 & 1,29 & 14,25 \\
\hline & 7,40 & 10,23 & 0,67 & 10,90 \\
\hline MW & 8,00 & 8,94 & 1,29 & 10,23 \\
\hline SD & $\mathbf{0 , 8 0}$ & 2,59 & 0,64 & 2,67 \\
\hline \multirow{6}{*}{24} & 8,70 & 11,38 & 2,52 & 13,90 \\
\hline & 9,90 & - & - & - \\
\hline & 7,80 & 10,26 & 1,47 & 11,73 \\
\hline & 6,80 & 9,53 & 1,00 & 10,53 \\
\hline & 8,00 & 10,92 & 1,68 & 12,60 \\
\hline & 9,10 & 12,55 & 1,50 & 14,05 \\
\hline MW & 8,40 & 10,93 & 1,63 & 12,56 \\
\hline SD & 1,10 & 1,14 & 0,56 & 1,49 \\
\hline
\end{tabular}

- Ausreißer 
Tab. A7: TDG-Aktivität in der Rattenleber $(n=6)$, Versuch 7

\begin{tabular}{|c|c|c|c|c|}
\hline \multirow{2}{*}{$\begin{array}{c}\text { XP-/ Thr- } \\
\text { Stufen }\end{array}$} & \multirow[t]{2}{*}{ Lebermasse (g) } & \multicolumn{3}{|c|}{ TDG-Aktivität (nmol/ $30 \mathrm{~min} / \mathrm{mg}$ Protein) } \\
\hline & & Aminoaceton & Glycin & Gesamtaktivität \\
\hline \multirow{6}{*}{$\begin{array}{c}12 \% \text { XP- } \\
0,28 \% \text { Thr }\end{array}$} & 7,70 & 5,10 & 1,37 & 6,47 \\
\hline & 9,90 & 6,39 & 0,44 & 6,83 \\
\hline & 9,70 & 7,18 & 0,78 & 7,95 \\
\hline & 9,10 & 8,92 & 0,73 & 9,66 \\
\hline & 9,30 & 9,76 & 0,99 & 10,75 \\
\hline & 10,00 & 8,82 & 0,85 & 9,67 \\
\hline \multirow{2}{*}{$\begin{array}{l}\text { MW } \\
\text { SD }\end{array}$} & $\mathbf{9 , 3 0}$ & $\mathbf{7 , 7 0}$ & 0,86 & 8,56 \\
\hline & $\mathbf{0 , 8 0}$ & 1,77 & 0,31 & 1,73 \\
\hline \multirow{6}{*}{$\begin{array}{c}12 \% \text { XP- } \\
0,42 \% \text { Thr }\end{array}$} & 10,10 & 8,67 & 0,97 & 9,64 \\
\hline & 8,90 & 10,34 & 1,32 & 11,65 \\
\hline & 10,00 & 10,33 & 0,89 & 11,22 \\
\hline & 9,10 & 9,53 & 0,64 & 10,17 \\
\hline & 9,70 & 10,95 & 0,73 & 11,68 \\
\hline & 10,20 & - & - & - \\
\hline \multirow{2}{*}{$\begin{array}{l}\text { MW } \\
\text { SD }\end{array}$} & $\mathbf{9 , 7 0}$ & 9,96 & 0,91 & 10,87 \\
\hline & $\mathbf{0 , 5 0}$ & $\mathbf{0 , 8 8}$ & $\mathbf{0 , 2 6}$ & 0,92 \\
\hline \multirow{6}{*}{$\begin{array}{c}12 \% \text { XP- } \\
0,72 \% \text { Thr }\end{array}$} & 9,90 & 17,29 & 0,98 & 18,27 \\
\hline & 9,50 & 9,88 & 0,70 & 10,58 \\
\hline & 9,80 & 11,15 & 0,65 & 11,80 \\
\hline & 11,20 & 8,91 & 1,12 & 10,03 \\
\hline & 9,90 & 13,86 & 0,41 & 14,27 \\
\hline & 10,50 & - & - & - \\
\hline \multirow{2}{*}{$\begin{array}{l}\text { MW } \\
\text { SD }\end{array}$} & 10,10 & 12,22 & 0,77 & 12,99 \\
\hline & $\mathbf{0 , 6 0}$ & $\mathbf{3 , 3 9}$ & $\mathbf{0 , 2 8}$ & $\mathbf{3 , 3 7}$ \\
\hline \multirow{6}{*}{$\begin{array}{c}18 \% \text { XP- } \\
0,42 \% \text { Thr }\end{array}$} & 9,90 & 13,51 & 1,33 & 14,85 \\
\hline & 10,00 & 12,05 & 0,87 & 12,92 \\
\hline & 10,00 & 11,12 & 0,86 & 11,98 \\
\hline & 11,40 & 9,33 & 0,84 & 10,17 \\
\hline & - & 10,24 & 0,96 & 11,20 \\
\hline & 11,20 & 7,27 & 1,23 & 8,50 \\
\hline \multirow{2}{*}{$\begin{array}{l}\text { MW } \\
\text { SD }\end{array}$} & 10,50 & 10,59 & 1,02 & 11,60 \\
\hline & $\mathbf{0 , 7 0}$ & 2,18 & 0,21 & 2,20 \\
\hline \multirow{6}{*}{$\begin{array}{c}18 \% \text { XP- } \\
0,52 \% \text { Thr }\end{array}$} & 11,00 & 13,25 & 0,29 & 13,54 \\
\hline & 9,90 & 11,30 & 0,52 & 11,82 \\
\hline & 11,10 & 17,08 & 0,49 & 17,57 \\
\hline & 12,00 & 9,42 & 0,47 & 9,89 \\
\hline & 9,50 & 14,21 & 1,05 & 15,26 \\
\hline & 12,80 & 13,54 & 0,81 & 14,35 \\
\hline \multirow{2}{*}{$\begin{array}{l}\text { MW } \\
\text { SD }\end{array}$} & 11,10 & 13,13 & $\mathbf{0 , 6 0}$ & 13,74 \\
\hline & 1,20 & 2,61 & 0,28 & 2,68 \\
\hline \multirow{6}{*}{$\begin{array}{c}18 \% \text { XP- } \\
0,72 \% \text { Thr }\end{array}$} & 11,60 & 15,09 & 2,06 & 17,14 \\
\hline & 9,80 & 17,17 & 1,65 & 18,82 \\
\hline & 8,80 & 15,24 & 1,69 & 16,93 \\
\hline & 10,40 & 16,12 & 1,14 & 17,26 \\
\hline & 11,10 & 13,56 & 0,80 & 14,36 \\
\hline & 9,80 & 13,76 & 1,16 & 14,92 \\
\hline MW & 10,30 & 15,16 & 1,42 & 16,57 \\
\hline SD & 1,00 & 1,38 & 0,46 & 1,65 \\
\hline
\end{tabular}

- Ausreißer 
Tab. A8: N-Bilanzergebnisse, Versuch 6

\begin{tabular}{|c|c|c|c|c|c|c|}
\hline $\begin{array}{c}\text { XP- } \\
\text { Stufen }(\%)\end{array}$ & $\begin{array}{c}\text { Mittlere } \\
\text { LM (g) }\end{array}$ & $\begin{array}{c}\text { N-Aufnahme } \\
{\left[\mathrm{mg} / \mathrm{LM} \mathrm{kg} \mathrm{kg}^{0,67} / \mathrm{d}\right]}\end{array}$ & $\begin{array}{c}\text { N-Bilanz } \\
{\left[\mathrm{mg} / \mathrm{LM} \mathrm{kg}^{0,67} / \mathrm{d}\right]}\end{array}$ & $b \cdot 10^{6}$ & $b^{-1}$ & $\mathrm{PNu}(\%)^{*}$ \\
\hline \multirow{6}{*}{6} & 128 & 438 & 233 & 1402 & 335 & 61,06 \\
\hline & 132 & 429 & 215 & 1349 & 323 & 60,14 \\
\hline & 131 & 431 & 224 & 1379 & 330 & 60,67 \\
\hline & 141 & 411 & 231 & 1483 & 355 & 62,35 \\
\hline & 115 & 473 & 279 & 1505 & 360 & 62,68 \\
\hline & 123 & 451 & 245 & 1414 & 338 & 61,26 \\
\hline MW & 128 & 439 & 238 & 1422 & 340 & 61,36 \\
\hline SD & 9 & 21 & 22 & 60 & 14 & 1,00 \\
\hline \multirow{6}{*}{12} & 152 & 808 & 548 & 2048 & 490 & 68,58 \\
\hline & 143 & 839 & 547 & 1968 & 471 & 67,93 \\
\hline & 145 & 834 & 542 & 1940 & 464 & 67,69 \\
\hline & 145 & 832 & 535 & 1900 & 454 & 67,33 \\
\hline & 148 & 733 & 475 & 1778 & 425 & 66,12 \\
\hline & 146 & 832 & 554 & 2034 & 487 & 68,47 \\
\hline MW & 146 & 813 & 534 & 1945 & 465 & 67,69 \\
\hline SD & 3 & 41 & 29 & 99 & 24 & 1,00 \\
\hline \multirow{6}{*}{18} & 156 & 1188 & 637 & 2004 & 479 & 68,23 \\
\hline & 152 & 1209 & 642 & 2019 & 483 & 68,35 \\
\hline & 157 & 1179 & 597 & 1686 & 403 & 65,09 \\
\hline & 155 & 1190 & 520 & 1263 & 302 & 58,52 \\
\hline & 157 & 1180 & 578 & 1565 & 374 & 63,53 \\
\hline & 144 & 1252 & 485 & 1072 & 256 & 54,27 \\
\hline MW & 153 & 1200 & 576 & 1601 & 383 & 63,00 \\
\hline SD & 5 & 28 & 63 & 385 & 92 & 6,00 \\
\hline \multirow{6}{*}{24} & 140 & 1696 & 697 & 2164 & 518 & 69,41 \\
\hline & 152 & 1650 & 766 & - & - & - \\
\hline & 154 & 1637 & 695 & 2190 & 524 & 69,58 \\
\hline & 152 & 1651 & 566 & 1069 & 256 & 54,21 \\
\hline & 149 & 1671 & 548 & 990 & 237 & 52,14 \\
\hline & 161 & 1594 & 647 & 1575 & 377 & 63,67 \\
\hline MW & 151 & 1650 & 653 & 1598 & 382 & 61,80 \\
\hline SD & 7 & 34 & 84 & 574 & 137 & $\mathbf{8 , 0 0}$ \\
\hline
\end{tabular}

- Ausreißer * Standardisiert für N-Aufnahme von $1200 \mathrm{mg} / \mathrm{LM} \mathrm{kg}^{0,67} / \mathrm{d}$ 
Tab. A9: N-Bilanzergebnisse, Versuch 7

\begin{tabular}{|c|c|c|c|c|c|c|}
\hline $\begin{array}{l}\text { XP-/ Thr- } \\
\text { Stufen }\end{array}$ & $\begin{array}{c}\text { Mittlere } \\
\text { LM (g) }\end{array}$ & $\begin{array}{c}\text { N-Aufnahme } \\
{[\mathrm{mg} / \mathrm{LM} \mathrm{kg,67} / \mathrm{d}]}\end{array}$ & $\begin{array}{c}\text { N-Bilanz } \\
{\left[\mathrm{mg} / \mathrm{LM} \mathrm{kg}^{\mathbf{0 , 6 7}} / \mathrm{d}\right]}\end{array}$ & $b \cdot 10^{6}$ & $b^{-1}$ & PNu (\%)* \\
\hline $12 \% \mathrm{XP}-$ & 149 & 1029 & 442 & 1142 & 524 & 55,95 \\
\hline \multirow[t]{5}{*}{$0,28 \%$ Thr } & 175 & 924 & 326 & - & - & - \\
\hline & 160 & 883 & 378 & 1095 & 502 & 54,84 \\
\hline & 144 & 1036 & 429 & 1089 & 499 & 54,69 \\
\hline & 150 & 1024 & 418 & 1065 & 489 & 54,11 \\
\hline & 166 & 959 & 400 & 1078 & 494 & 54,42 \\
\hline MW & 157 & 976 & 399 & 1094 & 502 & 54,80 \\
\hline SD & 12 & 64 & 42 & 29 & 13 & 1,00 \\
\hline $12 \%$ XP- & 171 & 967 & 549 & 1715 & 539 & 65,42 \\
\hline \multirow[t]{5}{*}{$0,42 \%$ Thr } & 170 & 969 & 597 & - & - & - \\
\hline & 178 & 936 & 538 & 1709 & 537 & 65,35 \\
\hline & 158 & 1018 & 567 & 1739 & 547 & 65,69 \\
\hline & 169 & 973 & 535 & 1624 & 511 & 64,31 \\
\hline & 171 & 965 & 527 & 1597 & 502 & 63,96 \\
\hline MW & 169 & 971 & 552 & 1677 & 527 & 64,95 \\
\hline SD & 6 & 26 & 26 & 62 & 20 & 1,00 \\
\hline $12 \%$ XP- & 175 & 960 & 534 & 1643 & 304 & 64,56 \\
\hline \multirow[t]{5}{*}{$0,72 \%$ Thr } & 170 & 920 & 507 & 1565 & 289 & 63,53 \\
\hline & 183 & 931 & 475 & 1397 & 258 & 60,97 \\
\hline & 191 & 905 & 474 & 1431 & 265 & 61,53 \\
\hline & 166 & 992 & 572 & 1818 & 336 & 66,54 \\
\hline & 178 & 949 & 500 & 1482 & 274 & 62,34 \\
\hline MW & 177 & 943 & 510 & 1556 & 288 & 63,25 \\
\hline SD & 9 & 31 & 38 & 157 & 29 & 2,00 \\
\hline $18 \%$ XP- & 164 & 1428 & 607 & 1451 & 656 & 61,85 \\
\hline \multirow{5}{*}{$0,42 \%$ Thr } & 163 & 1434 & 570 & 1251 & 566 & 58,29 \\
\hline & 172 & 1386 & 559 & 1242 & 562 & 58,11 \\
\hline & 179 & 1347 & 553 & 1249 & 565 & 58,25 \\
\hline & 156 & 1477 & 659 & - & - & - \\
\hline & 167 & 1396 & 551 & 1197 & 542 & 57,17 \\
\hline MW & 167 & 1411 & 583 & 1278 & 578 & 58,73 \\
\hline SD & 8 & 45 & 43 & 99 & 45 & 2,00 \\
\hline \multirow{6}{*}{$\begin{array}{c}18 \% \text { XP- } \\
0,52 \% \text { Thr }\end{array}$} & 177 & 1376 & 704 & - & - & - \\
\hline & 171 & 1408 & 625 & 1596 & 589 & 63,95 \\
\hline & 180 & 1361 & 589 & 1417 & 523 & 61,31 \\
\hline & 187 & 1326 & 666 & 2118 & 782 & 69,10 \\
\hline & 167 & 1420 & 679 & 2181 & 805 & 69,52 \\
\hline & 179 & 1363 & 645 & 1822 & 672 & 66,58 \\
\hline MW & 177 & 1376 & 651 & 1827 & 674 & 66,09 \\
\hline SD & 7 & 34 & 41 & 328 & 121 & 3,00 \\
\hline \multirow{6}{*}{$\begin{array}{c}18 \% \text { XP- } \\
0,72 \% \text { Thr }\end{array}$} & 189 & 1337 & 632 & 1736 & 471 & 65,66 \\
\hline & 175 & 1405 & 587 & 1360 & 369 & 74,47 \\
\hline & 181 & 1252 & 600 & 1611 & 437 & 64,15 \\
\hline & 176 & 1403 & 656 & 1885 & 511 & 67,19 \\
\hline & 175 & 1405 & 644 & 1761 & 477 & 65,93 \\
\hline & 178 & 1389 & 609 & 1509 & 409 & 62,73 \\
\hline MW & 179 & 1365 & 621 & 1644 & 445 & 66,69 \\
\hline SD & 5 & 61 & 27 & 190 & 51 & 4,00 \\
\hline
\end{tabular}

- Ausreißer * Standardisiert für N-Aufnahme von $1200 \mathrm{mg} / \mathrm{LM} \mathrm{kg}^{0,67} / \mathrm{d}$ 


\section{DANKSAGUNG}

Ich danke meinem Gott, der mich während meiner Promotionszeit treu und fürsorglich geleitet hat.

Herrn Prof. Dr. F. Liebert möchte ich für die Aufnahme als Doktorand, für die Überlassung des Themas und für die ständige wissenschaftliche Betreuung im Verlauf der Promotionsarbeit am Institut für Tierphysiologie und Tierernährung danken.

Herrn Prof. Dr. U. Eberhardt vom Isotopenlaboratorium danke ich herzlich für die Übernahme des Korreferates.

Besonders möchte ich mich bei Herrn Dr. H. Mohme für seine Hilfe bei der Glycinbestimmung bedanken. Weiterhin möchte ich mich bei Frau Dr. H. Rosenow für ihre reichlich Hilfe bei der Korrektur der vorliegenden Arbeit bedanken.

Für seine freundliche Unterstützung bei der Durchführung der Tierversuche bin ich Herrn W. Kulp herzlich dankbar. Bedanken möchte ich mich herzlich bei Herrn M. Rimbach für die Unterstützung bei der Durchführung der Versuche im Threonin-Team.

Bedanken möchte ich mich bei Frau K. Sauerland, O. Warnecke, H. Kittel, M. Hübner, C. Pieper und M. Winter für die Unterstützung bei der Durchführung der chemischen Analysen. Ich danke Frau H. Marbell für ihre vielfältige Hilfe während der ganzen Promotionszeit.

Ich bedanke mich bei meinen Mitdoktoranden Khaled, Abdul, Nassir, Bernhard und John für die gute Zusammenarbeit am Institut. Ich danke auch allen Mitarbeiterinnen und Mitarbeitern des Institutes für Tierphysiologie und Tierernährung für die Unterstützung.

Ich bedanke mich bei meiner Familie, meinen Eltern, Schwiegereltern, meiner Frau und meinen Kinder für ihre vielfältige Hilfe. Ich danke auch allen Christen der koreanischen ev. Kirchengemeinde in Göttingen für ihre herzliche Hilfe und Gebete. 


\section{LEBENSLAUF}

Name:

Geburtsdatum:

Geburtsort:

Eltern:

Familienstand:

Schulen:

Studium:

Beruf:

(1)

Chul-Won Lee

13. Okt. 1957

Jeju, Korea

Ki-Song Lee

Chun-Ja Lee, geb. Lim

verheiratet, 2 Kinder

1964 - 1970 Grundschule Soy, Seoul

1970 - 1976 Gymnasium Daedong und Kyeongseong, Seoul

1976 - 1978 Studium an der Cheju-National Universität, Jeju Fachbereich Agrarwissenschaft

1981 - 1983 Fortsetzung des Studiums Abschluß: Bachelor Sci.

1983 - 1985 Master-Studium an der Korea Universität, Seoul Fachbereich Tierernährung und Molkereiwissenschaft Abschluß: Master Sci.

1984 - 1985 Wissenschaftlicher Mitarbeiter an der Korea Universität, Seoul

1986 - 1989 Wissenschaftlicher Mitarbeiter in der "Dep. of Food Science and Nutrition" der Cheju-National Universität, Jeju

1991 - 1993 Wissenschaftlicher Mitarbeiter im Institut für Klinische Chemie an der Gießen Universität, Gießen

1993 - 2000 Lehrer (Teilzeit) in der koreanischen Schule in Frankfurt/ Main

Seit 1998 Doktorand am Institut für Tierphysiologie und Tierernährung der Universität Göttingen 